\title{
Geochemical and iron isotopic insights into hydrothermal iron oxyhydroxide deposit formation at loihi seamount
}

\author{
Rouxel Olivier ${ }^{1,2,{ }^{*}}$, Toner Brandy ${ }^{3}$, Germain Yoan ${ }^{1}$, Glazer Brian ${ }^{2}$
}

${ }^{1}$ Department of Marine Geoscience, Institut Français de Recherche pour l'Exploitation de la Mer, Centre de Brest, 29280 Plouzané, France

${ }^{2}$ Department of Oceanography, University of Hawaii, Honolulu, HI 96822, USA

${ }^{3}$ Department of Soil, Water, and Climate, University of Minnesota, St. Paul, MN 55108, USA

* Corresponding author :Olivier Rouxel, email address : orouxel@hawaii.edu

\begin{abstract}
:
Low-temperature hydrothermal vents, such as those encountered at Loihi Seamount, harbor abundant microbial communities and provide ideal systems to test hypotheses on biotic versus abiotic formation of hydrous ferric oxide ( $\mathrm{FeOx}$ ) deposits at the seafloor. Hydrothermal activity at Loihi Seamount produces abundant microbial mats associated with rust-colored FeOx deposits and variably encrusted with $\mathrm{Mn}$ oxyhydroxides. Here, we applied Fe isotope systematics together with major and trace element geochemistry to study the formation mechanisms and preservation of such mineralized microbial mats. Iron isotope composition of warm $\left(<60^{\circ} \mathrm{C}\right)$, Fe-rich and H2S-depleted hydrothermal fluids yielded $\delta 56 \mathrm{Fe}$ values near +0.1 $\%$, indistinguishable from basalt values. Suspended particles in the vent fluids and FeOx deposits recovered nearby active vents yielded systematically positive $\delta 56 \mathrm{Fe}$ values. The enrichment in heavy $\mathrm{Fe}$ isotopes between $+1.05 \%$ and $+1.43 \%$ relative to $\mathrm{Fe}(\mathrm{II})$ in vent fluids suggest partial oxidation of $\mathrm{Fe}(\mathrm{II})$ during mixing of the hydrothermal fluid with seawater. By comparing the results with experimentally determined Fe isotope fractionation factors, we determined that less than $20 \%$ of $\mathrm{Fe}(\mathrm{II})$ is oxidized within active microbial mats, although this number may reach $80 \%$ in aged or less active deposits. These results are consistent with $\mathrm{Fe}$ (II) oxidation mediated by microbial processes considering the expected slow kinetics of abiotic Fe oxidation in low oxygen bottom water at Loihi Seamount. In contrast, FeOx deposits recovered at extinct sites have distinctly negative Fe-isotope values down to $-1.77 \%$ together with significant enrichment in $\mathrm{Mn}$ and occurrence of negative $\mathrm{Ce}$ anomalies. These results are best explained by the near-complete oxidation of an isotopically light $\mathrm{Fe}$ (II) source produced during the waning stage of hydrothermal activity under more oxidizing conditions. Light $\mathrm{Fe}$ isotope values of $\mathrm{FeOx}$ are therefore generated by subsurface precipitation of isotopically heavy Fe-oxides rather than by the activity of dissimilatory Fe reduction in the subsurface. Overall, Fe-isotope compositions of microbial mats at Loihi Seamount display a remarkable range between $-1.2 \%$ and $+1.6 \%$ which indicate that $\mathrm{Fe}$ isotope compositions of hydrothermal Fe-oxide precipitates are particularly sensitive to local environmental conditions where they form, and are less sensitive to abiotic versus biotic origins. It follows that FeOx deposits at Loihi Seamount provides important modern analogues for ancient seafloor Ferich deposits allowing for testing hypotheses about the biogeochemical cycling of Fe isotopes on early Earth.
\end{abstract}




\section{Introduction}

Seafloor metalliferous deposits enriched in Fe oxides, hydroxides, and oxyhydroxides (hereafter referred as $\mathrm{FeOx}$ deposits) are widespread in seafloor hydrothermal systems along mid-ocean ridges and back-arc spreading centers. FeOx deposits also form the main type of hydrothermal deposits associated with active submarine volcanoes. Likewise, FeOx deposits were reported along the East Pacific Rise (EPR) (Juniper and Fouquet, 1988; Hekinian et al., 1993), Explorer Ridge (Grill et al., 1981), the Mid-Atlantic Ridge (MAR) (Scott et al., 1974; Mills, 1995; Scott et al., 2015), the Southwest Indian Ridge (SWIR) (Peng et al., 2011; Sun et al., 2015), the Mohns Ridge (Pedersen et al., 2010; Moeller et al., 2014) and back-arc spreading centers (Sun et al., 2011; Sun et al., 2012a; Zeng et al., 2012; Sun et al., 2013). These deposits have been also widely reported in association with submarine volcanoes from off-axis settings along the Juan de Fuca Ridge and EPR (Grill et al., 1981; Alt, 1988; Juniper and Fouquet, 1988; Hekinian et al., 1993; Kennedy et al., 2003), from arc and back-arc seamounts (Binns et al., 1993; Boyd and Scott, 2001; Dekov et al., 2007), and from intraplate submarine volcanoes in the Pacific (De Carlo et al., 1983; Exon and Cronan, 1983; Puteanus et al., 1991; Stoffers et al., 1993; Edwards et al., 2011).

In general, $\mathrm{FeOx}$ deposits resulting from the precipitation of low-temperature hydrothermal fluids are variably enriched in amorphous silica and may also contain Fe-rich phyllosilicates such as nontronite (De Carlo et al., 1983; Alt, 1988; Dekov et al., 2007; Hrischeva and Scott, 2007; Toner et al., 2012). These deposits vary in appearance from stratified microbial mats (Edwards et al., 2011) to several meters high mounds (Corliss et al., 1978) and may form chimney structures (Juniper and Fouquet, 1988; Sun et al., 2012b). FeOx deposits may also accumulate on the surface of massive sulfides (Mills et al., 2001) and hydrothermal chimneys (Toner et al., 2016) or occur as incipient crusts on basalts (Templeton et al., 2009; Wang et al., 2014 ) as the result of seafloor weathering. Sometimes, Mn (oxyhydr)oxides represent the main constituent of the deposit depending on the hydrothermal fluid source and growth history or age of the deposits (Moorby et al., 1984; Usui et al., 1986; Bolton et al., 1988; Murphy et al., 1991). Textural evidence, such as the occurrence of twisted branching filaments of Fe-oxyhydroxides, 
as well as molecular biological studies suggest that microorganisms, in particular iron-oxidizing bacteria (hereafter referred as $\mathrm{FeOB}$ ) are essential in the formation of $\mathrm{FeOx}$ deposits (Juniper and Fouquet, 1988; Emerson and Moyer, 2002; Chan et al., 2011; Edwards et al., 2011; Peng et al., 2011; Toner et al., 2012; Scott et al., 2015). The implication of FeOB in the formation of FeOxrich microbial mats has been particularly well documented at Loihi Seamount where several pure strains of FeOB including the Zeta-Proteobacteria Mariprofundus ferrooxydans were isolated and studied in pure culture (Emerson et al., 2007). Although FeOB are often identified by the distinctive morphologies of their FeOx products, such as the extracellular twisted stalks, morphology alone is not a good diagnostic indicator of the process of Fe oxidation (biotic versus abiotic) since a significant proportion of $\mathrm{Fe}^{2+}$ could be oxidized abiotically (Chan et al., 2011).

Here, we aim at using Fe isotope ratios and major/trace element geochemistry of lowtemperature hydrothermal fluids and $\mathrm{FeOx}$ deposits to study the formation mechanisms and preservation of FeOx-rich microbial mats at the seafloor. An important goal of this study is to test whether $\mathrm{FeOB}$ play a major role in $\mathrm{FeOx}$ formation in seafloor environments and imprint distinct chemical and isotopic signatures. Although our study did not intended to apply $\mathrm{Fe}$ isotopes as direct evidence for microbial Fe(II) oxidation considering that the fractionation factors for inorganic and microbial Fe oxidation are rather similar (Croal et al., 2004; Balci et al., 2006; Kappler et al., 2010), Fe isotopes are expected to provide an important redox framework (i.e. extent of $\mathrm{Fe}(\mathrm{II})$ oxidation) associated with the early stage of Fe oxidation and precipitation at the seafloor. Loihi Seamount is arguably one of the most well-studied submarine volcanoes in the world, where considerable prior efforts have focused on the geology, geochemistry, mineralogy and microbiology (Klein, 1982; De Carlo et al., 1983; Frey and Clague, 1983; Gamo et al., 1987; Malahof, 1987; Karl et al., 1988; Karl et al., 1989; Sedwick et al., 1992; Moyer et al., 1994; Emerson and Moyer, 1997; Kent et al., 1999; Wheat et al., 2000; Emerson and Moyer, 2002). Hence, Loihi Seamount provides an ideal system in which to study active microbial communities and biogeochemical cycling of $\mathrm{Fe}$ and test hypotheses related to $\mathrm{FeOx}$ deposit formation that are likely preserved throughout the geological record (Grenne and Slack, 2003; Little et al., 2004; Slack et al., 2007; Bekker et al., 2010). Ultimately, the multidisciplinary approach undertaken at Loihi seamount, linking Fe geomicrobiology, geochemistry and Fe isotopes composition of microbial mats and associated fluids, over a range of environmental 
conditions should provide important modern analogues for the study of Fe biogeochemical cycling in ancient marine environments.

\section{Hydrothermal activity at Loihi Seamount}

Loihi Seamount is located $35 \mathrm{~km}$ south of the island of Hawaii (Fig. 1) and has been the focus of numerous multi-disciplinary studies since its discovery in 1950's. It is the youngest volcano in the Hawaiian-Emperor Chain, rising $\sim 4 \mathrm{~km}$ above the abyssal plain to a depth about $960 \mathrm{~m}$ below sea surface (Klein, 1982). It is likely that Loihi began forming about 400,000 years ago (Garcia et al., 2006). Petrologic and geochemical studies of lavas showed that the volcano is associated with a relatively primitive part of the Hawaiian plume, producing a wide range of magma compositions (Klein, 1982). Hence, Loihi is considered the type example of the early phase of growth of plume related oceanic island, hot spot, volcanoes (Moore et al., 1982; Kurz et al., 1983).

Hydrothermal venting at Loihi is best known and studied at the summit near pit craters (Gamo et al., 1987; Sakai et al., 1987; Karl et al., 1988; Wheat et al., 2000; Malahoff et al., 2006). Vent fluids at Loihi are enriched in $\mathrm{CO}_{2}, \mathrm{CH}_{4}, \mathrm{NH}_{4}, \mathrm{PO}_{4}, \mathrm{Fe}$, and $\mathrm{Mn}$ and depleted in $\mathrm{H}_{2} \mathrm{~S}$, rendering Loihi distinct from mid-ocean ridge hydrothermal systems (Karl et al., 1988; Sedwick et al., 1992; Wheat et al., 2000; Glazer and Rouxel, 2009). The high $\mathrm{CO}_{2}$ content also results in lower $\mathrm{pH}$ conditions (5.3-5.6) than many other low-temperature vents promoting higher Fe concentrations due to enhanced chemical weathering of wall rocks (Sedwick et al., 1992; Wheat et al., 2000; Glazer and Rouxel, 2009). Prior to 1996, Pele's Vents were located in the southern flank of the summit, at a water depth of 980 m (Karl et al., 1988; Sedwick et al., 1994). The vent fields were characterized by several individual vents discharging diffuse fluids with a maximum temperature of $31^{\circ} \mathrm{C}$ (Sedwick et al., 1992). In July-August 1996 a tectonic-volcanic event occurred that destroyed Pele's Vents, creating a Pit crater (Pele's Pit) and produced several sites with active hydrothermal venting (Hilton et al., 1998; Wheat et al., 2000; Caplan-Auerbach and Duennebier, 2001). Between 1996 and 1997, new hydrothermal vents were discovered (Fig. 1) (1) on the north rim of Pele's Pit: Lohiau Vents (markers M2 and M5); (2) on the south-west floor of Pele's Pit: Spillway (markers M36 and M39); Tower Area (marker M48); Hiolo Area 
(markers M34 and M38); (3) on the South Rift: Pohaku (marker M57), Kaupo's Vents, Naha vents (markers M3 and M6), Keiki vents (markers M17 and M17A). An additional site in Pele's Pit was surveyed and sampled for the first time in 2009 (Little Dike) nearby marker M48. Another area of weak, but still active venting was also reported in the Pit of Death located northern of Pele's Pit (marker M56) (Glazer and Rouxel, 2009).

A time-series survey at Loihi Seamount between 2006 and 2009 reported a steady hydrothermal activity in Pele's Pit in the Hiolo Area (M36, M39), Spillway Area (M34, M38) but diminishing at Loihau (M2, M5) and along the southern rift at Pohaku (M57) with cessation of hydrothermal activity at Naha (M3/M6) and Keiki vents (M17A) (Glazer and Rouxel, 2009). Pele's Pit vents had decreased in temperature from about $200^{\circ} \mathrm{C}$ in 1996-1997 to a range of $21.6^{\circ} \mathrm{C}$ to $55^{\circ} \mathrm{C}$ in $2006-2009$ (Wheat et al., 2000; Glazer and Rouxel, 2009). The Fe/Mn ratios at Pele's Pit vents generally ranged from 20 to 40 (average of about 30 ), which is similar to values reported before the volcanic event (Wheat et al., 2000; Glazer and Rouxel, 2009). This likely corresponds to the "steady state" value for quiescent discharge at Loihi (Wheat et al., 2000; Malahoff et al., 2006). While $\mathrm{H}_{2} \mathrm{~S}$ was never reported at any vent sites at Loihi in previous studies, free sulfide was detected using in situ measurements at the Hiolo Area (M39, M36, M31) but remained always $<50 \mu \mathrm{M}$ and variable between sampling years (Glazer and Rouxel, 2009). Free sulfide was below detection limit in Tower, Lohiau and Pohaku areas (Glazer and Rouxel, 2009). This suggests that $\mathrm{HS} / \mathrm{Fe}$ molar ratio remained essentially $<0.1$ in Hiolo Area, and below 0.01 in other area, suggesting a minor importance of $\mathrm{H}_{2} \mathrm{~S}$ in affecting Fe aqueous chemistry.

Perhaps the most peculiar characteristic of the style of hydrothermal venting at Loihi is the widespread occurrence of ochreous and unconsolidated $\mathrm{FeOx}$ deposits, which have also been referred to as microbial mats (Karl et al., 1989; Moyer et al., 1994; Emerson and Moyer, 2002). The mixing zone between hydrothermal fluid and seawater leads to opposing Fe and oxygen gradients (Glazer and Rouxel, 2009), providing an ideal environment for FeOB growth (Emerson and Moyer, 2002; Rassa et al., 2009; Fleming et al., 2013). A variety of filamentous, nonfilamentous, tubular, and branching Fe-rich microbial structures have been described in the mats and are composed of nanoparticulate ferrihydrite (Toner et al., 2012) and organic polymers (Chan et al., 2011). Previous studies combining terminal-restriction fragment length polymorphism (T-RFLP), culturing studies, and FeOx morphology demonstrated that 
lithotrophic FeOB are abundant and active at Loihi, and that biological Fe-oxidation contributes up to $\sim 60 \%$ of total Fe-oxidation (Emerson and Moyer, 2002). FeOx deposits at Loihi are pervasive, forming at a range of temperatures $\left(<10-60^{\circ} \mathrm{C}\right)$ and habitus that could be grouped in three categories (Wheat et al., 2000; Glazer and Rouxel, 2009): (1) focused venting along fractures and open cracks with microbial mats forming at the periphery; (2) diffuse fracturedcontrolled venting generally covered by microbial mats (and cm-size chimneys); (3) patchy venting occurring through basaltic outcrop (e.g. between pillow lavas). The lack of any significant sulfide mineral occurrence within the deposits (De Carlo et al., 1983; Toner et al., 2012) is also consistent with the $\mathrm{H}_{2} \mathrm{~S}$-depleted nature of the vent fluid (Glazer and Rouxel, 2009). A more detailed description of studied vent sites is provided in the Electronic Annex.

\section{Materials and Methods}

A comprehensive set of $\mathrm{FeOx}$ deposits and hydrothermal fluids were recovered during four cruises to the Loihi Seamount as part of the NSF-funded FEMO "Iron Microbial Observatory" project (Emerson, 2009; Glazer and Rouxel, 2009; Edwards et al., 2011). The FEMO project was conducted over a period of four ROV Jason-II cruises (2006-2009). Additional samples (microbial mats) were also selected from former cruises using the deep-sea submersible Pisces V (Emerson and Moyer, 2002). Details regarding the temporal and spatial variability of the different sampling sites are presented in Glazer and Rouxel (2009) and summarized in the Electronic Annex, together with the main characteristics of the samples.

\subsection{Hydrothermal fluid sampling and geochemical analysis}

Fluid samples were collected with the DSV Jason 2 using the $750 \mathrm{ml}$ titanium « major » samplers. The operation of the Ti-samplers has been described previously in Von Damm et al. (1985). Briefly, the Ti-samplers were filled using a titanium snorkel that can be inserted directly into the vent orifice or above microbial mat area with diffuse venting. Immediately after the recovery, the $\mathrm{pH}$ and alkalinity were measured onboard. Fe(II) and total Fe were also measured spectrophotometrically using the ferrozine method (Stookey, 1970). Several fluid aliquots were extracted from the Ti-samplers using gas-tight metal-clean syringes and filtered through $0.2 \mu \mathrm{m}$ (nylon Acrodisc ${ }^{\circledR}$ or polyethersulfone Sterivex ${ }^{\mathrm{TM}}$ syringe filters) and transferred to an acid 
cleaned HDPE bottle. Filtered samples were then acidified to $0.06 \mathrm{M} \mathrm{HCl}$ with concentrated ultrapure $\mathrm{HCl}$ and stored at $4^{\circ} \mathrm{C}$. Insoluble or precipitated particles remaining in the Ti-samplers were recovered when the sampler was disassembled and collected onto $0.45 \mu \mathrm{m}$ filters (durapore $^{\mathrm{TM}}$ ). This fraction is not included in the final fluid analysis as it contains suspended $\mathrm{FeOx}$ deposit particles entrained during fluid sampling rather than particulate formed inside the Ti-sampler upon recovery (Wheat et al., 2000; Glazer and Rouxel, 2009). Although the entrainment of particles of volcanic glass during sampling may have occurred for some of the studied vent fluids, it should not affect trace metal analysis because the fluids are filtered immediately upon recovery, and before acidification of the subsamples.

Bottom seawater samples from Pele's Pit were obtained using Niskin bottles (11 or 51-size bottles) on-board ROV Jason 2 in areas remote from active venting. Niskin bottles were triggered 1 to 2 meters above seafloor after sufficient settling time to avoid too much particle resuspension. For each sample, between 250 to $500 \mathrm{ml}$ was filtered upon recovery through 0.45 $\mu \mathrm{m}$ filters and stored acidified to $\mathrm{pH} 1.8$.

Major (e.g. Ca, Mg, Fe, Mn, Si) and trace element (e.g. Mo, P, V, U, Co, Cu) compositions in hydrothermal fluids were determined by high-resolution inductively coupled plasma mass spectrometry (HR-ICPMS) Element 2 operated at the Woods Hole Oceanographic Institution (WHOI) and Element XR operated at the French Research Institute for Exploitation of the Sea (IFREMER). Indium solution was added before analysis or mixed on-line at a final concentration of $5 \mathrm{ppb}$ to correct for instrument sensitivity changes. Solutions were introduced into the plasma torch using a quartz spray chamber system equipped with a microconcentric PFA nebulizer operating at a flow rate of about $100 \mu \mathrm{l} / \mathrm{min}$. For each element, ICPMS sensitivity was calibrated using matrix matched standard solutions corresponding to seawater matrices. Note that preliminary $\mathrm{Si}, \mathrm{Mg}, \mathrm{Ca}, \mathrm{P}, \mathrm{Fe}$ and $\mathrm{Mn}$ data have been already reported in Glazer and Rouxel (2009) for a subset of samples.

\subsection{FeOx deposit sampling and geochemical analysis}

FeOx deposits were mainly composed of unconsolidated flocs of iron-oxyhydroxide with minor amounts of amorphous silica and organic materials (i.e. microbial mats, senso stricto). The deposits were collected using a variety of specific sampling techniques, including DSV Jason's "slurp sampler" and "scoop sampler" (referred as 'SS' and 'SC' samples respectively). Slurp 
sampling has been the main technique to recover large volumes of $\mathrm{FeOx}$ deposits. This sampler, developed at the National Deep Submergence Facility at WHOI is equipped with five canisters of 51 each that can be flushed between each sampling operation. Scoop sampling has been also used to recover additional samples, albeit in lower quantity. The scoop sampler consists of 20 to $40 \mathrm{~cm}$ long PVC tubing that could be open and closed with a ball valve. The scoop was pushed through the mat and then closed when the sample was collected. Once retrieved, the samples were sub-sampled for various chemical, mineralogical, and biological analyses. After removal of seawater by centrifugation, Fe-rich deposits were air-dried at $30^{\circ} \mathrm{C}$ and powdered in agate mortar for geochemical analysis. Other set of samples, having limited amount of material available, were centrifuged but not air-dried and directly processed for geochemical analysis. Since element concentrations could not be determined on a dry-weight basis, major and element concentrations are therefore reported after normalization to the major element Fe.

Additional samples were also recovered using a suction sampler mounted on DSV Pisces $\mathrm{V}$ (University of Hawaii). In addition, one sample of freshly precipitated $\mathrm{FeOx}$ deposits was recovered using a "slide trap" (ST) device. It consists of a set of microscope slides positioned vertically inside a plastic housing that is deployed directly on-top of active venting area to collect microbial mats growing in situ on their surfaces. The ST sample was recovered from M39 area after several days of deployment and placed in $50 \mathrm{~mL}$ centrifuge tube. The Fe-oxyhydroxide coatings on the glass slide were then dissolved in $1.2 \mathrm{M} \mathrm{HCl}$.

All mineral samples were analyzed for major and trace elements by ICP-AES (atomic emission spectrometry) at the Pole Spectrometry Ocean, Brest and by HR-ICPMS Element 2 at WHOI. Additional samples were also measured by HR-ICPMS Element XR at PSO/Ifremer, Brest for major and trace elements. Between $10 \mathrm{mg}$ to $100 \mathrm{mg}$ of dry powder was dissolved in PTFE beaker on hot plate using an acid mixture of $\mathrm{HCl}, \mathrm{HNO}_{3}$ and $\mathrm{HF}$. For samples having significant enrichment of basaltic materials, the powder was subjected to partial chemical leaching. The leaching protocol involved the preferential dissolution of $\mathrm{FeOx}$ materials in diluted acid $\left(1.4 \mathrm{M} \mathrm{HNO}_{3}\right)$ for $6 \mathrm{~h}$, leaving volcanic glass and silicates as solid residue easily separated by centrifugation. The use of diluted acid was preferred over other reagents such as reducing agents to avoid potential $\mathrm{Fe}$ isotope fractionation due to incomplete Fe reduction. Although partial leaching of volcanic glass or silicates may occur under these conditions, these phases are present 
in minor amounts relative to the Fe-oxyhydroxide-rich matrix and do not contribute significantly to the total Fe concentration.

A subset of powdered samples of $\mathrm{FeOx}$ deposits were also sent to Activation Laboratories Ltd. (Ancaster, Ontario) for geochemical analysis. Major and trace elements were analyzed at Activation Laboratories by ICP-AES and ICP-MS, respectively, after lithium metaborate/tetraborate fusion.

\subsection{Experimental simulation of Fe(II) oxidation in seawater}

We performed Fe oxidation incubation experiments following similar approach than Statham et al. (2005) and Wang et al. (2012). All experiments were performed onboard using freshly recovered background seawater from the Niskin bottles mounted on ROV Jason 2. For each experiments, between 30 to $50 \mathrm{mg}$ of $\mathrm{Fe}(\mathrm{II}) . \mathrm{Cl}_{2}$ salt (Sigma-Aldrich) were weighted in gastight septum vials and flushed with $\mathrm{N}_{2}$ to avoid air oxidation during storage. About $50 \mathrm{~mL}$ of background seawater, previously filtered through $0.2 \mu \mathrm{m}$ size filter to remove particles and bacteria, was inserted in the septum vials using a syringe. The Fe(II) concentration at the starting of incubation was about $8 \mathrm{mM}$, which is representative of high-temperature hydrothermal vent fluids (German and Von Damm, 2003). The vials were kept in the dark at room temperature (about $20^{\circ} \mathrm{C}$ ). At the end of the experiment, the solution was filtered and $\mathrm{Fe}(\mathrm{II})$ concentration was determined using the colorimetric ferrozine technique (Stookey, 1970). Total Fe concentration was also measured and yielded identical values than $\mathrm{Fe}(\mathrm{II})$ concentrations suggesting that dissolved Fe contains mainly Fe(II). Suspended particles recovered on filters, containing insoluble Fe-oxyhydroxides, were dissolved in diluted $\mathrm{HCl}$.

\subsection{Iron isotope analysis}

Methods for Fe isotope analysis followed previously used methods for hydrothermal fluids and mineral deposits analysis (e.g. Rouxel et al., 2008; Rouxel et al., 2016). In short, an appropriate amount of hydrothermal fluids and solutions of digested solid materials (e.g. FeOx deposits or suspended particulate matter recovered on filters), corresponding to about $100 \mu \mathrm{g}$ of Fe was evaporated to dryness at $80^{\circ} \mathrm{C}$ with $10 \mathrm{~mL}$ of distilled concentrated $\mathrm{HNO}_{3}$ and $1 \mathrm{ml}$ of $\mathrm{H}_{2} \mathrm{O}_{2}$ (ultrapure grade). The dry residue was subsequently dissolved in $6 \mathrm{M} \mathrm{HCl}$ and purified 
through anion exchange resin (AG1-X8 or AG-MP1, Bio-rad). Procedural blanks, including evaporation and dissolution steps and ion-exchange purification was below $5 \mathrm{ng}$.

Iron isotope compositions were determined with a Neptune (Thermo-Scientific) multicollector inductively coupled plasma mass spectrometry (MC-ICPMS) operating at WHOI and IFREMER using medium or high-resolution mode. It involves both "sample-standard bracketing" and "internal normalization" using Ni of known isotope composition (Arnold et al., 2003; Malinovski et al., 2003; Weyer and Schwieters, 2003; Poitrasson and Freydier, 2005; Rouxel et al., 2005). This method yields an internal precision from 0.04 to $0.09 \%$ (2SD) for total quantities of $\mathrm{Fe}$ as low as $100 \mathrm{ng}$. All analyses are reported in delta notation relative to the IRMM-014 standard, expressed as $\delta^{56} \mathrm{Fe}$, which represents the deviation in per mil relative to the reference material. Based on $>50$ replicate dissolutions, purifications and analyses of internal standard BHVO-1 and BHVO-2 (Hawaiian basalt), we have obtained: $\delta^{56} \mathrm{Fe}=0.09 \pm 0.07 \%$ (2 $\mathrm{SD}, \mathrm{n}=39$ ). For the analysis of Fe isotope composition of hydrothermal fluid samples, we further assessed the robustness of the method by measuring artificial samples corresponding to seawaterlike matrix doped with Fe standard (Rouxel et al., 2016).

Bottom seawater analysis followed the method described in Rouxel and Auro (2010) which involves the preconcentration of Fe by passing through NTA resin (Qiagen Inc., Valencia, $\mathrm{CA}$ ) having nitrilotriacetic acid functional groups. The $\mathrm{pH}$ of each sample was first checked and adjusted to 1.8 using ultra-clean HCl. Hydrogen peroxide (30\% v/v Optima grade, Fisher) was then added to a concentration of $1 \mathrm{ml} / 1$ to oxidize any ferrous Fe present in the sample prior to sample processing. The NTA resin was packed into chromatographic columns to a wet volume of $1.8 \mathrm{ml}$. Between $100 \mathrm{ml}$ and $250 \mathrm{ml}$ of water sample were passed through the NTA chromatographic columns at a constant flow rate of $2.5 \mathrm{ml} / \mathrm{min}$. After eluting the remaining matrix from the column, Fe was finally eluted with $7 \mathrm{ml}$ of $1.4 \mathrm{M} \mathrm{HNO}_{3}$ and evaporated to dryness. Evaporated samples were then redissolved in $6 \mathrm{M} \mathrm{HCl}$ for further purification through anion resin following the method described above.

\subsection{X-ray microscopy}

Particle morphology was described with scanning transmission X-ray microscopy using beamlines 5.3.2.2 and 11.0.2, Advanced Light Source, Lawrence Berkeley National Laboratory, 
USA. Mat samples were rinsed of seasalts using purified water. A small volume $(\sim 1 \mu \mathrm{l})$ of dilute mat suspension was applied to a silicon nitride membrane (Silson LTD) and the bulk water was allowed to evaporate under ambient laboratory conditions. All measurements were performed at ambient temperature and $\leq 1 \mathrm{~atm}$ He. The theoretical spatial and spectral resolutions of the beamlines were $40 \mathrm{~nm}$ and $\pm 0.1 \mathrm{eV}$, respectively. Image processing was conducted in the freeware axis2000.

\section{Results}

\subsection{Fe oxidation experiments}

The results reported in Table 1 include the $\%$ of Fe(II) oxidized (i.e. determined as the ratio of precipitated $\mathrm{Fe}$ to total $\mathrm{Fe}$ ), the incubation time (in minutes) and the $\delta^{56} \mathrm{Fe}$ values for both dissolved $\mathrm{Fe}(\mathrm{DFe})$ as proxy for $\mathrm{Fe}(\mathrm{II})$ and particulate $\mathrm{Fe}(\mathrm{PFe})$ as proxy for $\mathrm{Fe}(\mathrm{III})$ oxyhydroxides. Although this approach is certainly valid for the oxidation of $\mathrm{Fe}(\mathrm{II})$ in $\mathrm{Fe}$-rich solution and circumneutral $\mathrm{pH}$, the formation of nano-particulate (i.e. colloidal) hydrous $\mathrm{Fe}$ oxides may contribute to the total DFe pool at lower Fe(II) concentrations and/or high extent of Fe oxidation. For all experiments, regardless of reaction time and selected seawater medium, we obtained a fractionation factor $\Delta^{56} \mathrm{Fe}_{\mathrm{PFe} \text {-DFe }}$ ranging from $+1.22+$ to $+1.85 \%$. These values are consistent with previous experimental studies, reporting Fe isotope fractionation factor between goethite and $\mathrm{Fe}(\mathrm{II})_{\mathrm{aq}}$ at $+1.05 \%$ (Beard et al., 2010) and fractionation factors between hydrous ferric oxides and Fe(II) aq ranging from $+2.6 \%$ to $+3.2 \%$ (Wu et al., 2011b). The results are also consistent with previous study of ferrihydrite precipitation by oxidizing a ferrous chloride solution (Bullen et al., 2001), although slightly lower fraction factor at $+1 \%$ was obtained in this previous study. Since the percentage of Fe remaining in solution was greater than $90 \%$, the determination of $\mathrm{Fe}$ isotope fractionation factor was nearly independent of the fraction model (e.g. Rayleigh fractionation model or closed system) but may be affected by competing kinetic

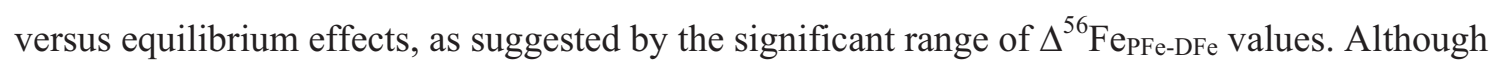
our incubation experiments were not undertaken with the goal to provide a robust assessment of 
$\mathrm{Fe}$ isotope fractionation factor and mechanisms of $\mathrm{Fe}$ isotope fractionation in seawater, it nevertheless provides an important comparison with natural samples.

The kinetics of Fe(II) oxidation in seawater has been the subject of numerous studies that demonstrated the effect of $\mathrm{pH}, \mathrm{O}_{2}$, hydroxyl radical, nutrients, and organic ligands in controlling reaction rates (King et al., 1995; Rose and Waite, 2002; Statham et al., 2005; Gonzalez et al., 2010). Here, since we used high concentration of Fe(II) far above natural background values, leading to probable change of $\mathrm{pH}$ and $\mathrm{O}_{2}$ concentration; the determined rate of $\mathrm{Fe}$ (II) oxidation could not be compared with previous studies.

\subsection{Bottom seawater}

Bottom seawater samples were recovered from Pele's Pit, Loihau (M57) and Pohaku (M6) in 2007 for Fe concentration and isotope analysis (Table 2). Dissolved Fe concentration in Pele's Pit was $230 \mathrm{nM}$ in Pele's Pit while $13 \mathrm{nM}$ and 70nM were measured near M6 and M57 respectively, both sites being located outside of Pele's Pit. The high values in Pele's Pit are identical to dissolved Fe concentration measured in Pele's Pit two years later using CTD rosette sampling (Bennett et al., 2011). Lowest dissolved Fe concentration at $13 \mathrm{nM}$ near M6 is more consistent with open seawater value, while background seawater value of $70 \mathrm{nM}$ at M57 is consistent with significant hydrothermal input. $\delta^{56} \mathrm{Fe}$ values ranged from $-1.27 \%$ o to $-0.50 \%$, with lowest value obtained for the most Fe-rich background seawater in Pele's Pit. Hence, these negative values show a systematic enrichment in light Fe isotopes compared to hydrothermal fluid sources in Pele's Pit (see below) and open deep seawater measured elsewhere, such as the equatorial Pacific Ocean and far-field hydrothermal plume from the Southern East Pacific Rise where $\delta^{56} \mathrm{Fe}$ values ranged from $-0.19 \%$ to $+0.58 \%$ (Radic et al., 2011; Fitzsimmons et al., 2017). These values are however within the range of $\delta^{56} \mathrm{Fe}_{\mathrm{DFe}}$ values measured in a buoyant plume in the East Scotia Sea which yielded distinctly lower $\delta^{56} \mathrm{Fe}_{\mathrm{DFe}}$ (as low as $-1.19 \%$ ) than the initial hydrothermal fluids (-0.29\%o) (Lough et al., 2017). These values are also lighter than the value $\left(\delta^{56} \mathrm{Fe}_{\mathrm{DFe}}=+0.02 \pm 0.03 \%\right.$ o $)$ measured downstream of the Loihi Seamount hydrothermal system at Station ALOHA on July 2012 (Fitzsimmons et al., 2016).

\subsection{Hydrothermal vent fluids}


Loihi vent fluids had a maximum temperature of $55^{\circ} \mathrm{C}$ and were all enriched in $\mathrm{Fe}, \mathrm{Mn}$, and Si relative to background seawater (Table 2). Besides Fe and Mn, other metals also show several orders of magnitude enrichment relative to seawater, including $\mathrm{Co}$, and $\mathrm{Cu}$ (Table 2, Fig. 2). Although on occasion, aqueous sulfur species have been observed in the warmest vent fluids $\left(>50^{\circ} \mathrm{C}\right)$ by in situ voltametric measurements (Glazer and Rouxel, 2009), Loihi vents lacked significant $\mathrm{H}_{2} \mathrm{~S}$ enrichment, which contrasts with typical seafloor hydrothermal systems at midoceanic ridges (MOR). Another important feature of hydrothermal fluids at Loihi is that $\mathrm{Mg}$ concentrations remained very close to background seawater or even higher (Table 2), precluding the determination of "zero Mg" hydrothermal fluid end-members as classically done for hightemperature mid-oceanic ridge vents (e.g. Von Damm et al., 1985). Since S (i.e. sulfate) and Mg were positively correlated in the vent fluids, with values generally lower than background seawater, it is possible that Loihi vents were fed by small proportion of high-temperature vents at depth characterized by near-zero Mg and sulfate concentrations (Sedwick et al., 1992). Other alkaline Earths such as $\mathrm{Ca}, \mathrm{Sr}$ and $\mathrm{Ba}$ and alkaline elements $(\mathrm{Li}, \mathrm{Rb})$ are all enriched relative to seawater, with up to two-fold enrichment for $\mathrm{Ca}$ while $\mathrm{Na}$ (data reported in Glazer and Rouxel, 2009) remains similar to seawater suggesting lack of phase separation in the end-member fluid.

Iron isotope composition of the hydrothermal fluids sampled in Pele's Pit show remarkably homogeneity, with average $\delta^{56} \mathrm{Fe}_{\text {fluid }}=+0.05 \pm 0.21 \%$ o $(2 \mathrm{SD}, \mathrm{n}=21)$ (Table 2). This value is indistinguishable, within uncertainty, from a basaltic value defined at $+0.11 \pm 0.04 \%$ $(2 \mathrm{SD}, \mathrm{n}=43)$ (Teng et al., 2013). Another important result is that $\delta^{56} \mathrm{Fe}_{\text {fluid }}$ at Pele's Pit are significantly higher than hydrothermal vent fluids from mid-oceanic ridge systems ranging from -0.67 to $-0,14 \%$ (Sharma et al., 2001; Beard et al., 2003; Severmann et al., 2004; Rouxel et al., 2008; Bennett et al., 2009).

Iron isotope composition of the lower-temperature vents at M5 yielded $\delta^{56} \mathrm{Fe}_{\text {fluid }}$ between -0.46 and $-0.84 \%$. These values, when plotted together with Pele's Pit samples show significant correlation with $\mathrm{Fe} / \mathrm{Mn}$ ratios $\left(\mathrm{r}^{2}=0.84\right.$, Fig. 3$)$. All fluid samples at M5 and one sample at M36 with lowest $\delta^{56} \mathrm{Fe}_{\text {fluid }}$ values are also characterized by higher $\mathrm{U}$ concentrations.

\subsection{Suspended particulate matter}


The geochemical and Fe isotope compositions of the suspended particulate matter in the vent fluids are shown in Table 3. Although such particles may form due to partial Fe(II) oxidation during the rapid mixing between vent fluid and seawater, they rather reflect the entrainment of freshly formed microbial mats from the venting orifice (Wheat et al., 2000; Glazer and Rouxel, 2009). $\delta^{56} \mathrm{Fe}$ values ranged from $+0.65 \%$ to $+1.94 \%$, which correspond to $\Delta^{56} \mathrm{Fe}$ PFe-DFe between $+1.09 \%$ and $+2.21 \%$. This range of $\mathrm{Fe}$ isotope fractionation factors is very similar, albeit larger, to the one measured in our incubation experiments yielding $\Delta^{56} \mathrm{Fe} \mathrm{PFe}_{\mathrm{PF}}$ DFe between $+1.29 \%$ and $+1.85 \%$ (Table 1$)$.

Other geochemical parameters, such as $\mathrm{Mn} / \mathrm{Fe}, \mathrm{P} / \mathrm{Fe}, \mathrm{Ca} / \mathrm{Fe}, \mathrm{U} / \mathrm{Fe}$ are generally similar to values measured for FeOx deposits in the same area (Table 4, 5). However, several exceptions should be noted: (i) $\mathrm{Cr} / \mathrm{Fe}$ ratios in suspended particles are generally higher than in $\mathrm{FeOx}$ deposits, probably reflecting lower solubility of $\mathrm{Cr}$ in reducing fluids than in $\mathrm{FeOx}$ deposits exposed to seawater (see discussion below) (ii) chalcophile/Fe ratios $(\mathrm{Co} / \mathrm{Fe}, \mathrm{Cu} / \mathrm{Fe}, \mathrm{Ni} / \mathrm{Fe}$, $\mathrm{Zn} / \mathrm{Fe}$ ) are also higher in suspended particles, in particular at M36 and M39 where traces of $\mathrm{H}_{2} \mathrm{~S} / \mathrm{HS}^{-}$were reported (Glazer and Rouxel, 2009). Such enrichments may therefore reflect the contribution of minute amounts of metal sulfide species in the vent fluid.

\subsection{FeOx deposits at Pele's Pit}

FeOx deposits were composed essentially of Fe-oxyhydroxides and amorphous silica, which is reflected by total $\mathrm{Fe}_{2} \mathrm{O}_{3}$ and $\mathrm{SiO}_{2}$ concentrations ranging from 31.2 to $57.7 \mathrm{wt} \%$ and 5.4 to $20.5 \mathrm{wt} \%$, respectively (Table 4). However, $\mathrm{Al}_{2} \mathrm{O}_{3}$ and $\mathrm{TiO}_{2}$ concentrations reached up 3.5 and $0.9 \mathrm{wt} \%$ respectively, suggesting significant contribution of lithogenic materials in $\mathrm{FeOx}$ deposits. This is consistent with a visual inspection of the $\mathrm{FeOx}$ deposit under binocular microscope showing numerous black, silt- to sand-size basaltic fragments. In addition, XRD analysis revealed significant amounts of silicates such as plagioclase, clinopyroxene and olivine derived from surrounding basaltic rocks (data not shown). Although authigenic minerals such as goethite, Fe-montmorillonite and nontronite were reported in previous studies (De Carlo et al., 1983), our XRD analysis could not detect any clay minerals or more crystalline Feoxyhydroxides.

$\mathrm{MnO}$ concentrations in actively forming FeOx deposit were systematically below 0.05 $\mathrm{wt} \%$ with the highest values found in samples containing significant amount of lithogenic 
material (i.e. higher $\mathrm{Al}_{2} \mathrm{O}_{3}$, Table 4). Trace elements displayed large variations among the different sites. By comparing trace element enrichment patterns in $\mathrm{FeOx}$ deposits relative to basaltic values (Garcia et al., 1995; Dixon and Clague, 2001; Pietruszka et al., 2011), it is possible to define several groups:(1) trace elements associated with authigenic phases showing the strongest enrichment factors relative to basaltic values ( $\mathrm{P}, \mathrm{As}, \mathrm{Ba}, \mathrm{Cr}, \mathrm{Ge}, \mathrm{U}, \mathrm{V}, \mathrm{Hf}$ and Rare Earth Elements), hence, these elements include seawater oxyanions and particle-reactive elements enriched in the hydrothermal fluid; (2) elements associated with lithogenic phases showing minimal enrichment factors relative to basaltic values ( $\mathrm{Zr}, \mathrm{Ga}, \mathrm{Nb}, \mathrm{Sc}, \mathrm{Th})$; (3) elements showing clear enrichment in hydrothermal fluids but rather depleted in $\mathrm{FeOx}$ deposits (Co, Y); and (4) elements with mixed behaviors ( $\mathrm{Cu}, \mathrm{Zn}, \mathrm{Mo}, \mathrm{Sb})$.

The presence of volcanic materials is well illustrated by the strong correlation between $\mathrm{Al} / \mathrm{Fe}$ and Ti/Fe in bulk FeOx deposit (Fig. 4). The overall Ti/Al ratio is about 0.237 (g/g), which is similar, albeit slightly higher than the average Ti/Al ratio of 0.209 measured in Loihi basalts (Garcia et al., 1995; Dixon and Clague, 2001). The Ti enrichment relative to basalt (also observed for $\mathrm{Mg}$ ) may either reflect source material heterogeneity and/or higher contribution of minerals such as titanomagnetite (or olivine for $\mathrm{Mg}$ ). Other elements such as $\mathrm{Cr}$, Si and $\mathrm{V}$ are both associated with volcanic materials and authigenic phases, as shown by the relationships between $\mathrm{Si} / \mathrm{Al}, \mathrm{V} / \mathrm{Fe}, \mathrm{Cr} / \mathrm{Fe}$ and $\mathrm{Al} / \mathrm{Fe}$ demonstrating a clear excess above basaltic values (Fig. 4). Chromium was found particularly enriched in the Lohiau Area (M5) where significant subsurface mixing occurs between hydrothermal fluid and seawater. By comparing $\mathrm{U} / \mathrm{Fe}, \mathrm{P} / \mathrm{Fe}$ and $\mathrm{Al} / \mathrm{Fe}, \mathrm{U}$ and $\mathrm{P}$ are found systematically enriched by 1 or 2 orders of magnitude relative to basalts. $\mathrm{U}$ was more enriched in $\mathrm{FeOx}$ deposits formed from higher temperature fluids $\left(51^{\circ} \mathrm{C}\right)$.

Rare earth element (REE) concentrations are reported in Table 4 and chondritenormalized value (CHU) diagrams are reported in Fig. 5. In general, REE patterns provide a means of looking at element sources in $\mathrm{FeOx}$ deposits, in particular to address the relative contribution of hydrothermally-derived or seawater-derived REE, as well as the mechanisms of precipitation (Mills and Elderfield, 1995). Results show that REE patterns of FeOx-deposits from Pele's Pit are similar to REE patterns of OIB basalts at Loihi, with typical enrichment in light REE (Frey and Clague, 1983; Garcia et al., 1995). All REE patterns lacked negative Ce anomalies indicative of minor seawater contribution while FeOx deposits at M39 showed pronounced positive Eu anomalies. This unique feature at M39 (and M36 to a lesser extent) 
suggests higher contributions of high temperature hydrothermal fluids at this site. In general, REE patterns in high-temperature hydrothermal fluids from mid-oceanic ridge systems show light-REE enrichment and positive Eu anomaly primarily reflecting exchange of REE during plagioclase recrystallization (Campbell et al., 1988; Klinkhammer et al., 1994; Douville et al., 1999). This result is consistent with in situ measurements suggesting the existence of free sulfide or Fe-sulfide clusters in M36 vent fluids that could be related to higher temperature vent fluids at depth (Glazer and Rouxel, 2009), as well as the lower Mg concentrations in the M36-M39 area.

Iron isotope composition of $\mathrm{FeOx}$ deposits in Lohiau Area (M2 and M5) ranged from +0.47 to $+0.89 \%$ while heavier values from +0.82 to $+1.57 \%$ were systematically reported in Spillway Area (M34 and M38) (Table 4, Fig. 6). Hiolo Area (M36 and M39) and Tower Area (M48, Little Dike) show the largest range of $\delta^{56} \mathrm{Fe}$ values, from +0.29 to $+1.19 \%$.

\subsection{FeOx deposits along the Southern Rift and Pit of Death (M56)}

The FeOx deposits of Spillway, Pit of Death, Pohaku, and Naha are composed of particles with a variety of morphologies including sheaths, stalks and fine particles (Fig. 7) which are similar to previously reported particle morphologies of mats recovered from Pele's Pit (Emerson and Moyer 1997) and from pure culture of Mariprofundus ferrooxydans (Chan et al., 2011). Hence, although these deposits have $\delta^{56} \mathrm{Fe}$ values ranging widely from -0.27 to $+1.57 \%$, no direct relationships could be drawn between the morphologies and $\mathrm{Fe}$ isotope signatures of their Fe-oxyhydroxide components.

The single FeOx deposit sampled at Pit of Death (M56, sample J2-310-SS1) yields geochemical signatures generally similar to Pele's Pit and Lohiau (Table 4; Fig. 4). However, the $\delta^{56} \mathrm{Fe}$ value measured at M56 (-0.14\%) is significantly lower than average values at Lohiau $\left(\delta^{56} \mathrm{Fe}=+0.74 \pm 0.16 \%\right.$, 1s.d. $)$ and Pele's Pit $\left(\delta^{56} \mathrm{Fe}=+0.98 \pm 0.31 \%\right.$, 1s.d. $)$. Although $\mathrm{FeOx}$ deposit samples recovered at M56 show significant contribution of volcanic material, simple mass balance considerations using Fe/Al ratios suggest that less than 10\% of total Fe could be attributed to volcanic materials. Hence, the near-zero $\delta^{56} \mathrm{Fe}$ value cannot be explained by a simple contribution of volcanic materials to the deposit.

Pohaku (M57) is the only site from the Southern Rift (i.e. outside of Pele's Pit) where active venting was still observed. Both geochemical composition and $\delta^{56} \mathrm{Fe}$ values of the $\mathrm{FeOx}$ 
deposits overlap with the range of composition measured in Pele's Pit (Table 4; Fig. 4). In particular, $\delta^{56} \mathrm{Fe}$ values show the same variability between $+0.82 \%$ and $+1.41 \%$, well within the range of Pele's Pit values $\left(\delta^{56} \mathrm{Fe}=+0.98 \pm 0.31 \%\right.$, 1s.d. $)$. The most notable difference is a much lower $\mathrm{SiO}_{2}$ concentration below $6 \mathrm{wt} \%$, which corresponds to a smaller enrichment in amorphous silica. The relative Si depletion at M57 is also reflected in the Si-depleted nature of the vent fluid at M57 compared to Pele's Pit vent sites (Fig. 2).

FeOx deposits recovered at M3 and M6 (Naha site), although located within less than 10 meters from each other, show very contrasted $\delta^{56} \mathrm{Fe}$ values (Table 5), with M3 having $\delta^{56} \mathrm{Fe}$ from +0.83 to $+0.92 \%$ and M6 having $\delta^{56} \mathrm{Fe}$ from -0.14 to $-0.27 \%$. The Mn/Fe ratios are also contrasted, with the FeOx deposit at M6 having higher Mn than the deposit at M3.

FeOx deposits recovered at the inactive area M17 and M17A are unlike any other deposits found in Pele's Pit (Table 4; Fig. 6): (1) $\delta^{56} \mathrm{Fe}$ values from $-0.65 \%$ down to $-1.77 \%$ o show a systematic enrichment in light isotopes which contrast with $\delta^{56} \mathrm{Fe}$ values up to $+1.57 \%$ in Pele's Pit; (2) MnO concentrations are high, up to $6.6 \mathrm{wt} \%$, in particular at M17A; and (3) elements such as $\mathrm{Cu}, \mathrm{Mo}, \mathrm{Ni}$, and $\mathrm{Co}$ that typically show strong affinity for Mn oxyhydroxide phases are also enriched. This feature is well illustrated by the strong correlation between $\mathrm{Ni} / \mathrm{Fe}$, $\mathrm{Co} / \mathrm{Fe}$ and $\mathrm{Mn} / \mathrm{Fe}$ (Fig. 6). The same trend is also observed at Naha (M3-M6) to a lesser extent. Overall, the strong relationship between $\delta^{56} \mathrm{Fe}$ and $\mathrm{Mn} / \mathrm{Fe}$ ratios (Fig. 6) is remarkable, considering the large range of $\delta^{56} \mathrm{Fe}$ values up to $+3.5 \%$.

\section{Discussion}

\subsection{Subsurface processes at Loihi Seamount as inferred from hydrothermal fluid geochemistry}

As already discussed in previous studies (Karl et al., 1988; Sedwick et al., 1992; Wheat et al., 2000; Glazer and Rouxel, 2009), the positive correlation between Si, Fe and Mn concentrations (Fig. 2) reflects a simple dilution between hydrothermal vent fluids and background seawater, either at the seafloor or in the subsurface. Due to the relatively homogeneous Fe/Mn ratios ranging from 22 to $41 \mu \mathrm{mol} / \mathrm{mol}$ (averaging $27 \mu \mathrm{mol} / \mathrm{mol}$ ), Pele's Pit 
vents were likely derived from the same fluid source at depth (hereafter referred to as the endmember fluid) (Glazer and Rouxel, 2009). In details, however, hydrothermal fluids from Spillway (M34-M38) and Hiolo (M36-M39) have slightly different Fe/Mn ratios, as well as $\mathrm{Si} / \mathrm{Mn}$ and other metal/Mn ratios suggesting different fluid sources in the subsurface (Fig. 2). In particular, vents from the Spillway (M34-M38) and Hiolo (M36-M39) areas are characterized by a strong, but distinct, positive correlation between $\mathrm{Si}$ and $\mathrm{Mn}$ (with $\mathrm{Si} / \mathrm{Mn}=191, \mathrm{r}^{2}=0.96$ and $\mathrm{Si} / \mathrm{Mn}=127, \mathrm{r}^{2}=0.81$ respectively, Fig. 2).

Pohaku vents (M57), located south of Pele's Pit were also characterized by lower temperatures $\left(28^{\circ} \mathrm{C}\right.$ maximum) but with higher $\mathrm{Fe} / \mathrm{Mn}$ ratios suggestive of subsurface interactions with volcanic rocks, with a relative increase in Fe concentrations due to basalt dissolution in the subsurface (Glazer and Rouxel, 2009). A similar mechanism was proposed based on Ge isotope and Ge/Si systematics (Escoube et al., 2015). The importance of chemical weathering, in particular at Pohaku (M57) is also illustrated in the enrichment of Al, Cr and V in vent fluid, as well as the alkaline earths: $\mathrm{Mg}, \mathrm{Ca}$, and $\mathrm{Sr}$ (Table 2).

In general, $\mathrm{Cu}$ and $\mathrm{Co}$ concentrations in hydrothermal vent fluids decrease sharply at temperatures below $350^{\circ} \mathrm{C}$ (Metz and Trefry, 2000). At Loihi, $\mathrm{Cu}$ concentration remained below $500 \mathrm{nM}$ consistent with low temperature vent fluids (Table 2). In contrast, Co yields concentrations up to $200 \mathrm{nM}$, which is equivalent or even higher than most high temperature hydrothermal fluids sampled along mid-oceanic ridges (Metz and Trefry, 2000; Douville et al., 2002). In addition, Co shows strong correlation with $\mathrm{Mn}\left(\mathrm{r}^{2}=0.96\right.$ for M34-M38 area, $\mathrm{r}^{2}=0.81$ for M36-M39 area, Fig. 2) suggesting that this element behaves as conservative element during hydrothermal fluid mixing with seawater. The relatively large enrichment in Co compared to typical mid-oceanic ridge fluids is probably the result of the $\mathrm{Fe}(\mathrm{II})$ - and $\mathrm{CO}_{2}$-rich conditions of the subseafloor mixing zone at Loihi. Under these conditions, most of the $\mathrm{H}_{2} \mathrm{~S}$ initially present in the end-member fluid would have been titrated with $\mathrm{Fe}(\mathrm{II})$ at depth, preventing the precipitation of $\mathrm{Co}$ in the subsurface as insoluble sulfide species. It is also likely that $\mathrm{Co}$ and probably $\mathrm{Cu}$ were further released into solution through enhanced chemical weathering of the basalt in the upflow zone. 
Uranium is readily removed from seawater during water-rock interaction at mid-oceanic ridges (Michard et al., 1983; Michard and Albarede, 1985) due to the efficient reduction of uranyl carbonate and precipitation of insoluble oxide $\mathrm{UO}_{2}$. Hence, the negative correlation between $\mathrm{U}$ and $\mathrm{Mn}\left(\mathrm{r}^{2}=0.95\right.$ for M34-M38 area and $\mathrm{r}^{2}=0.80$ for M36-M39 area, Fig. 2) suggest that end-member hydrothermal fluids at Loihi are depleted in $\mathrm{U}$ relative to seawater.

Molybdenum has also been shown to be generally depleted in seafloor hydrothermal fluids (Trefry et al., 1994), with the exception of high temperature vent fluids above $350^{\circ} \mathrm{C}$ (Metz and Trefry, 2000). Results at Loihi show a strong negative correlation $\left(r^{2}=0.92\right)$ between Mo and Mn concentrations (Fig. 2) suggesting that changes in Mo concentrations in vent fluids result from the mixing between seawater with $\mathrm{Mo}=120 \mathrm{nM}$ (i.e. $\mathrm{Mn}=0$ intercept) and hydrothermal fluids having near-zero Mo concentrations. However, the extrapolation of $\mathrm{U}$ versus $\mathrm{Mn}$ and Mo versus Mn concentration trends gives contrasted results. By analogy with the determination of endmember hydrothermal fluid composition using an extrapolation to zero-Mg (Edmond et al., 1979), we determined end-member Mn concentrations at Loihi of $28.6 \mu \mathrm{M}$ and $41.7 \mu \mathrm{M}$ by extrapolation to zero- $U$ and zero-Mo, respectively. These contrasted results suggest that $\mathrm{U}$ is not conservative during hydrothermal fluid-seawater mixing and is likely to be precipitated in the mixing zone at the seafloor. In contrast, Mo is less reactive in $\mathrm{Fe}(\mathrm{II})$-rich and $\mathrm{H}_{2} \mathrm{~S}$-depleted fluids and behave as a more conservative element during hydrothermal fluid-seawater mixing. Hence, it can be proposed that $\mathrm{U}$ enrichment in diluted hydrothermal fluid is a good tracer of hydrothermal fluid-seawater mixing extent at the seafloor.

In this context, the low $\mathrm{Fe} / \mathrm{Mn}$ ratios and relatively high $\mathrm{U}$ concentrations reported in the low temperature vent from Lohiau (M5 area, Fig. 3), likely reflect Fe oxidation and precipitation due to the subsurface entrainment of seawater. This hypothesis is based on the near-conservative behavior of Mn during hydrothermal fluid-seawater mixing at the seafloor due to its expected slow rate of oxidation. In contrast, it is expected that $\mathrm{Fe}(\mathrm{II})$ oxidation will proceed at a much faster rate (potentially microbially mediated), leading to a preferential depletion in Fe relative to $\mathrm{Mn}$ during the mixing process. This suggests that the subsurface processes affecting Fe/Mn ratios and $\mathrm{U}$ enrichment (or $\mathrm{U}$ depletion relative to background seawater) may also fractionate $\mathrm{Fe}$ isotopes as shown by the observed relationships between $\delta^{56} \mathrm{Fe}$ values and, $\mathrm{U}$ and Fe/ $\mathrm{Mn}$ (Fig. 3). The mechanisms of Fe isotope fractionation during subsurface Fe(II) oxidation is discussed in more details below. 


\subsection{Mechanisms of Fe isotope fractionation during $\mathrm{Fe}(I I)$ oxidation in vent fluids}

As shown in Table 6, the calculated Fe isotope fractionation factor between suspended $\mathrm{Fe}$-(oxyhydr)oxide precipitates (i.e. PFe) and dissolved Fe(II) (i.e. DFe), reported as $\Delta \delta^{56} \mathrm{Fe}$ PFeDFe, ranged, on average from +1.12 to $+1.51 \%$ (this is excluding the value calculated at M5 which showed relatively large propagated error). In comparison, the freshly precipitated $\mathrm{FeOx}$ recovered on glass slides placed directly in the vent fluid (referred as "slide trap" in Table 5, located in Hiolo Area, M36) yielded $\Delta^{56} \mathrm{Fe}$ PFe-DFe $=+1.5 \%$. These empirical values are in great agreement with our incubation experiments (Table 1), showing a range of $\Delta^{56} \mathrm{Fe}$ PFe-DFe from $+1.22 \%$ to $+1.85 \%$, regardless of reaction time and seawater sample origin and extent of $\mathrm{Fe}(\mathrm{II})$ oxidation. Although the reasons for such variability in $\Delta^{56} \mathrm{Fe}$ PFe-DFe values remain unclear, it is likely that kinetic effects during $\mathrm{Fe}(\mathrm{III})_{\text {aq }}$ precipitation may be important. In particular, the experiment that lasted more than 3 hours showed the largest $\Delta^{56} \mathrm{Fe}$ PFe-DFe suggesting that $\delta^{56} \mathrm{Fe}$ values may have reached partial equilibrium after longer incubation periods.

The largest equilibrium Fe isotope fractionations reported so far were observed and theoretically calculated for coexisting $\mathrm{Fe}(\mathrm{III})_{\mathrm{aq}}$ and $\mathrm{Fe}(\mathrm{II})_{\mathrm{aq}}$ aqueous species, with $\Delta^{56} \mathrm{Fe}_{\mathrm{Fe}(\mathrm{III}) \mathrm{aq}-}$ $\mathrm{Fe}(\mathrm{II}) \mathrm{aq}=+3 \%$ at $20^{\circ} \mathrm{C}$ (Johnson et al., 2002; Welch et al., 2003; Anbar et al., 2005).

Microbiological experiments have shown that significant Fe isotope fractionations are also produced during microbial Fe(II) oxidation. Balci et al. (2006) performed a range of abiotic and biotic experiments using pure culture of Acidothiobacillus ferrooxidans to investigate Fe isotope fractionation during low-pH Fe(II) oxidation. For microbially-stimulated Fe(II) oxidation, $\delta^{56} \mathrm{Fe}$ of residual $\mathrm{Fe}(\mathrm{II})_{\mathrm{aq}}$ evolved along an apparent Rayleigh trend characterized by a fractionation factor $\Delta^{56} \mathrm{Fe}_{\mathrm{Fe}(\mathrm{III}) \mathrm{aq}-\mathrm{Fe}(\mathrm{II}) \mathrm{aq}}$ of $+2.2 \%$. This fractionation factor was significantly less than that measured in their sterile control experiments (i.e. $+3.4 \%$ ), which probably reflects a significant isotope fractionation between aqueous $\mathrm{Fe}(\mathrm{III})_{\mathrm{aq}}$ and solid-phase $\mathrm{Fe}(\mathrm{III})_{\mathrm{s}}$ upon precipitation. The combination of both fractionation factors result in a decrease of the overall $\mathrm{Fe}(\mathrm{III})_{\mathrm{s}}-\mathrm{Fe}(\mathrm{II})_{\mathrm{aq}}$ fractionation. Croal et al. (2004) investigated Fe isotope fractionation produced by freshwater $\mathrm{Fe}(\mathrm{II})$-oxidizing phototrophs under anaerobic conditions. Among key results, the ferrihydrite 
precipitate had $\delta^{56} \mathrm{Fe}$ value that is $\sim+1.5 \%$ higher than the aqueous Fe(II) source. Since the degree of isotopic fractionation was not correlated to the rate of oxidation (controlled by changing the light intensity), it has been suggested that kinetic isotope effects were not of great importance in controlling the fractionation factor. Instead, Croal et al. (2004) suggested that an $\mathrm{Fe}(\mathrm{III})$-organic ligand species may be in isotopic equilibrium with aqueous $\mathrm{Fe}(\mathrm{II})$. A similar mechanism was proposed by Swanner et al. (2015) to explain the fractionation of Fe isotopes during Fe(II) oxidation by marine photoferrotrophs. In particular, a range of Fe isotope fractionation factors between $\mathrm{Fe}(\mathrm{II})_{\mathrm{aq}}$ and $\mathrm{Fe}(\mathrm{III})_{\mathrm{s}}(-0.40 \%$ to $+2.22 \%$ ) was obtained and could not be modeled by a simple kinetic Rayleigh fractionation model. In contrast, experiments with cultures of nitrate-reducing $\mathrm{Fe}(\mathrm{II})$-oxidizing bacteria yielded $\Delta^{56} \mathrm{Fe}_{\mathrm{Fe}(\mathrm{III}) \mathrm{s}-\mathrm{Fe}(\mathrm{II}) \mathrm{aq}}=+3 \%$ consistent with an equilibrium model (Kappler et al., 2010). The sign of the overall fractionation $\Delta^{56} \mathrm{Fe} \mathrm{PFe}-$ DFe obtained in our experiments (Table 1) and inferred from hydrothermal plume studies (Lough et al., 2017) is therefore similar to non-marine redox environments, contradicting a previous study of Fe isotope fractionation between dissolyed and suspended particulate Fe in the Baltic Sea (Staubwasser et al., 2013).

Despite previous studies, it is difficult to determine Fe isotope fractionation between aqueous $\mathrm{Fe}(\mathrm{II})$ and poorly crystalline ferric hydrous oxides (ferrihydrite) due to fast transformation of the latter to more stable minerals (see recent review by Dauphas et al., 2017). Wu et al. (2011b) determined experimentally the equilibrium $\mathrm{Fe}(\mathrm{II})_{\mathrm{aq}}-\mathrm{Fe}(\mathrm{III})_{\mathrm{s}}$ fractionation factor using a three-isotope method. Iron isotope exchange between $\mathrm{Fe}(\mathrm{II})$ and ferrihydrite was rapid and nearly complete in the presence of dissolved silica. Equilibrium $\Delta^{56} \mathrm{Fe}_{\mathrm{Fe}(\mathrm{III}) \mathrm{s}-\mathrm{Fe}(\mathrm{II}) \mathrm{aq}}$ factors of $+3.17 \%$ were obtained for ferrihydrite plus silica. In contrast, when Si-rich ferrihydrite co-precipitated during the experiment, a smaller fractionation factor of $+2.6 \%$ was obtained, possibly reflecting blockage of oxide surface sites by sorbed silica leading to incomplete isotope exchange. The importance of Fe-Si species may explain the range of $\Delta^{56} \mathrm{Fe}_{\mathrm{Fe}(\mathrm{III}) \mathrm{s}-\mathrm{Fe}(\mathrm{II}) \mathrm{aq}}$ observed in natural systems, in particular in hot springs or groundwater discharge settings (Bullen et al., 2001; Wu et al., 2013) and seafloor hydrothermal systems such as Loihi Seamount, although no clear relationships could be identified between $\mathrm{Si} / \mathrm{Fe}$ and $\delta^{56} \mathrm{Fe}$ of the deposits (Table 4 and 5). 
Since the rate of Fe(II) oxidation in background seawater at Loihi Seamount is unknown, it is difficult to speculate on the mechanisms of Fe(II) oxidation at the seafloor. The Fe(II) oxidation rates in hydrothermal plumes have been estimated in several studies (Rudnicki and Elderfield, 1993; Field and Sherrell, 2000; Statham et al., 2005), showing that Fe(II) half-life (t) may vary from a few minutes for some Atlantic sites with $\mathrm{O}_{2}=250 \mu \mathrm{M}$ to hours at Pacific sites with $\mathrm{O}_{2}=100 \mu \mathrm{M}$. Considering a background $\mathrm{O}_{2}$ concentration in Pele's Pit below $30 \mu \mathrm{M}$, the expected half-life for Fe (II) is probably close to 20 hours. In addition, using in situ voltammetric microprofiling, Glazer and Rouxel (2009) reported no detectable $\mathrm{O}_{2}$ by $1 \mathrm{~mm}$ below the mat surface, and Fe(II) concentrations increased steadily with depth, leading to the assumption that $\mathrm{Fe}(\mathrm{II})$ oxidation is probably entirely microbially-mediated at or below the seafloor (Glazer and Rouxel, 2009). However, Fe isotopes can contribute little to this distinction here because previous experiments and studies from natural systems suggest that the range of isotope largely fractionations overlap. Further experiments are now required to determine $\mathrm{Fe}$ isotope fractionation factors during Fe(II) oxidation by zeta-proterobacteria FeOB group. An important mechanism to also consider is the formation and stabilization of nanoparticulate $\mathrm{Fe}$ oxyhydroxide phase and/or organically-bound Fe(III) that would produce a decrease of the apparent $\Delta^{56} \mathrm{Fe}$ PFe-DFe. Although this mechanism is unlikely to affect our experiments considering the low extent of Fe(II) oxidation, it has been shown to control both Fe isotope composition and concentration of DFe in distal hydrothermal plume (Fitzsimmons et al., 2017).

\subsection{Iron isotope systematics of $\mathrm{FeOx}$ deposits}

Regardless of the mechanisms of Fe(II) oxidation and range of Fe isotope fraction factors, the extent of $\mathrm{Fe}(\mathrm{II})$ oxidation is probably the most important parameter controlling $\delta^{56} \mathrm{Fe}_{\mathrm{Fe}(\mathrm{III}) \mathrm{s}}$ of the $\mathrm{FeOx}$ deposits at Loihi, through the so-called reservoir effect. Under oxic conditions and circum-neutral $\mathrm{pH}, \mathrm{Fe}(\mathrm{II})$ species are rapidly oxidized by $\mathrm{O}_{2}$ to the thermodynamically stable Fe(III) form. Hence, no significant variations in Fe isotope composition of $\mathrm{Fe}(\mathrm{III})_{\mathrm{s}}$ is expected in the case of quantitative Fe oxidation. In contrast, significant variability is expected when Fe(II) $)_{\text {aq }}$ is partially oxidized near hydrothermal vents where the oxidation rate is slow relative to the length-scales of fluid transport, due to the large $\mathrm{Fe}$ isotope fractionation factor between Fe(II) and Fe(III) species. Following the approach of 
Dauphas and Rouxel (2006) and later used by Moeller et al. (2014), we modeled the precipitation of Fe-oxyhydroxides from the oxidation of aqueous Fe(II) using a two-stage model, such as:

$$
\mathrm{Fe}(\mathrm{II})_{\mathrm{aq}} \Leftrightarrow \mathrm{Fe}(\mathrm{III})_{\mathrm{aq}} \Rightarrow \mathrm{Fe}(\mathrm{III})_{s} .
$$

where aqueous $\mathrm{Fe}(\mathrm{II})$ aq is oxidized to $\mathrm{Fe}(\mathrm{III})$ aq under equilibrium conditions, while $\mathrm{Fe}(\mathrm{III})$ aq precipitation to $\mathrm{Fe}(\mathrm{III}) \mathrm{s}$ involved significant isotopic effects. Based on the experimental data of Welch et al. (2003), we calculated $\Delta \delta^{56} \mathrm{Fe}_{\mathrm{Fe}(\mathrm{III}) \mathrm{aq}-\mathrm{Fe}(\mathrm{II}) \mathrm{aq}}=+2.22 \%$ at $55^{\circ} \mathrm{C}$ (referred as $\Delta_{\text {IIaq }}^{\text {IIlaq }}$, which is the maximum temperature of vent fluids in Pele's Pit. Considering our best estimation for $\Delta^{56} \mathrm{Fe}_{\mathrm{Fe}(\mathrm{III}) \mathrm{s}-\mathrm{Fe}(\mathrm{II}) \mathrm{aq}}$ of $+1.5 \%$, then it is possible to estimate the kinetic isotope effects during $\mathrm{Fe}(\mathrm{III})_{\mathrm{aq}}$ precipitation at around $+0.7 \%$ (referred as $\Delta_{\text {IIIIaq }}^{\mathrm{III}}$ ). Using a first order kinetic model, Dauphas and Rouxel (2006) obtained the following equations:

$$
\begin{aligned}
& F e(I I)_{a q}=e^{-k_{1} t} \\
& F e(I I I)_{a q}=\frac{k_{1}}{k_{2}-k_{1}}\left(e^{-k 1 t}-e^{-k 2 t}\right) \\
& F e(I I I)_{s}=1-F e(I I)_{a q}-F e(I I I)_{a q}
\end{aligned}
$$

with $\mathrm{k}_{1}$ and $\mathrm{k}_{2}$ being the rate constants for oxidation and precipitation, respectively.

The equations for the isotope composition of the remaining Fe(II) pool is defined as:

$$
\delta^{56} \mathrm{Fe}_{\mathrm{Fe}(\mathrm{II}) a q}=\left(\frac{\Delta_{\text {IIIsa }}^{\text {IIIs }}}{\mu-1}+\frac{\Delta_{\text {IIIaq }}^{\text {IIIaq }}}{\mu}\right) \ln X+\left(\Delta_{\text {IIIaq }}^{\text {IIIs }}-\frac{\Delta_{\text {IIIaq }}^{\text {IIIaq }}}{\mu}\right) \ln \left(\frac{X-\mu}{1-\mu}\right)
$$

with $\mu=\mathrm{k}_{2} / \mathrm{k}_{1}$ and $X=\mathrm{e}^{(\mathrm{k} 1-\mathrm{k} 2) \mathrm{t}}$

The isotopic composition of the other Fe pools, $\delta^{56} \mathrm{Fe}_{\mathrm{Fe}(\mathrm{III}) \mathrm{aq}}$ and $\delta^{56} \mathrm{Fe}_{\mathrm{Fe}(\mathrm{III}) \mathrm{s}}$, are easily solved using mass balance considerations.

In the case of partial Fe(II) oxidation along a flow path, the Fe isotope composition of the $\mathrm{Fe}(\mathrm{HII}) \mathrm{s}$ is determined as:

$$
\delta^{56} \mathrm{Fe}_{\mathrm{Fe}(I I I) s}=\delta^{56} \mathrm{Fe}_{\mathrm{Fe}(I I) a q}+\Delta_{\text {IIIaq }}^{\text {IIIs }}+\Delta_{\text {IIIaq }}^{\text {IIIaq }}
$$

For illustration, Fig. 8 shows the calculated isotopic compositions of the different reservoirs as a function of the fraction of Fe precipitated for $\mu=\mathrm{k}_{2} / \mathrm{k}_{1}=10$ (Dauphas and Rouxel, 2006), corresponding to a high rate of Fe(III) precipitation versus Fe(II) oxidation. In the first 
model (Fig. 8a), it is considered that Fe(II) is progressively oxidized at the seafloor, either during rapid mixing with seawater (e.g. suspended Fe-oxyhydroxide particles in vent fluids) or within microbial mats (i.e. case of most $\mathrm{FeOx}$ deposits formed by diffuse venting). In the case of freshly formed $\mathrm{FeOx}$ (e.g. slide trap sample placed within vent flow) having $\delta^{56} \mathrm{Fe}$ of about $+1.5 \pm 0.3$ $\%$, the model suggests less than $20 \%$ of Fe(II) is oxidized. Small extents of Fe(II) oxidation are also recorded in seafloor FeOx deposits, such as those recovered at M34 and M38 area. In contrast, $\mathrm{FeOx}$ deposits recovered at M36 in 2007 yielded $\delta^{56} \mathrm{Fe}$ from $+0.3 \%$ to $+0.4 \%$, indicative of much higher extent of Fe(II) oxidation, presumably up to $90 \%$. Such higher extent of $\mathrm{Fe}(\mathrm{II})$ oxidation may be explained by the relatively mature nature of the deposit and by its location further away from the most active venting area. In the following sampling years, new $\mathrm{FeOx}$ deposits had formed in the vicinity of the vent area and were characterized by more positive $\delta^{56} \mathrm{Fe}$ values up to $+1.13 \%$ (Table 5 ) consistent with this assumption.

In the second model (Fig. 8b), it is considered that Fe(II) is progressively oxidized below the seafloor, leading to significant loss of Fe in the venting fluid due to subsurface Feoxyhydroxide precipitation. Under this scenario, lighter $\delta^{56} \mathrm{Fe}$ values of the vent fluid are expected, as observed in the Lohiau area (M2, M5). This Rayleigh-type fractionation is further supported by the relationships between $\delta^{56} \mathrm{Fe}$ and $\mathrm{Fe} / \mathrm{Mn}$ values in the vent fluids (Fig. 9). As explained above, $\mathrm{Mn}$ is expected to behave conservatively during partial Fe(II) oxidation under low-oxygen environments, such as during subsurface entrainment of seawater. Hence, Fe/Mn ratio is a good indicator of Fe precipitation below seafloor. The Rayleigh curves shown in Fig. 9 were obtained by considering fractionation factors between $\mathrm{Fe}(\mathrm{III})_{\mathrm{s}}$ and $\mathrm{Fe}(\mathrm{II})_{\mathrm{aq}}$ ranging from $+0.6 \%$ to $+1 \%$ o $(\alpha=1.0006$ to 1.001 respectively). This is significantly less than the estimated in situ $\mathrm{Fe}$ isotope fractionation but still consistent with equilibrium $\mathrm{Fe}$ isotope fractionation factors between more crystalline Fe-oxyhydroxides (e.g. goethite) and Fe(II) of $+1.04 \%$ to $+1.22 \%$ (Frierdich et al., 2014).

Following the same lines, it is expected that late-stage hydrothermal fluids (i.e. undergoing extensive cooling and mixing with seawater) would have even lighter $\delta^{56} \mathrm{Fe}$ (Fig. $8 \mathrm{~b})$, leading to the precipitation of isotopically light $\mathrm{FeOx}$ deposits. This is indeed what is currently observed in Naha area where FeOx deposit ranged from $-0.3 \%$ to $+0.8 \%$, consistent 
with the decrease of hydrothermal activity at this site over the years. Finally, the now extinct $\mathrm{FeOx}$ deposit at M17 shows the lightest $\delta^{56} \mathrm{Fe}$ values, suggesting that these deposits recorded the last stage of hydrothermal venting, before it became completely extinct (i.e. $>70 \%$ of $\mathrm{Fe}$ has been precipitated below seafloor). Under this scenario, Mn would have started to oxidize due to more oxic conditions, leading to the observed enrichment in $\mathrm{Mn}$ in the deposits. Once precipitated, such Mn oxyhydroxide would continue scavenging seawater-derived elements, such as REE which is consistent with the negative Ce anomaly of the deposits (Fig. 5). The subsurface entrainment of oxic seawater is the most plausible mechanism leading to subsurface Fe oxidation and precipitation, and therefore loss of isotopically heavy Fe-oxide pool from the fluid. This hypothesis is supported by the marked increase in U concentrations (Fig. 3) in hydrothermal vent fluids from M5, which reflect the higher contribution of oxygenated seawater due to the more diffuse nature of hydrothermal venting at M5.

A similar relationship between $\delta^{56} \mathrm{Fe}$ values and $\mathrm{U}$ concentration was already observed in subterranean estuaries (Rouxel et al., 2008b) where anoxic Fe(II)-rich (and U-depleted) porewater were mixed with oxic (and U-enriched) seawater. This mechanism has been shown to lead to isotopically light $\mathrm{Fe}(\mathrm{II})$ in sediment porewater $\left(\delta^{56} \mathrm{Fe}\right.$ down to $-4.9 \%$ ) due to the precipitation of $\mathrm{Fe}$ (III) during partial Fe(II) oxidation along a flow path. This also led to a range of $\delta^{56} \mathrm{Fe}$ values for precipitated Fe-oxyhydroxides between -2 and $+1.5 \%$. Similar reservoir effects were also reported in spring systems (Chocolate Pots Hot Springs in Yellowstone NP) by $\mathrm{Wu}$ et al. (2013) where the $\mathrm{Fe}$ isotope compositions of $\mathrm{Fe}(\mathrm{II})_{\mathrm{aq}}$ and $\mathrm{FeOx}$ precipitates varied significantly along a flow path from $+0.88 \%$ down to $-1.57 \%$.

\subsection{Implication for the hydrothermal Fe source to the ocean}

The range of Fe isotope composition of the hydrothermal fluids from Pele's Pit is remarkably limited, with average $\delta^{56} \mathrm{Fe}_{\text {fluid }}=+0.05 \pm 0.21 \%(2 \mathrm{SD}, \mathrm{n}=21)($ Table 2$)$. This value is indistinguishable within uncertainty from basaltic values defined at $+0.11 \pm 0.04 \%$ $(2 \mathrm{SD}, \mathrm{n}=43)$ (Teng et al., 2013). Another important result is that $\delta^{56} \mathrm{Fe}_{\text {fluid }}$ at Pele's Pit are among the heaviest values reported from seafloor hydrothermal systems. So far, $\delta^{56} \mathrm{Fe}$ values as low as $-0.67 \%$ and as high as $-0.14 \%$ were reported in high-temperature hydrothermal vent 
fluids along the Mid-Atlantic Ridge and East Pacific Rise, averaging $-0.43 \pm 0.32 \%$ ( 2 SD; $n=$ 39)(Sharma et al., 2001; Beard et al., 2003; Severmann et al., 2004; Rouxel et al., 2008; Bennett et al., 2009; Rouxel et al., 2016). Heaviest values were found for high-temperature hydrothermal fluids from the Rainbow and TAG fields $(-0.14 \pm 0.04 \%$ when normalized to IRMM-14) from the Mid-Atlantic Ridge (Severmann et al., 2004) while lighter values were reported for Fedepleted vents from basaltic-hosted vent sites at EPR 950'N (e.g. Bio-vent, Rouxel et al., 2008). Although Rouxel et al. (2003) demonstrated that isotopically light Fe is preferentially leached from basalt during low-temperature alteration of the oceanic crust, $\delta^{56} \mathrm{Fe}_{\text {fluid }}$ at Pele's Pit suggests rather minor isotopic effect during basalt alteration. It has been previously proposed (Sedwick et al., 1992; Wheat et al., 2000) that the high $\mathrm{CO}_{2}$ content of the hydrothermal fluids at Loihi Seamount, resulting in higher alkalinity, may induce an important chemical weathering process of the volcanic rocks by carbonic acid due to lower $\mathrm{pH}$ conditions ( $\mathrm{pH}$ as low as 5.7 and Alkalinity up to $15.6 \mathrm{meq} / \mathrm{kg}$, Table 2). This more intense weathering (i.e. near congruent dissolution due to $\mathrm{CO}_{2}$-induced alteration) provides an adequate explanation for basaltic $\delta^{56} \mathrm{Fe}_{\text {fluid }}$ values.

Iron isotope composition of diffuse venting fluid at M5 yielded $\delta^{56} \mathrm{Fe}_{\text {fluid }}$ between -0.46 and $-0.84 \%$. These values, when plotted together with Pele's Pit samples showed strong correlation with Fe/Mn $\left(\mathrm{r}^{2}=0.84\right.$, Fig. 3$)$ consistent with subsurface Fe oxidation and precipitation. Hence, it is expected that most of the hydrothermal Fe input in the water column above Pele's Pit is characterized by lower $\delta^{56} \mathrm{Fe}$ values from diffuse venting area affected by extensive mixing with seawater. In fact, $\delta^{56} \mathrm{Fe}$ values for dissolved $\mathrm{Fe}$ in bottom seawater overlying Pele's Pit yielded the lowest value down to $-1.27 \%$ consistent with partial Fe(II) oxidation and precipitation of Fe at the seafloor and/or within the water column. This is also consistent with previous results showing that the Fe/Mn ratios of the seawater within Pele's Pit $(17.3-21.1)$ are on the low end compared to those measured in the hydrothermal end-member fluids within Pele's Pit (20-40), and may be a result of Fe oxidation and precipitation from the plume (Bennett et al., 2011). Using the same Fe isotope model used for hydrothermal fluids (Fig. 8), we found that about $60 \%$ of $\mathrm{Fe}(\mathrm{II})$ underwent oxidation in seawater at the bottom of Pele's Pit. Surprisingly, Emerson and Moyer (1997) also estimated that up to $60 \%$ of Fe oxyhydroxides 
occur as sheaths or filaments in $\mathrm{FeOx}$ deposits and can be directly attributed to microbial activity.

Other bottom seawater sampled away from Pele's Pit at M6 and M57 (and therefore less directly related to the hydrothermal plume) show lower Fe concentrations (13nM and $70 \mathrm{nM}$, respectively) and $\delta^{56} \mathrm{Fe}$ values between $-0.83 \%$ and $-0.50 \%$. Hence, these values cannot be explained by further oxidation of Fe(II) as the plume spreads away from Pele's Pit, as it would have resulted in lower Fe concentrations but also more negative $\delta^{56} \mathrm{Fe}$ compared to Pele's Pit. Instead, it is likely that Fe behaves more conservatively away from the hydrothermal plume, probably through the formation of soluble, and isotopically heavy Fe(III) colloidal species, contributing to the residual dissolved Fe pool as suggested in recent studies (Fitzsimmons et al., 2015a; Lough et al., 2017). An alternate, and also likely mechanism, is formation of organicallybound Fe(III) species which are evidenced to stabilize a fraction of DFe in hydrothermal vents (Toner et al., 2009; Hawkes et al., 2013; Kleint et al., 2016), potentially producing an enrichment in heavy Fe isotopes in DFe (Dideriksen et al., 2008; Fitzsimmons et al., 2015a). Higher $\delta^{56} \mathrm{Fe}$ values may also reflect mixing with open deep seawater around Loihi considering that deep Pacific seawater $\delta^{56} \mathrm{Fe}$ values are enriched in heavy isotopes, as shown by previous studies in the subtropical deep Pacific Ocean where $\delta^{56} \mathrm{Fe}$ values ranged from $-0.4 \%$ to $+0.6 \%$ (Radic et al., 2011; Fitzsimmons et al., 2016). However, we do not favor this hypothesis considering that open seawater Fe concentrations in this region of the Pacific Ocean (e.g. station ALOHA, 463 km, northwest of Loihi) is expected to be between 0.6 to $1.2 \mathrm{nM}$ (Boyle et al., 2005; Fitzsimmons et al., 2015b), which is much lower than the DFe concentrations of 13 to $70 \mathrm{nM}$ measured in bottom seawater at Pele's Pit. Surprisingly, the far-field hydrothermal $\delta^{56} \mathrm{Fe}$ signature of Loihi Seamount measured at Station ALOHA, determined at $+0.02 \pm 0.03 \%$ o (Fitzsimmons et al., 2016) is significantly heavier than bottom seawater $\delta^{56} \mathrm{Fe}$ values at Loihi. Reconciling both observations would require a more comprehensive study of Fe isotope fractionation in the nearfield plume environment, which is beyond the scope of this study.

Although it has been commonly considered that dissolved Fe was largely removed from hydrothermal plumes through the precipitation of a range of iron-bearing minerals, recent studies have shown that the contribution of hydrothermal fluxes to the oceanic Fe budget is not as negligible as originally thought. Research in near-vent settings have identified several mechanisms enhancing 
the input of hydrothermally sourced metals to the open ocean, including: (i) formation of stable metal-complexes with dissolved and particulate organic carbon (DOC and POC) (Bennett et al., 2008; Toner et al., 2009; Sander and Koschinsky, 2011); (ii) nanoparticulate minerals, in particular pyrite (Yucel et al., 2011; Gartman et al., 2014); and (iii) metal uptake by water-column microorganisms (Li et al., 2014). Long-range transports of hydrothermal Fe have been also revealed by mid-water column Fe "anomalies" in the central and south Pacific ocean (Wu et al., 2011a; Fitzsimmons et al., 2014; Resing et al., 2015), the Southern and Artic oceans (Klunder et al., 2012), the equatorial and North Atlantic ocean (Saito et al., 2013; Conway and John, 2014), and the Indian ocean (Nishioka et al., 2013). As a consequence, the global contribution of hydrothermal Fe to the open ocean should be considered in order to balance oceanic Fe budgets (Tagliabue et al., 2010).

Previous studies at EPR $9^{\circ} 50^{\prime} \mathrm{N}$ (Rouxel et al., 2016) and at MAR $5^{\circ} \mathrm{S}$ (Bennett et al., 2009) have shown that Fe-sulfide precipitation in hydrothermal plume environment should lead to $\delta^{56} \mathrm{Fe}$ signatures of the hydrothermal input in seawater which are heavier than end-member vent fluid values. By non-buoyant plume height, a large amount of Fe-sulfide precipitates will have been lost from the plume with a concomitant removal of isotopically light $\mathrm{Fe}$. A similar model has been also proposed to explain the relatively heavy Fe isotope signatures of the water column Fe enrichment attributed to the EPR at $25^{\circ} \mathrm{S} ; 105-90^{\circ} \mathrm{W}$ (Fitzsimmons et al., 2016; Fitzsimmons et al., 2017) and Scotia Sea (Klar et al., 2017; Lough et al., 2017).

Here, we show in contrast that Fe-oxyhydroxide precipitation at Loihi Seamount should result in $\delta^{56} \mathrm{Fe}$ for dissolved $\mathrm{Fe}$, which is lighter than the end-member fluid value. More generally, hydrothermal plumes exhibiting unusually high $\mathrm{Fe} / \mathrm{H}_{2} \mathrm{~S}$ ratios should be characterized by isotopically lighter values for dissolved Fe in distal plumes due to the precipitation of isotopically heavy Fe-oxyhydroxide particles before non-buoyant plume height is reached. This feature, which may be common in slow spreading ridges and ultramafic-influenced settings has previously been proposed for the Rainbow hydrothermal field (Severmann et al., 2004) and observed in dissolved $\delta^{56} \mathrm{Fe}$ data from a plume at the TAG site in the North Atlantic (Conway and John, 2014). We further expect that this feature should be common for low-temperature hydrothermal vent systems from volcanic seamounts, which may represent a significant source of Fe in oceanic basin interior. Hence, depending the geological setting, the Fe isotope composition of the far-field hydrothermal source to the deep ocean is expected to have $\delta^{56} \mathrm{Fe}$ 
values either heavier or lighted than the high-temperature hydrothermal vent fluids. In accord with this hypothesis, Lough et al. (2017) and Rouxel et al. (2016) recently showed that the proportion of authigenic Fe-sulfide and Fe-oxyhydroxide minerals precipitating in the buoyant plume exert opposing controls on the resultant isotope composition of dissolved Fe passed into the neutrally buoyant plume.

\subsection{Geochemical evolution of seafloor FeOx deposits at Loihi}

In our study, $\delta^{56} \mathrm{Fe}$ values of $\mathrm{FeOx}$ deposits ranged from $-1.77 \%$ to $+1.57 \%$ and are therefore both heavier and lighter than typical hydrothermal fluid and basaltic values clustered at ca. $0 \%$. By comparison, FeOx particles within near-vent (buoyant) hydrothermal plumes at the Rainbow hydrothermal field (Mid Atlantic Ridge) had variable $\delta^{56} \mathrm{Fe}$ values $(+0.25$ to $+1.3 \%$ ) relative to the original vent fluid, consistent with fractionation during partial oxidation of $\mathrm{Fe}(\mathrm{II})_{\mathrm{aq}}$ to $\mathrm{Fe}(\mathrm{III})_{\mathrm{aq}}$ in seawater (Severmann et al., 2004). In contrast, FeOx-rich sediments precipitated from non-buoyant hydrothermal plumes had $\delta^{56} \mathrm{Fe}$ values that were indistinguishable from that of high-temperature hydrothermal fluids reflecting quantitative Fe(II) oxidation. In another study, Fe oxyhydroxide deposits from the Jan Mayen hydrothermal vent fields yielded $\delta^{56} \mathrm{Fe}$ values either indistinguishable from low-temperature hydrothermal fluids from which they precipitated $(-1.84 \%$ to $-1.53 \%$ ) or enriched in the heavy Fe isotopes due to partial oxidation of hydrothermally derived Fe(II)aq (Moeller et al., 2014).

At Loihi Seamount, perhaps the most striking feature is that FeOx deposits recovered from active vents yielded systematically positive $\delta^{56} \mathrm{Fe}$ values up to $+1.57 \%$, while $\mathrm{FeOx}$ deposits recovered from extinct or vanishing vents have distinctly negative Fe-isotope values down to $-1.5 \%$ (Fig. 2). As explained in previous sections, these negative values are best explained by near-complete oxidation of an isotopically light Fe(II) source formed by subsurface cooling and mixing with seawater. This hypothesis indicates that Fe isotope compositions of hydrothermal $\mathrm{FeOx}$ precipitates are not well preserved after cessation of hydrothermal activity, as they tend to be overprinted by more negative values, reflecting the latest stage of Fe precipitation. It also implies that $\mathrm{Fe}$ isotopes are particularly sensitive to oxygen levels of the local environment where they form (e.g. seawater, diffuse hydrothermal fluids). 
As already noted by Moeller et al. (2014), dissimilatory iron reduction (DIR), which is known to produce isotopically light Fe in diagenetic environments (Crosby et al., 2007; Tangalos et al., 2010; Percak-Dennett et al., 2011) may potentially contribute to the generation of Fe(II) pool with negative $\delta^{56} \mathrm{Fe}$. Considering that significant amounts of $\mathrm{FeOx}$ deposits may have accumulated in the subsurface environment, it is possible that a fraction of Fe-oxyhydroxide was recycled through DIR, thereby generating a source of isotopically light $\mathrm{Fe}(\mathrm{II})$ for FeOx formation at the seafloor (Emerson, 2009; Langley et al., 2009; Gault et al., 2011). The potential for DIR in FeOx-rich Microbial Mats at Loihi Seamount was previously investigated by Emerson (2009) by incubating freshly recovered mats under anaerobic conditions with $5 \mathrm{mM}$ acetate. Although active DIR was observed within a couple of days, DIR bacteria represented less than $1 \%$ of the total bacterial population when measured by the most probable number approach. In addition, mat samples not amended with acetate showed significantly less Fe-reduction, suggesting that the FeOx deposits at Loihi Seamount are limited for carbon sources. Hence, it seems that although DIR bacteria are present, they contribute only in a minor way to the Fe budget at Loihi. More generally, it is unlikely that deep-sea FeOx deposits are capable of sustaining an anaerobic ecosystem that can feed itself via the breakdown and fermentation of organic carbon due to limited biomass availability.

Interestingly, Cr was found particularly enriched in the Lohiau Area (M5) where significant subsurface mixing occurs between hydrothermal fluid and seawater while $U$ was more enriched in $\mathrm{FeOx}$ deposits formed from higher temperature fluids (e.g. M36-M39 areas). Hence, in addition to $\mathrm{Fe}$ isotope systematics, $\mathrm{Cr} / \mathrm{Fe}$ and $\mathrm{U} / \mathrm{Fe}$ in $\mathrm{FeOx}$ deposits are also sensitive to local redox conditions and mechanisms of $\mathrm{FeOx}$ formation. Significant enrichment in $\mathrm{Cr}$ and depletion in $\mathrm{U}$ is also observed in extinct deposits from M17 and M17A areas, suggesting that aging of the deposits at the seafloor significantly modifies their geochemical signatures. Presumably, $\mathrm{U}$ is expected to undergo late-stage oxidation and released as soluble $\mathrm{U}(\mathrm{VI})$ species as observed in oxidizing diagenetic settings (Cochran et al., 1986; Zheng et al., 2002). In contrast, it appears that Cr was not significantly remobilized in inactive deposits (Fig. 4), except in the most Mn-rich samples from M17A probably due to oxidation of insoluble $\mathrm{Cr}$ (III) to $\mathrm{Cr}(\mathrm{VI})$ by reaction with manganese dioxide (Eary and Rai, 1987). 
Elements such as $\mathrm{Cu}, \mathrm{Mo}, \mathrm{Ni}$, and $\mathrm{Co}$ that typically show strong affinity for $\mathrm{Mn}$ oxyhydroxide phases in hydrogenetic crusts (Koschinsky and Hein, 2003) are enriched in Mnrich samples from M17 and M17A area. This observation, together with the negative Ce anomaly in the deposit (Fig. 5) suggests protracted scavenging of seawater-derived elements onto Mnoxyhydroxide phases. This late-stage hydrogenetic Mn mineralization has been previously reported in inactive Fe-rich deposits from other volcanic seamount in the Pacific Ocean (Puteanus et al., 1991; Hein et al., 1994) and probably a common feature of the evolution of lowtemperature hydrothermal deposits.

Finally, the preservation of microbial textures, and probably geochemical signatures of $\mathrm{FeOx}$ deposits remain difficult in most cases but appears favored when significant amounts of $\mathrm{Si}$ is coprecipitated with Fe (Juniper and Fouquet, 1988; Little et al., 2004; Glasauer et al., 2013). Both modern and fossil iron-silica deposits (the later being often referred as jasper deposits) containing microbial textures have total silica $\left(\mathrm{SiO}_{2}\right)$ concentrations within a range of $50-90 \mathrm{wt}$. $\%$ (Alt and Teagle, 2003; Grenne and Slack, 2003; Slack et al., 2007). In comparison, Fe-rich deposits at Loihi are characterized by total $\mathrm{SiO}_{2}$ concentrations generally below $25 \%$ (Table 4). Hence, although inactive FeOx deposits at Loihi Seamount do not record their initial stage of formation in terms of Fe isotope signatures and geochemistry, it can be hypothesized that higher Si content may help preserving both mineralogy and Fe isotope signature in the geological record (Toner et al., 2012). Addressing such a hypothesis would bear important implications for the study of more ancient hydrothermal Fe-Si deposits as discussed below.

\subsection{Implication for the geological record}

The Fe isotope compositions of $\mathrm{FeOx}$ deposits at Loihi Seamount display a remarkable range between $-1.5 \%$ and $+1.6 \%$, which is similar to the range reported in a 76 Ma-old central Pacific Fe-Mn crust (Horner et al., 2015). Although the exact controls on the Fe isotope variability of Fe-Mn crusts remain debated (Dauphas et al., 2017), such large and systematic changes in the deep seawater Fe isotopic composition over the Cenozoic should reflect the influence of several, distinct Fe sources to the central Pacific Ocean (Horner et al., 2015). Considering the importance of $\mathrm{Fe}$-sulfide and Fe-oxyhydroxide minerals precipitation on the $\mathrm{Fe}$ isotope composition of hydrothermally-sourced Fe in the deep ocean (Rouxel et al., 2016; Lough 
et al., 2017), it is possible that Fe-Mn crusts record several hydrothermal sources with distinct $\delta^{56} \mathrm{Fe}$ signature. However, a better understanding of biogeochemical processes that fractionate $\mathrm{Fe}$ isotopes between hydrothermal vents and the open ocean is required to better constrain isotope mass-balance quantifications of Fe sources to the ocean (Conway and John, 2014).

With respect to longer geological time scales, the range of Fe isotope compositions of $\mathrm{FeOx}$ deposits at Loihi Seamount encompasses the range of Precambrian Banded Iron Formations (Bekker et al., 2010; Planavsky et al., 2012; Li et al., 2015) (Fig. 10). The ubiquitous positive $\delta^{56} \mathrm{Fe}$ values of Archean IF indicate that $\mathrm{Fe}(\mathrm{III})$ delivery was the main process driving the deposition of IF. In addition, the expression of the Fe isotope fractionation implies partial Fe(II) oxidation, pointing towards oxidation at low Eh conditions (Dauphas et al., 2004; Planavsky et al., 2009; Planavsky et al., 2012). If oxidation took place during mixing of anoxic Fe-rich and fully oxic marine waters, oxidation would have been essentially quantitative given the rapid oxidation kinetics of $\mathrm{Fe}$ at neutral to alkaline $\mathrm{pH}$. This rapid and quantitative oxidation would have prevented any significant expression of Fe isotope fractionation as is the case with modern hydrothermal plume fall-outs (Severmann et al., 2004).

An important implication of our study is that higher oxygenation and/or microbial activity leading to Mn-oxidation (e.g. precipitation of Mn-oxide crusts on surfaces of FeOx mats) should result in a near quantitative oxidation of hydrothermal Fe(II), translating into isotopically lighter $\delta^{56} \mathrm{Fe}$ values of the FeOx deposit. As shown in Fig. 10, lowest $\delta^{56} \mathrm{Fe}$ values down to -2.35 \%o and -1.82 \%o are found in ca. 2.22 Ga Hotazel Formation and ca. 2.4 Koegas Subgroup Mnrich Iron Formations, respectively (Tsikos et al., 2010; Kurzweil et al., 2016). This feature may reflect deposition of $\mathrm{Fe}$ and $\mathrm{Mn}$ from water masses depleted in heavy Fe isotopes by progressive Fe oxidation and precipitation in the deeper part of the basin (Tsikos et al., 2010). In particular, the negative correlation between $\delta^{56} \mathrm{Fe}$ values and $\mathrm{Mn}$ concentrations were related to Fe isotope fractionation during $\mathrm{Fe}(\mathrm{II})$ oxidation by Mn oxides, resulting in lower $\delta^{56} \mathrm{Fe}$ values of dissolved Fe in the uppermost water column close to a Mn chemocline (Kurzweil et al., 2016). Similar redox-driven Fe isotope fractionation throughout the water column has also been reported in modern anoxic lakes. A depth-profile in the water column of Lac Pavin showed a remarkable increase in dissolved Fe concentration and $\delta^{56} \mathrm{Fe}$ values $(-2.14 \%$ to $+0.31 \%$ ) across the oxic- 
anoxic boundary to the lake bottom (Busigny et al., 2014). The largest Fe isotope variability was found at the redox boundary and was related to partial $\mathrm{Fe}(\mathrm{II})$ oxidation (from $\approx 70$ to $>90 \%$ ), leaving the residual $\mathrm{Fe}$ enriched in light isotopes.

For modern $\mathrm{FeOx}$ deposits, $\delta^{56} \mathrm{Fe}$ variability over short distance reflects evolving local redox conditions. Based on mass-balance considerations, we proposed that a reservoir effect is created during partial $\mathrm{Fe}(\mathrm{II})$ oxidation and can explain the entire range of $\delta^{56} \mathrm{Fe}$ values (Fig. 8): (1) heavier $\delta^{56} \mathrm{Fe}$ values, up to $+1.5 \pm 0.3 \%$ are consistent with small extent of Fe(II) oxidation; (2) near-zero $\delta^{56} \mathrm{Fe}$ values are consistent with a greater extent of $\mathrm{Fe}(\mathrm{II})$ oxidation; and (3) lightest $\delta^{56} \mathrm{Fe}$ values $<0 \%$ are consistent with loss of $\mathrm{Fe}$ oxyhydroxides along a flow path (i.e. open system Fe oxidation). These results indicate that $\mathrm{Fe}$ isotope compositions of hydrothermal Fe oxyhydroxide precipitates are particularly sensitive to oxygen levels in the local environment where they form and reservoir effects, regardless of the mechanisms involved in Fe(II) oxidation. Similar mechanisms, i.e. partial Fe(II) oxidation at, or below seafloor, have already been hypothesized to explain the relatively large range of $\delta^{56} \mathrm{Fe}$ values for hydrothermal Fe-rich cherts recovered at the sediment-basement interface from the Jurassic oceanic crust in the West Pacific (Rouxel et al., 2003).

Hence, a comparative approach between modern FeOx deposits at Loihi Seamount and ancient deposits provides a mechanistic constraint on the origin of Fe isotope fractionation in IFs. We propose that negative $\delta^{56} \mathrm{Fe}$ values in oxide-facies of BIFs could be explained by similar mechanism, i.e. a progressive oxidation of Fe-rich anoxic seawater following a Rayleigh-type fractionation-type model across an Fe chemocline. As previously suggested (Rouxel et al., 2005; von Blanckenburg et al., 2008; Steinhoefel et al., 2009; Tsikos et al., 2010; Planavsky et al., 2012; Busigny et al., 2014; Kurzweil et al., 2016), anoxygenic phototrophic oxidation could have established significant water column Fe concentration gradients - and therefore Fe isotope gradients - through ferric Fe removal during upwelling. The effect of $\mathrm{O}_{2}$ on Fe isotope composition of the most shallow part of the Archean ocean has been also modelled by Czaja et al. (2012). The model predicts that $\mathrm{Fe}(\mathrm{OH})_{3}$ precipitation in the photic zone (the zone over which $\mathrm{O}_{2}$ is produced) largely controls the $\mathrm{Fe}$ isotope fractionation. The calculated $\delta^{56} \mathrm{Fe}$ values in the shallow part of the water column are extremely negative (from - $10 \%$ to $-20 \%$, Czaja et al., 2012), and because the dissolved Fe contents at shallow water depths in the reaction model are 
vanishingly small because oxidation is nearly complete, such values are unlikely to be transferred in the sediments record. In addition, atmospheric and shelf or continental input of $\mathrm{Fe}$ in the shallow ocean would result in increasing $\delta^{56} \mathrm{Fe}$ values toward more crustal (i.e. near $0 \%$ o) values. In contrast, the precipitation of around half of an initial hydrothermal Fe pool as isotopically heavy $\mathrm{Fe}$ oxides is needed for the formation of marine deposits with $\delta^{56} \mathrm{Fe}$ values of -1.5 to $-2 \%$, which are the lowest values reported in Iron Formations (Planavsky et al., 2012; Dauphas et al., 2017). Hence, this mechanism may adequately explain large amounts of Fe-rich deposits with distinctly isotopically light values. It follows that the rise of atmospheric $\mathrm{O}_{2}$ and ultimately the oxygenation of the deep ocean led to the contraction of marine environments where active Fe redox cycling produced isotopically fractionated seafloor FeOx-type deposits, from the scale of oceanic basins in the Archean, to the scale of microbial mats and subseafloor environments in modern hydrothermal systems.

\section{Conclusions}

In this study, we applied Fe isotope systematics together with major and trace element geochemistry to study the formation mechanisms and preservation of mineralized microbial mat at Loihi Seamount. Overall, Fe-isotope compositions of microbial mats at Loihi Seamount display a remarkable range between -1.2 and $1.6 \%$ and we demonstrated that the Fe isotope compositions of hydrothermal Fe-oxyhydroxide precipitates are particularly sensitive to local environmental conditions where they form, and are less sensitive to abiotic versus biotic origins. Although isotopically heavy $\delta^{56} \mathrm{Fe}$ values resulting from partial $\mathrm{Fe}(\mathrm{II})$-oxidation may be consistent with bacterial processes considering the slow rate of inorganic Fe(II) oxidation in redox-stratified microbial mats, it is difficult to attribute specific biotic/abiotic processes based solely on Fe isotopes.

FeOx deposits recovered at extinct sites have distinctly negative Fe-isotope values down to $-1.77 \%$. These results, supported by the enrichment in $\mathrm{Mn}$ and depletion in U, are best explained by the near-complete oxidation of an isotopically light Fe(II) source produced during the waning stage of hydrothermal activity. Hence, upon cessation of hydrothermal venting, these FeOx deposits are preserved but undergo significant alteration of their geochemical composition, with significant enrichment in Mn-oxyhydroxides and $\delta^{56} \mathrm{Fe}$ shifted toward lighter values. We 
demonstrated that such isotopically light $\mathrm{Fe}$ isotope values are likely generated by subsurface precipitation of isotopically heavy Fe-oxides rather than by the activity of dissimilatory Fe reduction in the subsurface.

Iron isotope composition in warm $\left(<60^{\circ} \mathrm{C}\right)$, Fe-rich and $\mathrm{H}_{2} \mathrm{~S}$-depleted hydrothermal fluids near $+0.1 \%$ contrasts with Fe-isotope composition in high-temperature fluids from mid-oceanic ridge systems. Suspended particles in the vent fluids and hydrous ferric oxide ( $\mathrm{FeOx}$ ) deposits recovered in the vicinity of active vents yielded systematically positive $\delta^{56} \mathrm{Fe}$ values consistent with partial oxidation of $\mathrm{Fe}(\mathrm{II})$ during mixing of the hydrothermal fluids with seawater. Hence, it can be hypothesized that the stabilized dissolved Fe fraction that is exported to the deep ocean via non-buoyant hydrothermal plumes should have an Fe isotope signature that is lighter than its original vent fluid. Together with recent studies at EPR 950'N (Rouxel et al., 2016) and Scotia Sea (Lough et al., 2017), this suggests that both the initial Fe isotope composition of hydrothermal vent fluids and the $\mathrm{Fe} / \mathrm{H}_{2} \mathrm{~S}$ ratio of that source should combine to impose characteristic Fe isotope "fingerprints" for hydrothermally sourced Fe exported to the deep ocean.

Low-temperature hydrothermal vents, such as those encountered at Loihi Seamount, harbor abundant microbial communities and provided ideal systems to test hypotheses on biotic versus abiotic formation of $\mathrm{FeOx}$ deposits at the seafloor and their preservation in the geological record. Considering that the range of $\delta^{56} \mathrm{Fe}$ values of Fe-rich deposits at Loihi encompass the entire range of $\delta^{56} \mathrm{Fe}$ values measured in precambrian Iron Formations (IF), we evaluated different hypotheses about the biogeochemical cycling of Fe-isotopes on early Earth. We proposed that both positive and negative $\delta^{56} \mathrm{Fe}$ values of IFs record redox-driven, water-column processing of hydrothermally-delivered Fe across a chemocline. 


\section{Acknowledgments}

This work is dedicated to the memory of Katrina Edwards. None of this work would have been possible without her support and intellectual contribution. We also thank the Microbial Observatory Project (FeMO) Principle Investigators: Katrina Edwards (University of Southern California), Dave Emerson (Bigelow Laboratory), Craig Moyer (Western Washington University), Hubert Staudigel (Scripps Institution of Oceanography), and Brad Tebo (Oregon Health \& Science University) for their support and input during cruise operations. We thank the ROV Jason-II pilots and the crews of the RV Melville, RV Kilo Moana, and RV T. Thompson for assistance with deployments and sample collection during the cruises. We thank Maureen Auro for laboratory assistance at the Woods Hole Oceanographic Institution (WHOI), Lary Ball and Emmanuel Ponzevera for daily maintenance of the MC-ICPMS at WHOI and Ifremer. We thank Maxence Guillermic for help with leaching experiments, Sandrine Cheron for XRD analysis and Celine Liorzou for ICP-AES analysis. The Woods Hole Oceanographic Institution (WHOI), the European Institute for Marine Studies (IUEM), the French Research Institute for Exploitation of the Sea (IFREMER), and the School of Ocean and Earth Science and Technology (SOEST) all provided support and research facilities for this study. Support for Rouxel was provided by the Institut Carnot Ifremer EDROME, the LabexMer ANR-10-LABX-19-01, Europole Mer and FP7 (\#247837) grant. Support for Toner was provided by the National Academies of Science and NASA post-doctoral fellowship programs. A portion of this work was conducted at beamlines 5.3.2.2 and 11.0.2 of the Advanced Light Source (ALS). We thank ALS beamline scientists David Kilcoyne and Tolek Tyliszczak for training, and Sirine Fakra (ALS), Beth Orcutt (Bigelow Laboratory for Ocean Sciences), and Katrina Edwards for collaborative interactions and staffing of beamtime. The Advanced Light Source is supported by the Director, Office of Science, Office of Basic Energy Sciences, of the U.S. Department of Energy under Contract No. DE-AC02-05CH11231. We thank the AE Silke Severmann, Tim Conway and two anonymous reviewers for their constructive and helpful comments, which improved the quality of this paper. 


\section{REFERENCES}

Alt, J.C. (1988) Hydrothermal oxide and Nontronite deposits on seamounts in the Eastern Pacific. Mar. Geol. 81, 227-239.

Alt, J.C. and Teagle, D.A.H. (2003) Hydrothermal alteration of upper oceanic crust formed at a fast-spreading ridge: mineral, chemical, and isotopic evidence from ODP Site 801. Chem. Geol. 201, 191-211.

Anbar, A.D., Jarzecki, A.A. and Spiro, T.G. (2005) Theoretical investigation of iron isotope fractionation between $\mathrm{Fe}(\mathrm{H} 2 \mathrm{O})(3+)(6)$ and $\mathrm{Fe}(\mathrm{H} 2 \mathrm{O})(2+)(6)$ : Implications for iron stable isotope geochemistry. Geochim. Cosmochim. Acta 69, 825-837.

Anders, E. and Grevesse, N. (1989) Abundances of the elements: Meteoritic and solar. Geochim. Cosmochim. Acta 53, 197-214.

Arnold, G.L., Weyer, S. and Anbar, A.D. (2003) Fe Isotope Variations in Natural Materials Measured Using High Mass Resolution Multiple Collector ICPMS. Anal Chem 76, 322327.

Balci, N., Bullen, T.D., Witte-Lien, K., Shanks, W.C., Motelica, M. and Mandernack, K.W. (2006) Iron isotope fractionation during microbially stimulated $\mathrm{Fe}(\mathrm{II})$ oxidation and $\mathrm{Fe}$ (III) precipitation. Geochim. Cosmochim. Acta 70, 622-639.

Beard, B.L., Johnson, C.M., Von Damm, K.L. and Poulson, R.L. (2003) Iron isotope constraints on Fe cycling and mass balance in oxygenated Earth oceans. Geology 31, 629-632.

Beard, B.L., Handler, R.M., Scherer, M.M., Wu, L., Czaja, A.D., Heimann, A. and Johnson, C.M. (2010) Iron isotope fractionation between aqueous ferrous iron and goethite. Earth. Planet. Sci. Lett. 295, 241-250.

Bekker, A., Slack, J.F., Planavsky, N., Krapez, B., Hofmann, A., Konhauser, K.O. and Rouxel, O.J. (2010) Iron Formation: The Sedimentary Product of a Complex Interplay among Mantle, Tectonic, Oceanic, and Biospheric Processes. Economic Geology 105, 467-508.

Bennett, S.A., Achterberg, E.P., Connelly, D.P., Statham, P.J., Fones, G.R. and German, C.R. (2008) The distribution and stabilisation of dissolved Fe in deep-sea hydrothermal plumes. Earth. Planet. Sci. Lett. 270, 157-167.

Bennett, S.A., Rouxel, O., Schmidt, K., Garbe-Schonberg, D., Statham, P.J. and German, C.R. (2009) Iron isotope fractionation in a buoyant hydrothermal plume, 5 degrees S MidAtlantic Ridge. Geochim. Cosmochim. Acta 73, 5619-5634.

Bennett, S.A., Hansman, R.L., Sessions, A.L., Nakamura, K. and Edwards, K.J. (2011) Tracing iron-fueled microbial carbon production within the hydrothermal plume at the Loihi seamount. Geochim. Cosmochim. Acta 75, 5526-5539.

Binns, R.A., Scott, S.D., Bogdanov, Y.A., Lisitzin, A.P., Gordeev, V.V., Gurvich, E.G., Finlayson, E.J., Boyd, T., Dotter, L.E., Wheller, G.E. and Muravyev, K.G. (1993) Hydrothermal Oxide and Gold-Rich Sulfate Deposits of Franklin Seamount, Western Woodlark Basin, Papua New Guinea. Econ Geol Bull Soc 88, 2122-2153.

Bolton, B.R., Both, R., Exon, N.F., Hamilton, T.F., Ostwald, J. and Smith, J.D. (1988) Geochemistry and mineralogy of seafloor hydrothermal and hydrogenetic Mn oxide deposits from the Manus Basin and Bismarck Archipelago region of the southwest Pacific Ocean. Mar. Geol. 85, 65-87. 
Boyd, T.D. and Scott, S.D. (2001) Microbial and hydrothermal aspects of ferric oxyhydroxides and ferrosic hydroxides: the example of Franklin Seamount, Western Woodlark Basin, Papua New Guinea. Geochem. Trans. 7, DOI: 10.1039/b105277m.

Boyle, E.A., Bergquist, B.A., Kayser, R.A. and Mahowald, N. (2005) Iron, manganese, and lead at Hawaii Ocean Time-series station ALOHA: Temporal variability and an intermediate water hydrothermal plume. Geochim. Cosmochim. Acta 69, 933-952.

Bullen, T.D., White, A.F., Childs, C.W., Vivit, D.V. and Schulz, M.S. (2001) Demonstration of significant abiotic iron isotope fractionation in nature. Geology 29, 699-702.

Busigny, V., Planavsky, N.J., Jezequel, D., Crowe, S., Louvat, P., Moureau, J., Viollier, E. and Lyons, T.W. (2014) Iron isotopes in an Archean ocean analogue. Geochim. Cosmochim. Acta 133, 443-462.

Campbell, A.C., Palmer, M.R., P., K.G., Bowers, T.S., Edmond, J.M., Lawrence, J.R., Casey, J.F., Thompson, G., Humphris, S.E. and Rona, P. (1988) Chemistry of hot springs on the Mid-Atlantic Ridge. Nature 335, 514-519.

Caplan-Auerbach, J. and Duennebier, F.K. (2001) Seismicity and velocity structure of Loihi seamount from the 1996 earthquake swarm. Bulletin of the Seismological Society of America 91, 178-190.

Chan, C.S., Fakra, S.C., Emerson, D., Fleming, E.J. and Edwards, K.J. (2011) Lithotrophic ironoxidizing bacteria produce organic stalks to control mineral growth: implications for biosignature formation. ISME Journal 5, 717-727.

Cochran, J.K., Carey, A.E., Sholkovitz, E.R. and Surprenant, L.D. (1986) The geochemistry of uranium and thorium in coastal marine sediments and sediment pore waters. Geochim. Cosmochim. Acta 50, 663-680.

Conway, T.M. and John, S.G. (2014) Quantification of dissolved iron sources to the North Atlantic Ocean. Nature 511, 212-216.

Corliss, J.B., Lyle, M., Dymond, J. and Crane, K. (1978) The chemistry of hydrothermal mounds near the Galapagos Rift. Earth. Planet. Sci. Lett. 40, 12-24.

Croal, L.R., Johnson, C.M., Beard, B.L. and Newman, D.K. (2004) Iron isotope fractionation by $\mathrm{Fe}(\mathrm{II})$-oxidizing photoautotrophic bacteria. Geochim. Cosmochim. Acta 68, 1227-1242.

Crosby, H.A., Roden, E.E., Johnson, C.M. and Beard, B.L. (2007) The mechanisms of iron isotope fractionation produced during dissimilatory Fe(III) reduction by Shewanella putrefaciens and Geobacter sulfurreducens. Geobiology 5, 169-189.

Czaja, A.D., Johnson, C.M., Roden, E.E., Beard, B.L., Voegelin, A.R., Nagler, T.F., Beukes, N.J. and Wille, M. (2012) Evidence for free oxygen in the Neoarchean ocean based on coupled iron-molybdenum isotope fractionation. Geochim. Cosmochim. Acta 86, 118-137.

Dauphas, N., vanZuilen, M., Wadhwa, M., Davis, A.M., Marty, B. and Janney, P.E. (2004) Clues from $\mathrm{Fe}$ isotope variations on the origin of early archean BIFs from Greenland. Science 306, 2077-2080.

Dauphas, N. and Rouxel, O. (2006) Mass spectrometry and natural variations of iron isotopes. Mass Spectrom. Rev. 25, 515-550.

Dauphas, N., John, S. and Rouxel, O. (2017) Iron Isotope Systematics. Reviews in Mineralogy \& Geochemistry 82, 415 - 510.

De Carlo, E.H., McMurtry, G.M. and Yeh, H.-W. (1983) Geochemistry of hydrothermal deposits from the Loihi submarine volcano, Hawaii. Earth. Planet. Sci. Lett. 66, 438-449. 
Dekov, V.M., Kamenov, G.D., Stummeyer, J., Thiry, M., Savelli, C., Shanks, W.C., Fortin, D., Kuzmann, E. and Vértes, A. (2007) Hydrothermal nontronite formation at Eolo Seamount (Aeolian volcanic arc, Tyrrhenian Sea). Chem. Geol. 245, 103-119.

Dideriksen, K., Baker, J.A. and Stipp, S.L.S. (2008) Equilibrium Fe isotope fractionation between inorganic aqueous $\mathrm{Fe}(\mathrm{III})$ and the siderophore complex, $\mathrm{Fe}(\mathrm{III})$-desferrioxamine B. Earth. Planet. Sci. Lett. 269, 280-290.

Dixon, J.E. and Clague, D.A. (2001) Volatiles in basaltic glasses from Loihi seamount, Hawaii: Evidence for a relatively dry plume component. Journal of Petrology 42, 627-654.

Douville, E., Bienvenu, P., Charlou, J.-L., Donval, J.-P., Fouquet, Y., Appriou, P. and Gamo, T. (1999) Yttrium and rare earth elements in fluids from various deep-sea hydrothermal systems. Geochim. Cosmochim. Acta 63, 627-643.

Douville, E., Charlou, J.L., Oelkers, E.H., Bienvenu, P., Colon, C.F.J., Donval, J.P., Fouquet, Y., Prieur, D. and Appriou, P. (2002) The rainbow vent fluids (36 degrees 14 'N, MAR): the influence of ultramafic rocks and phase separation on trace metal content in Mid-Atlantic Ridge hydrothermal fluids. Chem. Geol. 184, 37-48.

Eary, L.E. and Rai, D. (1987) Kinetics of chromium(III) oxidation to chromium(VI) by reaction with manganese dioxide. Environ. Sci. Technol. 21, 1187-1193.

Edmond, J.M., Measures, C.I., McDuff, R.E., Chan, L.H., Collier, R., Grant, B., Gordon, L.I. and Corliss, J.B. (1979) Ridge crest hydrothermal activity and the balances of the major and minor elements in the ocean: the Galapagos data. Earth. Planet. Sci. Lett. 46, 1-18.

Edwards, K.J., Glazer, B.T., Rouxel, O.J., Bach, W., Emerson, D., Davis, R.E., Toner, B.M., Chan, C.S., Tebo, B.M., Staudigel, H. and Moyer, C.L. (2011) Ultra-diffuse hydrothermal venting supports Fe-oxidizing bacteria and massive umber deposition at $5000 \mathrm{~m}$ off Hawaii. Isme Journal 5, 1748-1758.

Emerson, D. and Moyer, C. (1997) Isolation and characterization of novel iron-oxidizing bacteria that grow at circumneutral pH. Appl. Environ. Microbiol. 61, 2681-2687.

Emerson, D. and Moyer, C.L. (2002) Neutrophilic Fe-oxidizing bacteria are abundant at the Loihi seamount hydrothermal vents and play a major role in Fe oxide deposition. Appl. Environ. Microbiol. 68, 3085-3093.

Emerson, D., Rentz, J.A., Lilburn, T.G., Davis, R.E., Aldrich, H., Chan, C. and Moyer, C.L. (2007) A Novel Lineage of Proteobacteria Involved in Formation of Marine Fe-Oxidizing Microbial Mat Communities. PLoS ONE 2, e667.

Emerson, D. (2009) Potential for Iron-reduction and Iron-cycling in Iron Oxyhydroxide-rich Microbial Mats at Loihi Seamount. Geomicrobiol. J. 26, 639-647.

Escoube, R., Rouxel, O., Edwards, K., Glazer, B. and Donard, O. (2015) Coupled Ge/Si and Ge isotope ratios as geochemical tracers of seafloor hydrothermal systems: case studies at Loihi Seamount and East Pacific Rise 950'N. Geochim. Cosmochim. Acta 167, 93-112.

Exon, N.F. and Cronan, D.S. (1983) Hydrothermal iron deposits and associated sediments from submarine volcanoes off Vanuatu, southwest Pacific. Mar. Geol. 52, M43-M52.

Field, M.P. and Sherrell, R.M. (2000) Dissolved and particulate Fe in a hydrothermal plume at 9 degrees 45' N, East Pacific Rise: slow Fe(II) oxidation kinetics in Pacific plumes. Geochim. Cosmochim. Acta 64, 619-628.

Fitzsimmons, J.N., Boyle, E.A. and Jenkins, W.J. (2014) Distal transport of dissolved hydrothermal iron in the deep South Pacific Ocean. Proc. Natl. Acad. Sci. USA 111.

Fitzsimmons, J.N., Carrasco, G.G., Wu, J.F., Roshan, S., Hatta, M., Measures, C.I., Conway, T.M., John, S.G. and Boyle, E.A. (2015a) Partitioning of dissolved iron and iron isotopes 
into soluble and colloidal phases along the GA03 GEOTRACES North Atlantic Transect. Deep-Sea Research Part Ii-Topical Studies in Oceanography 116, 130-151.

Fitzsimmons, J.N., Hayes, C.T., Al-Subiai, S.N., Zhang, R.F., Morton, P.L., Weisend, R.E., Ascani, F. and Boyle, E.A. (2015b) Daily to decadal variability of size-fractionated iron and iron-binding ligands at the Hawaii Ocean Time-series Station ALOHA. Geochim. Cosmochim. Acta 171, 303-324.

Fitzsimmons, J.N., Conway, T.M., Lee, J.M., Kayser, R., Thyng, K.M., John, S.G. and Boyle, E.A. (2016) Dissolved iron and iron isotopes in the southeastern Pacific Ocean. Global Biogeochem. Cycles 30, 1372-1395.

Fitzsimmons, J.N., John, S.G., Marsay, C.M., Hoffman, C.L., Nicholas, S.L., Toner, B.M., German, C.R. and Sherrell, R.M. (2017) Iron persistence in a distal hydrothermal plume supported by dissolved-particulate exchange. Nature Geoscience 10, 195-U150.

Fleming, E.J., Davis, R.E., McAllister, S.M., Chan, C.S., Moyer, C.L., Tebo, B.M. and Emerson, D. (2013) Hidden in plain sight: discovery of sheath-forming, iron-oxidizing Zetaproteobacteria at Loihi Seamount, Hawaii, USA. FEMS Microbiol. Ecol. 85, 116-127.

Frey, F.A. and Clague, D.A. (1983) Geochemistry of diverse basalt types from Loihi Seamount, Hawaii: Petrogenetic implications. Earth Planet. Sci. Lett. 66, 337-355.

Frierdich, A.J., Beard, B.L., Reddy, T.R., Scherer, M.M. and Johnson, C.M. (2014) Iron isotope fractionation between aqueous Fe(II) and goethite revisited: New insights based on a multidirection approach to equilibrium and isotopic exchange rate modification. Geochim. Cosmochim. Acta 139, 383-398.

Gamo, T., Ishibashi, J., Sakai, H. and Tilbrook, B. (1987) Methane anomalies in seawater above the Loihi submarine summit area, Hawaii. Geochim. Cosmochim. Acta 51, 2857-2864.

Garcia, M.O., Foss, D.J.P., West, H.B. and Mahoney, J.J. (1995) Geochemical and isotopic evolution of Loihi Volcano, Hawaii. Journal of Petrology 36, 1647-1674.

Garcia, M.O., Caplan-Auerbach, J., Carlo, E.H.D., Kurz, M.D. and Beckera, N. (2006) Geology, geochemistry and earthquake history of Lo "ihi Seamount, Hawai"i's youngest volcano. Chemie der Erde 66, 81-108.

Gartman, A., Findlay, A.J. and Luther, G.W. (2014) Nanoparticulate pyrite and other nanoparticles are a widespread component of hydrothermal vent black smoker emissions. Chem. Geol. 366, 32-41.

Gault, A.G., Ibrahim, A., Langley, S., Renaud, R., Takahashi, Y., Boothman, C., Lloyd, J.R., Clark, I.D., Ferris, F.G. and Fortin, D. (2011) Microbial and geochemical features suggest iron redox cycling within bacteriogenic iron oxide-rich sediments. Chem. Geol. 281, 41-51.

German, C.R. and Von Damm, K.L. (2003) Hydrothermal Processes, in: Elderfield, H. (Ed.), Treatise on Geochemistry. Elsevier, pp. 181-222.

Glasauer, S., Mattes, A. and Gehring, A. (2013) Constraints on the Preservation of Ferriferous Microfossils. Geomicrobiol. J. 30, 479-489.

Glazer, B.T. and Rouxel, O.J. (2009) Redox Speciation and Distribution within Diverse Irondominated Microbial Habitats at Loihi Seamount. Geomicrobiol. J. 26, 606-622.

Gonzalez, A.G., Santana-Casiano, J.M., Perez, N. and Gonzalez-Davila, M. (2010) Oxidation of $\mathrm{Fe}(\mathrm{II})$ in Natural Waters at High Nutrient Concentrations. Environ. Sci. Technol. 44, 80958101.

Grenne, T. and Slack, J.F. (2003) Paleozoic and Mesozoic silica-rich seawater:Evidence from hematitic chert (jasper) deposits. Geology 31, 319-322. 
Grill, E.V., Chase, R.L., Macdonald, R.D. and Murray, J.W. (1981) A hydrothermal deposit from explorer ridge in the northeast Pacific Ocean. Earth. Planet. Sci. Lett. 52, 142-150.

Hawkes, J.A., Connelly, D.P., Gledhill, M. and Achterberg, E.P. (2013) The stabilisation and transportation of dissolved iron from high temperature hydrothermal vent systems. Earth. Planet. Sci. Lett. 375, 280-290.

Hein, J.R., Hsueh-Wen, Y., Gunn, S.H., Gibbs, A.E. and Chung-ho, W. (1994) Composition and origin of hydrothermal ironstones from central Pacific seamounts. Geochim. Cosmochim. Acta, 179-189.

Hekinian, R., Hoffert, M., Larque, P., Cheminee, J.L., Stoffers, P. and Bideau, D. (1993) Hydrothermal $\mathrm{Fe}$ and Si oxyhydroxide deposits from South Pacific intraplate volcanoes and East Pacific Rise axial and off-axial regions. Econ Geol Bull Soc 88, 2099-2121.

Hilton, D.R., McMurtry, G.M. and Goff, F. (1998) Large variations in vent fluid CO2/He-3 ratios signal rapid changes in magma chemistry at Loihi seamount, Hawaii. Nature 396, 359-362.

Horner, T.J., Williams, H.M., Hein, J.R., Saito, M.A., Burton, K.W., Halliday, A.N. and Nielsen, S.G. (2015) Persistence of deeply sourced iron in the Pacific Ocean. Proc. Natl. Acad. Sci. USA 112, 1292-1297.

Hrischeva, E. and Scott, S.D. (2007) Geochemistry and morphology of metalliferous sediments and oxyhydroxides from the Endeavour segment, Juan de Fuca Ridge. Geochim. Cosmochim. Acta 71, 3476-3497.

Johnson, C.M., Skulan, J.L., Beard, B.L., Sun, H., Nealson, K.H. and Braterman, P.S. (2002) Isotopic fractionation between $\mathrm{Fe}(\mathrm{III})$ and $\mathrm{Fe}(\mathrm{II})$ in aqueous solutions. Earth Planet. Sci. Lett. 195, 141-153.

Johnson, C.M., Beard, B.L., Beukes, N.J., Klein, C. and O'Leary, J.M. (2003) Ancient geochemical cycling in the Earth as inferred from Fe isotope studies of banded iron formations from the Transvaal Craton. Contrib. Mineral. Petrol. 144, 523-547.

Johnson, C.M., Beard, B.L., Klein, C., Beukes, N.J. and Roden, E.E. (2008) Iron isotopes constrain biologic and abiologic processes in banded iron formation genesis. Geochim. Cosmochim. Acta 72, 151-169.

Juniper, S.K. and Fouquet, Y. (1988) Filamentous iron-silica deposits from modern and ancient hydrothermal sites. Can. Mineral. 26, 859-869.

Kappler, A., Johnson, C.M., Crosby, H.A., Beard, B.L. and Newman, D.K. (2010) Evidence for equilibrium iron isotope fractionation by nitrate-reducing iron(II)-oxidizing bacteria. Geochim. Cosmochim. Acta 74, 2826-2842.

Karl, D.M., McMurtry, G.M., Malahoff, A. and Garcia, M.O. (1988) Loihi Seamount, Hawaii: a mid-plate volcano with a distinctive hydrothermal system. Nature 335, 532-535.

Karl, D.M., Brittain, A.M. and Tilbrook, B.D. (1989) Hydrothermal and microbial processes at Loihi Seamount, a mid-plate hot-spot volcano. Deep-Sea Res 36, 1655-1673.

Kennedy, C.B., Scott, S.D. and Ferris, F.G. (2003) Characterization of bacteriogenic iron oxide deposits from Axial Volcano, Juan de Fuca Ridge, northeast Pacific Ocean. Geomicrobiol. J. 20, 199-214.

Kent, A.J., Norman, M.D., Hutcheon, I.D. and Stolper, E.M. (1999) Assimilation of seawaterderived components in an oceanic volcano: Evidence from matrix glasses and glass inclusions from Loihi Seamount, Hawaii. Chem. Geol. 156, 299-319.

King, D.W., Lounsbury, H.A. and Millero, F.J. (1995) Rates and Mechanism of Fe(II) Oxidation at Nanomolar Total Iron Concentrations. Environ. Sci. Technol. 29, 818-824. 
Klar, J.K., James, R.H., Gibbs, D., Lough, A., Parkinson, I., Milton, J.A., Hawkes, J.A. and Connelly, D.P. (2017) Isotopic signature of dissolved iron delivered to the Southern Ocean from hydrothermal vents in the East Scotia Sea. Geology 45, 351-354.

Klein, F.W. (1982) Earthquakes at Loihi submarine volcano and the Hawaiian hot spot. $J$. Geophys. Res. 87, 7719-7726.

Kleint, C., Hawkes, J.A., Sander, S.G. and Koschinsky, A. (2016) Voltammetric Investigation of Hydrothermal Iron Speciation. Frontiers in Marine Science 3.

Klinkhammer, G.P., Elderfield, H., Edmond, J.M. and Mitra, A. (1994) Geochemical implications of rare earth element patterns in hydrothermal fluids from mid-ocean ridges. Geochim. Cosmochim. Acta 58, 5105-5113.

Klunder, M.B., Laan, P., Middag, R., de Baar, H.J.W. and Bakker, K. (2012) Dissolved iron in the Arctic Ocean: Important role of hydrothermal sources, shelf input and scavenging removal. J. Geophys. Res. 117.

Koschinsky, A. and Hein, J.R. (2003) Uptake of elements from seawater by ferromanganese crusts:

solid-phase associations and seawater speciation. Mar. Geol. 198, 331-351.

Kurz, M.D., Jenkins, W.J., Hart, S.R. and Clague, D. (1983) Helium isotopic variations in volcanic rocks from Loihi Seamount and the Island of Hawaii. Earth. Planet. Sci. Lett. 66, 388-406.

Kurzweil, F., Wille, M., Gantert, N., Beukes, N.J. and Schoenberg, R. (2016) Manganese oxide shuttling in pre-GOE oceans - evidence from molybdenum and iron isotopes. Earth. Planet. Sci. Lett. 452, 69-78.

Langley, S., Igric, P., Takahashi, Y., Sakai, Y., Fortin, D., Hannington, M.D. and SchwarzSchampera, U. (2009) Preliminary characterization and biological reduction of putative biogenic iron oxides (BIOS) from the Tonga-Kermadec Arc, southwest Pacific Ocean. Geobiology 7, 35-49.

Li, M., Toner, B.M., Baker, B.J., Breier, J.A., Sheik, C.S. and Dick, G.J. (2014) Microbial iron uptake as a mechanism for dispersing iron from deep-sea hydrothermal vents. Nature Communications $\mathbf{5}$.

Li, W.Q., Beard, B.L. and Johnson, C.M. (2015) Biologically recycled continental iron is a major component in banded iron formations. Proceedings of the National Academy of Sciences of the United States of America 112, 8193-8198.

Little, C.T.S., Glynn, S.E.J. and Mills, R.A. (2004) Four-hundred-and-ninety-million-year record of bacteriogenic iron oxide precipitation at sea-floor hydrothermal vents. Geomicrobiol. $J$. 21, 415-429.

Lough, A.J.M., Klar, J.K., Homoky, W.B., Comer-Warner, S.A., Milton, J.A., Connelly, D.P., James, R.H. and Mills, R.A. (2017) Opposing authigenic controls on the isotopic signature of dissolved iron in hydrothermal plumes. Geochim. Cosmochim. Acta 202, 1-20.

Malahof, A. (1987) Geology of the summit of Loihi submarine volcano, in: Decker, R.W., Wright, T.L., Stauffer, P.H. (Eds.), Volcanism in Hawaii: United States Geological Survey Professional Paper 1350, pp. 133-144.

Malahoff, A., Kolotyrkina, I.Y., Midson, B.P. and Massoth, G.J. (2006) A decade of exploring a submarine intraplate volcano: Hydrothermal manganese and iron at Lo'ihi volcano, Hawai'i. Geochem Geophy Geosy 7. 
Malinovski, D., Stenberg, A., Rodushkin, I., Andren, H., Ingri, J., Ohlander, B. and Baxter, D.C. (2003) Performance of high resolution MC-ICPMS for Fe isotope ratio measurements in sedimentary geological materials. J. Anal. At. Spectrom. 18, 687-695.

Metz, S. and Trefry, J.H. (2000) Chemical and mineralogical influences on concentrations of trace metals in hydrothermal fluids. Geochim. Cosmochim. Acta 64, 2267-2279.

Michard, A., Albarede, F., Michard, G., Minster, J.F. and Charlou, J.L. (1983) Rare-earth elements and uranium in high-temperature solutions from East Pacific Rise hydrothermal vent field $\left(13^{\circ} \mathrm{N}\right)$. Nature 303, 795-797.

Michard, A. and Albarede, F. (1985) Hydrothermal uranium uptake at ridge crests. Nature 317, 244-246.

Mills, R.A. (1995) Hydrothermal deposits and metalliferous sediments from TAG, $26^{\circ} \mathrm{N}$ MidAtlantic Ridge, in: Parson, L.M., Walker, C.L., Dixon, D.R. (Eds.), Hydrothermal Vents and Processes. Geological Society Special Publication, pp. 121-132.

Mills, R.A. and Elderfield, H. (1995) Rare earth element geochemistry of hydrothermal deposits from the active TAG mound, $26^{\circ} \mathrm{N}$ Mid-Atlantic Ridge. Geochim. Cosmochim. Acta 59, 3511-3524.

Mills, R.A., Wells, D.M. and Roberts, S. (2001) Genesis of ferromanganese crusts from the TAG hydrothermal field. Chem. Geol. 176, 283-293.

Moeller, K., Schoenberg, R., Grenne, T., Thorseth, I.H., Drost, K. and Pedersen, R.B. (2014) Comparison of iron isotope variations in modern and Ordovician siliceous Fe oxyhydroxide deposits. Geochim. Cosmochim. Acta 126, 422-440.

Moorby, S.A., Cronan, D.S. and Glasby, G.P. (1984) Geochemistry of hydrothermal Mn-oxide deposits from the S.W. Pacific island arc. Geochim. Cosmochim. Acta 48, 433-441.

Moore, J.G., Clague, D.A. and Normark, W.R. (1982) Diverse basalt types from Loihi seamount, Hawaii. Geology 10, 88-92.

Moyer, C.L., Dobbs, F.C. and Karl, D.M. (1994) Estimation of diversity and community structure through restriction fragment length polymorphism distribution analysis of bacterial 16S rRNA genes from a microbial mat at an active hydrothermal vent system, Loihi Seamount, Hawaii. Appl. Environ. Microbiol. 60, 871-879.

Murphy, E., McMurtry, G.M., Kim, K.H. and De Carlo, E.H. (1991) Geochemistry and geochronology of a hydrothermal ferromanganese deposit from the North Fiji Basin. Mar. Geol. 98, 297-312.

Nishioka, J., Obata, H. and Tsumune, D. (2013) Evidence of an extensive spread of hydrothermal dissolved iron in the Indian Ocean. Earth. Planet. Sci. Lett. 361, 26-33.

Pedersen, R.B., Thorseth, I.H., Nygard, T.E., Lilley, M.D. and Kelley, D.S. (2010) Hydrothermal Activity at the Arctic Mid-Ocean Ridges, in: Rona, P.A., Devey, C.W., Dyment, J., Murton, B.J. (Eds.), Diversity of Hydrothermal Systems on Slow Spreading Ocean Ridges, pp. 67-89.

Peng, X.T., Chen, S., Zhou, H.Y., Zhang, L.X., Wu, Z.J., Li, J.T., Li, J.W. and Xu, H.C. (2011) Diversity of biogenic minerals in low-temperature Si-rich deposits from a newly discovered hydrothermal field on the ultraslow spreading Southwest Indian Ridge. Journal of Geophysical Research-Biogeosciences 116.

Percak-Dennett, E.M., Beard, B.L., Xu, H., Konishi, H., Johnson, C.M. and Roden, E.E. (2011) Iron isotope fractionation during microbial dissimilatory iron oxide reduction in simulated Archaean seawater. Geobiology 9, 205-220. 
Pietruszka, A.J., Keyes, M.J., Duncan, J.A., Hauri, E.H., Carlson, R.W. and Garcia, M.O. (2011) Excesses of seawater-derived U-234 in volcanic glasses from Loihi Seamount due to crustal contamination. Earth. Planet. Sci. Lett. 304, 280-289.

Planavsky, N., Rouxel, O., Bekker, A., Shapiro, R., Fralick, P. and Knudsen, A. (2009) Ironoxidizing microbial ecosystems thrived in late Paleoproterozoic redox-stratified oceans. Earth. Planet. Sci. Lett. 286, 230-242.

Planavsky, N., Rouxel, O.J., Bekker, A., Hofmann, A., Little, C.T.S. and Lyons, T.W. (2012) Iron isotope composition of some Archean and Proterozoic iron formations. Geochim. Cosmochim. Acta 80, 158-169.

Poitrasson, F. and Freydier, R. (2005) Heavy iron isotope composition of granites determined by high resolution MC-ICP-MS. Chem. Geol. 222, 132-147.

Puteanus, D., Glasby, G.P., Stoffers, P. and Kunzendorf, H. (1991) Hydrothermal iron-rich deposits from the Teahitia-Mehitia and Macdonald hot spot areas, Southwest Pacific. Mar. Geol. 98, 389-409.

Radic, A., Lacan, F. and Murray, J.W. (2011) Iron isotopes in the seawater of the equatorial Pacific Ocean: New constraints for the oceanic iron cycle. Earth. Planet. Sci. Lett. 306, 110.

Rassa, A.C., McAllister, S.M., Safran, S.A. and Moyer, C.L. (2009) Zeta-Proteobacteria Dominate the Colonization and Formation of Microbial Mats in Low-Temperature Hydrothermal Vents at Loihi Seamount, Hawaii. Geomicrobiol. J. 26, 623-638.

Resing, J.A., Sedwick, P.N., German, C.R., Jenkins, W.J., Moffett, J.W., Sohst, B.M. and Tagliabue, A. (2015) Basin-scale transport of hydrothermal dissolved metals across the South Pacific Ocean. Nature 523, 200-U140.

Rose, A.L. and Waite, T.D. (2002) Kinetic model for Fe(II) oxidation in seawater in the absence and presence of natural organic matter. Environ. Sci. Technol. 36, 433-444.

Rouxel, O., Dobbek, N., Ludden, J. and Fouquet, Y. (2003) Iron isotope fractionation during oceanic crust alteration. Chem. Geol. 202, 155-182.

Rouxel, O., Shanks Iii, W.C., Bach, W. and Edwards, K.J. (2008) Integrated Fe- and S-isotope study of seafloor hydrothermal vents at East Pacific Rise $9-10^{\circ}$ N. Chem. Geol. 252, 214227.

Rouxel, O., Toner, B.M., Manganini, S.J. and German, C.R. (2016) Geochemistry and iron isotope systematics of hydrothermal plume fall-out at East Pacific Rise 9 degrees 50 ' N. Chem. Geol. 441, 212-234.

Rouxel, O.J., Bekker, A. and Edwards, K.J. (2005) Iron isotope constraints on the Archean and Paleoproterozoic ocean redox state. Science 307, 1088-1091.

Rouxel, O.J. and Auro, M. (2010) Iron Isotope Variations in Coastal Seawater Determined by Multicollector ICP-MS. Geostand. Geoanal. Res. 34, 135-144.

Rudnicki, M.D. and Elderfield, H. (1993) A chemical model of the buoyant and neutrally buoyant plume above the TAG vent field, 26 degrees N, Mid-Altantic Ridge. Geochim. Cosmochim. Acta 57, 2939-2957.

Saito, M.A., Noble, A.E., Tagliabue, A., Goepfert, T.J., Lamborg, C.H. and Jenkins, W.J. (2013) Slow-spreading submarine ridges in the South Atlantic as a significant oceanic iron source. Nature Geoscience 6, 775-779.

Sakai, H., Tsubota, H., Nakai, T., Ishibashi, J., Akagi, T., Gamo, T., Tilbrook, B., Igarashi, G., Kodera, M., Shitashima, K., Nakamura, S., Fujioka, K., Watanabe, M., McMurtry, G., 
Malahoff, A. and Ozima, M. (1987) Hydrothermal activity on the summit of Loihi Seamount, Hawaii. Geochem. J. 21, 11-21.

Sander, S.G. and Koschinsky, A. (2011) Metal flux from hydrothermal vents increased by organic complexation. Nature Geoscience 4, 145-150.

Scott, J.J., Breier, J.A., Luther, G.W. and Emerson, D. (2015) Microbial Iron Mats at the MidAtlantic Ridge and Evidence that Zetaproteobacteria May Be Restricted to Iron-Oxidizing Marine Systems. Plos One $\mathbf{1 0 .}$

Scott, M.R., Scott, R.B., Rona, P.A., Butler, L.W. and Nalwalk, A. (1974) Rapidly accumulating manganese deposit from the median valley of the mid-atlantic rdige. Geophys, Res. Lett. 1, 355-358.

Sedwick, P.N., McMurtry, G.M. and Macdougall, J.D. (1992) Chemistry of hydrothermal solutions from Pele's Vents, Loihi Seamount, Hawaï. Geochim. Cosmochim. Acta 56, 3643 3667.

Sedwick, P.N., McMurtry, G.M., Hilton, D.R. and Goff, F. (1994) Carbon-Dioxide and Helium in Hydrothermal Fluids from Loihi Seamount, Hawaii, USA - Temporal Variabiity and Implications for the Release of Mantle Volatiles. Geochim. Cosmochim. Acta 58, 12191227.

Severmann, S., Johnson, C.M., Beard, B.L., German, C.R., Edmonds, H.N., Chiba, H. and Green, D.R.H. (2004) The effect of plume processes on the Fe isotope composition of hydrothermally derived $\mathrm{Fe}$ in the deep ocean as inferred from the Rainbow vent site, MidAtlantic Ridge, 36 degrees 14' N. Earth. Planet. Sci. Lett. 225, 63-76.

Sharma, M., Polizzotto, M. and Anbar, A.D. (2001) Iron isotopes in hot springs along the Juan de Fuca Ridge. Earth. Planet. Sci. Lett. 194, 39-51.

Slack, J.F., Grenne, T., Bekker, A., Rouxel, O.J. and Lindberg, P.A. (2007) Suboxic deep seawater in the late Paleoproterozoic: Evidence from hematitic chert and iron formation related to seafloor-hydrothermal sulfide deposits, central Arizona, USA. Earth. Planet. Sci. Lett. 255, 243-256.

Statham, P.J., German, C.R. and Connelly, D.P. (2005) Iron(II) distribution and oxidation kinetics in hydrothermal plumes at the Kairei and Edmond vent sites, Indian Ocean. Earth. Planet. Sci. Lett. 236, 588-596.

Staubwasser, M., Schoenberg, R., von Blanckenburg, F., Kruger, S. and Pohl, C. (2013) Isotope fractionation between dissolved and suspended particulate Fe in the oxic and anoxic water column of the Baltic Sea. Biogeosciences 10, 233-245.

Steinhoefel, G., Horn, I. and von Blanckenburg, F. (2009) Micro-scale tracing of Fe and Si isotope signatures in banded iron formation using femtosecond laser ablation. Gechimica et Cosmochimica Acta 73, 5343-5360.

Stoffers, P., Glasby, G.P., Stuben, D., Renner, R.M., St Pierre, T.G., Webb, J. and Cardile, C.M. (1993) Comparative mineralogy and geochemistry of hydrothermal iron-rich crusts from the Pitcairn, Teahitia-mehetia, and Macdonald hot spot areas of the S. W. pacific. Marine Georesources \& Geotechnology 11, 45-86.

Stookey, L.L. (1970) Ferrozine - a new spectrophotometric reagent for iron. Anal Chem 42, 779781.

Sun, Z.L., Zhou, H.Y., Yang, Q.H., Sun, Z.X., Bao, S.X. and Yao, H.Q. (2011) Hydrothermal Fe-Si-Mn oxide deposits from the Central and South Valu Fa Ridge, Lau Basin. Appl. Geochem. 26, 1192-1204. 
Sun, Z.L., Zhou, H.Y., Glasby, G.P., Yang, Q.H., Yin, X.J., Li, J.W. and Chen, Z.Q. (2012a) Formation of Fe-Mn-Si oxide and nontronite deposits in hydrothermal fields on the Valu Fa Ridge, Lau Basin. Journal of Asian Earth Sciences 43, 64-76.

Sun, Z.L., Zhou, H.Y., Yang, Q.H., Yin, X.J., Wang, H., Yao, H.Q. and Dong, C.F. (2012b) Growth model of a hydrothermal low-temperature Si-rich chimney: Example from the CDE hydrothermal field, Lau Basin. Science China-Earth Sciences 55, 1716-1730.

Sun, Z.L., Zhou, H.Y., Glasby, G.P., Sun, Z.X., Yang, Q.H., Yin, X.J. and Li, J.W. (2013) Mineralogical characterization and formation of $\mathrm{Fe}-\mathrm{Si}$ oxyhydroxide deposits from modern seafloor hydrothermal vents. Am. Miner. 98, 85-97.

Sun, Z.L., Li, J., Huang, W., Dong, H.L., Little, C.T.S. and Li, J.W. (2015) Generation of hydrothermal Fe-Si oxyhydroxide deposit on the Southwest Indian Ridge and its implication for the origin of ancient banded iron formations. Journal of Geophysical Research-Biogeosciences 120, 187-203.

Swanner, E.D., Wu, W.F., Schoenberg, R., Byrne, J., Michel, F.M., Pan, Y.X. and Kappler, A. (2015) Fractionation of Fe isotopes during Fe(II) oxidation by a marine photoferrotroph is controlled by the formation of organic Fe-complexes and colloidal Fe fractions. Geochim. Cosmochim. Acta 165, 44-61.

Tagliabue, A., Bopp, L., Dutay, J.C., Bowie, A.R., Chever, F., Jean-Baptiste, P., Bucciarelli, E., Lannuzel, D., Remenyi, T., Sarthou, G., Aumont, O., Gehlen, M. and Jeandel, C. (2010) Hydrothermal contribution to the oceanic dissolved iron inventory. Nature Geoscience $\mathbf{3}$, 252-256.

Tangalos, G.E., Beard, B.L., Johnson, C.M., Alpers, C.N., Shelobolina, E.S., Xu, H., Konishi, H. and Roden, E.E. (2010) Microbial production of isotopically light iron(II) in a modern chemically precipitated sediment and implications for isotopic variations in ancient rocks. Geobiology 8, 197-208.

Templeton, A.S., Knowles, E.J., Eldridge, D.L., Arey, B.W., Dohnalkova, A.C., Webb, S.M., Bailey, B.E., Tebo, B.M. and Staudigel, H. (2009) A seafloor microbial biome hosted within incipient ferromanganese crusts. Nature Geoscience 2, 872-876.

Teng, F.Z., Dauphas, N., Huang, S.C. and Marty, B. (2013) Iron isotopic systematics of oceanic basalts. Geochim. Cosmochim. Acta 107, 12-26.

Toner, B.M., Fakra, S.C., Manganini, S.J., Santelli, C.M., Marcus, M.A., Moffett, J., Rouxel, O., German, C.R. and Edwards, K.J. (2009) Preservation of iron(II) by carbon-rich matrices in a hydrothermal plume. Nature Geoscience 2, 197-201.

Toner, B.M., Berquo, T.S., Michel, F.M., Sorensen, J.V., Templeton, A.S. and Edwards, K.J. (2012) Mineralogy of iron microbial mats from loihi seamount. Frontiers in microbiology 3.

Toner, B.M., Rouxel, O.J., Santelli, C.M., Bach, W. and Edwards, K.J. (2016) Iron Transformation Pathways and Redox Micro-Environments in Seafloor Sulfide-Mineral Deposits: Spatially Resolved Fe XAS and delta Fe-57/54 Observations. Frontiers in Microbiology 7.

Trefry, J.H., Butterfield, D.B., Metz, S., Massoth, G.J., Trocine, R.P. and Feely, R.A. (1994) Trace metals in hydrothermal solutions from Cleft

segment on the southern Juan de Fuca Ridge. J. Geophys. Res.-Solid Earth 99, 4925-4935.

Tsikos, H., Matthews, A., Erel, Y. and Moore, J.M. (2010) Iron isotopes constrain biogeochemical redox cycling of iron and manganese in a Palaeoproterozoic stratified basin. Earth. Planet. Sci. Lett. 298, 125-134. 
Usui, A., Yuasa, M., Yokota, S., Nohara, M., Nishimura, A. and Murakami, F. (1986) Submarine hydrothermal manganese deposits from the Ogasawara (Bonin) Arc, off the Japan Islands. Mar. Geol. 73, 311-322.

von Blanckenburg, F., Marnberti, M., Schoenberg, R., Kamber, B.S. and Webb, G.E. (2008) The iron isotope composition of microbial carbonate. Chem. Geol. 249, 113-128.

Von Damm, K.L., Edmond, J.M., Grant, B., Measures, C.I., Walden, B. and Weiss, R.F. (1985) Chemistry of submarine hydrothermal solutions at $21^{\circ} \mathrm{N}$, East Pacific Rise. Geochim. Cosmochim. Acta 49, 2197-2220.

Wang, H., Yang, Q.H., Ji, F.W., Lilley, M.D. and Zhou, H.Y. (2012) The geochemical characteristics and $\mathrm{Fe}(\mathrm{II})$ oxidation kinetics of hydrothermal plumes at the Southwest Indian Ridge. Mar. Chem. 134, 29-35.

Wang, X.Y., Zeng, Z.G., Qi, H.Y., Chen, S., Yin, X.B. and Yang, B.J. (2014) Fe-Si-Mnoxyhydroxide encrustations on basalts at east pacific rise near 13A degrees N: An SEMEDS study. J. Ocean Univ. China 13, 917-925.

Welch, S.A., Beard, B.L., Johnson, C.M. and Braterman, P.S. (2003) Kinetic and equilibrium Fe isotope fractionation between aqueous Fe(II) and Fe(III). Geochim. Cosmochim. Acta 67, 4231-4250.

Weyer, S. and Schwieters, J.B. (2003) High precision Fe isotope measurements with high mass resolution MC-ICPMS. Int. J. Mass spectrom. 226, 355-368.

Wheat, C.G., Jannasch, H.W., Plant, J.N., Moyer, C.L., Samsone, F.J. and McMurtry, G.M. (2000) Continuous sampling of hydrothermal fluids from Loihi Seamount after the 1996 even. J Geophy Res 105, 19353-19367.

Wu, J.F., Wells, M.L. and Rember, R. (2011a) Dissolved iron anomaly in the deep tropicalsubtropical Pacific: Evidence for long-range transport of hydrothermal iron. Geochim. Cosmochim. Acta 75, 460-468.

Wu, L.L., Beard, B.L., Roden, E.E. and Johnson, C.M. (2011b) Stable Iron Isotope Fractionation Between Aqueous Fe(II) and Hydrous Ferric Oxide. Environ. Sci. Technol. 45, 1847-1852.

Wu, L.L., Brucker, R.P., Beard, B.L., Roden, E.E. and Johnson, C.M. (2013) Iron Isotope Characteristics of Hot Springs at Chocolate Pots, Yellowstone National Park. Astrobiology 13, 1091-1101.

Yucel, M., Gartman, A., Chan, C.S. and Luther, G.W. (2011) Hydrothermal vents as a kinetically stable source of iron-sulphide-bearing nanoparticles to the ocean. Nature Geoscience 4, 367-371.

Zeng, Z.G., Ouyang, H.G., Yin, X.B., Chen, S., Wang, X.Y. and Wu, L. (2012) Formation of FeSi-Mn oxyhydroxides at the PACMANUS hydrothermal field, Eastern Manus Basin: Mineralogical and geochemical evidence. Journal of Asian Earth Sciences 60, 130-146.

Zheng, Y., Anderson, R.F., Van Geen, A. and Fleisher, M.Q. (2002) Remobilization of authigenic uranium in marine sediments by bioturbation. Geochim. Cosmochim. Acta 66, $1759-1772$. 


\section{Table captions}

Table 1: Incubation experiments simulating Fe(II) oxidation in background seawater from Loihi Seamount.

Table 2: Geochemistry of hydrothermal fluids from Loihi Seamount.

Table 3: Geochemistry of suspended particles in sampled hydrothermal fluids from Loihi Seamount.

Table 4: Representative geochemical composition of Fe-rich deposits from Loihi Seamount.

Table 5: Iron isotope composition and Fe-normalized concentrations of selected elements of Fe-rich deposits from Loihi Seamount.

Table 6: Summary of calculated Fe isotope fractionation factors between fluid and Ferich deposits at each vent sites of Loihi Seamount. 


\section{Figure captions}

Figure 1: Multibeam bathymetric map of the summit of Loihi Seamount. Contour interval corresponds to $10 \mathrm{~m}$ and grid size is $350 \mathrm{~m}$. Active and inactive hydrothermal sites investigated in this study are shown, including Pele's Pit vents (Spillway Area: M34 and M38; Hiolo Area: M36 and M39; Lohiau Area: M2 and M5), Pohaku Area (M57), Naha (M3 and M6), Keiki (M17 and M17A).

Figure 2: Chemistry of Loihi hydrothermal fluids (and therefore excluding bottom seawater values reported in Table 2) showing the relationships between $\mathrm{Mn}$ and (a) Mo; (b) Fe; (c) U; (d) Si; (e) P; (f) Co. Relationships between Fe, Mn, Si and Co show mainly the effect of dilution of the vent fluids with seawater. Fluids from the venting sites at Loihi Seamount (M5, M36-M39, M34-M38, M57) may have different geochemical signatures as shown by the different slopes. Relationships between Mn, Mo and U show the removal of seawater-derived element Mo and U during mixing between hydrothermal fluid and seawater, either at the seafloor or in the subsurface. The P vs Mn relationship shows mixed behavior, with $\mathrm{P}$ being either depleted or enriched in the hydrothermal fluid relative to background seawater.

Figure 3: Fe isotope composition $\left(\delta^{56} \mathrm{Fe}\right)$ of the vent fluids at Loihi Seamount vs. (a) $\mathrm{Fe} / \mathrm{Mn}$ ratios and (b) U concentations. Low-temperature vent fluids from M5 area are affected by extensive mixing with seawater, as shown by their elevated $\mathrm{U}$ concentrations, most negative $\delta^{56} \mathrm{Fe}$ values and lower $\mathrm{Fe} / \mathrm{Mn}$ ratios due to partial Fe(II) oxidation. Note that the regression line and coefficient correlation in diagram (a) exclude the vent fluid data from M57, which is located southern of Pele's Pit and characterized by a different end-member Fe/Mn ratio (Glazer and Rouxel, 2009). See text for discussion.

Figure 4: Geochemistry of FeOx deposits recovered at Loihi Seamount. Note that all elemental data are normalized to the major element $\mathrm{Fe}$ and plotted against $\mathrm{Al} / \mathrm{Fe}$ to show the enrichment factors relative to volcanic materials that were often intermixed with FeOx deposit. Elemental ratios trends for basalts at Loihi Seamount are shown by the gray shaded area, using 
previously published data (Garcia et al., 1995; Dixon and Clague, 2001; Pietruszka et al., 2011): (a) $\mathrm{Ti} / \mathrm{Fe}$ vs $\mathrm{Al} / \mathrm{Fe}$ show strong correlation consistent with simple addition of volcanic material to FeOx deposit. All other plots, including (b) $\mathrm{V} / \mathrm{Fe}$ vs $\mathrm{Al} / \mathrm{Fe}$; (c) $\mathrm{Si} / \mathrm{Fe}$ vs $\mathrm{Al} / \mathrm{Fe}$; (d) $\mathrm{Cr} / \mathrm{Fe}$ vs $\mathrm{Al} / \mathrm{Fe}$; (e) $\mathrm{U} / \mathrm{Fe}$ vs $\mathrm{Al} / \mathrm{Fe}$; (f) $\mathrm{P} / \mathrm{Fe}$ vs $\mathrm{Al} / \mathrm{Fe}$; (b) show that all $\mathrm{FeOx}$ deposits have an excess of $\mathrm{V}$, $\mathrm{Si}, \mathrm{Cr}, \mathrm{U}$ and $\mathrm{P}$ above basalt values showing significant authigenic enrichment associated with $\mathrm{FeOx}$ deposits (except Si which associated with amorphous silica).

Figure 5: Rare Earth Element (REE) patterns of FeOx deposit at Loihi Seamount. REE concentrations are normalized to chondrite CHU (Anders and Grevesse, 1989). The gray shaded area correspond to the range of values for basalts at Loihi Seamount (Dixon and Clague, 2001).

Figure 6: Relationships between $\mathrm{Ni} / \mathrm{Fe}, \mathrm{Co} / \mathrm{Fe}, \mathrm{Mo} / \mathrm{Fe}, \delta^{56} \mathrm{Fe}$ and $\mathrm{Mn} / \mathrm{Fe}($ in $\mathrm{mg} / \mathrm{g}$ ) in $\mathrm{FeOx}$ deposits recovered at Loihi Seamount. See text for discussion.

Figure 7: Scanning transmission X-ray microscope images of Loihi mats: (a) Pohaku $2 \mu \mathrm{m}$ scale bar; (b) Naha $5 \mu \mathrm{m}$ scale bar; (c) M55 $2 \mu \mathrm{m}$ scale bar; (d) Spillway M38 $5 \mu \mathrm{m}$ scale bar; (e) M55 (Pit of Death?) $2 \mu \mathrm{m}$ scale bar; and (f) M55 $2 \mu \mathrm{m}$ scale bar.

Figure 8: Schematic model of the formation of $\mathrm{FeOx}$ deposits at Loihi Seamount and their Fe isotope signatures. Model (A) concerns the formation of the deposits via partial oxidation of $\mathrm{Fe}$ (II) from warm hydrothermal vents, either through direct interaction within microbial mats (proximal or young mats) or as precipitated particles from discharging fluid (distal or aged mats). The Fe isotopic model represented by the solid thick black line predicts heavy $\delta^{56} \mathrm{Fe}$ values of the deposit at low extent of Fe oxidation (case of proximal mats), while distal or more mature mats would have $\delta^{56} \mathrm{Fe}$ values closer to the vent source due to higher extent of $\mathrm{Fe}$ (II) oxidation. Model (B) concerns the formation of the deposits via either partial or quantitative $\mathrm{Fe}$ (II) oxidation at the seafloor, but after significant depletion of Fe from the vent fluid due to subsurface precipitation of Fe-oxyhydroxide. The Fe isotopic model represented by the solid thick black line predicts heavy $\delta^{56} \mathrm{Fe}$ values of the deposit at low extent of Fe oxidation (case of proximal mats), while extensive subsurface Fe precipitation would result in highly negative $\delta^{56} \mathrm{Fe}$ values of the deposit. In both models, the dashed and solid thin lines represent 
respectively the evolution of $\delta^{56} \mathrm{Fe}$ values of the hydrothermal fluid and associate suspended particles during partial Fe(II) oxidation. Numbered labels (1) through (6) represents the $\delta^{56} \mathrm{Fe}$ values and corresponding \% of Fe(II) oxidation for: (1) suspended Fe-rich particles and freshly formed microbial mats; (2) typical (i.e. average) Fe-rich microbial mats recovered in Pele's Pit; (3) aged Fe-rich deposits from M36; (4) Fe-rich deposits formed through diffuse venting of seawater-mixed hydrothermal fluid from Lohiau area; (5) inactive deposits from Naha area formed from partial Fe(II) oxidation; (6) inactive and Mn-rich deposits from M17 area formed from quantitative $\mathrm{Fe}(\mathrm{II})$ oxidation.

Figure 9: $\delta^{56} \mathrm{Fe}$ vs Fe/Mn in vent fluid modeled through Rayleigh-type fractionation model during partial Fe(II) oxidation in subsurface environments The solid line corresponds to fractionation factor of 1.0006 while the dashed line corresponds to a fractionation factor of 1.001 .

Figure 10: Compilation of $\delta^{56} \mathrm{Fe}$ values in modern and ancient FeOx deposit formed in contrasted environments: (1) Loihi Seamount: this study; (2) Jan Mayen siliceous ferrihydrite deposits (Moeller et al., 2014) (3) Jasper, ODP Hole 801C, Jurassic, Pacific oceanic Crust (Rouxel et al., 2003) (4) Lokken, Ordovician, Norway (Planavsky et al., 2012; Moeller et al., 2014) (5) Precambrian Iron Formations (Planavsky et al., 2012); (6) Hotazel Iron Formation and Mn Formation (Tsikos et al., 2010) and Koegas Subgroup Fe- and Mn-rich deposits (Kurzweil et al., 2016); (7) 2.4-2.5 Ga Kuruman and Brockman Iron Formations, magnetite-rich facies (Johnson et al., 2003; Johnson et al., 2008; Li et al., 2015). 
Table 1: Incubation experiments simulating Fe(II) oxidation in background seawater at Loihi Seamount

\begin{tabular}{ccccccccc}
\hline $\begin{array}{c}\text { Seawater } \\
\text { sample }\end{array}$ & $\begin{array}{c}\text { Time } \\
\text { elapsed } \\
\text { (min) }\end{array}$ & $\begin{array}{c}\text { Fe } \\
\text { (mM) ini }\end{array}$ & $\begin{array}{c}\% \\
\text { FeOx } \\
\text { (a) }\end{array}$ & $\begin{array}{c}{ }^{56} \mathrm{Fe}_{\mathrm{DFe}} \\
\text { (b) }\end{array}$ & $2 \mathrm{SD}$ & $\begin{array}{c}{ }^{56} \mathrm{Fe}_{\mathrm{PFe}} \\
\text { (c) }\end{array}$ & $2 \mathrm{SD}$ & $\begin{array}{c}{ }^{56} \mathrm{Fe} \mathrm{PFe}_{\mathrm{PFe}} \\
\text { (d) }\end{array}$ \\
\hline $\mathrm{J} 2-365-\mathrm{N}$ & 37 & 18.9 & 9.1 & -0.61 & 0.05 & 0.68 & 0.05 & 1.29 \\
$\mathrm{~J} 2-365-\mathrm{N}$ & 104 & 17.4 & 7.4 & -0.56 & 0.05 & 0.67 & 0.05 & 1.23 \\
$\mathrm{~J} 2-365-\mathrm{N}$ & 129 & 26.0 & 4.8 & -0.53 & 0.05 & 0.68 & 0.05 & 1.22 \\
$\mathrm{~J} 2-366-\mathrm{N}$ & 12 & 17.6 & 6.0 & -0.54 & 0.05 & 0.89 & 0.05 & 1.43 \\
$\mathrm{~J} 2-366-\mathrm{N}$ & 65 & 29.7 & 5.8 & -0.51 & 0.05 & 1.11 & 0.05 & 1.62 \\
$\mathrm{~J} 2-366-\mathrm{N}$ & 207 & 13.4 & 11.5 & -0.66 & 0.05 & 1.19 & 0.05 & 1.85 \\
\hline
\end{tabular}

(a) percentage of Fe(II) oxidized; (b) DFe: dissolved Fe; (c) PFe: particulate Fe; (d) fractionation factor between PFe and DFe 
Table 2: Geochemistry of hydrothermal fluids from Loihi Seamount

\begin{tabular}{|c|c|c|c|c|c|c|c|c|c|c|c|c|c|c|c|c|c|c|c|c|c|c|c|c|c|c|c|c|c|c|}
\hline \multirow[t]{2}{*}{$\begin{array}{l}\text { Sample } \\
\text { Name }\end{array}$} & \multirow[t]{2}{*}{ Marker } & \multirow[t]{2}{*}{ Year } & \multirow[t]{2}{*}{$\begin{array}{l}\text { Temp } \\
\text { C (a) }\end{array}$} & \multirow[t]{2}{*}{$\begin{array}{c}\mathrm{pH}\left(25^{\circ} \mathrm{C},\right. \\
1 \mathrm{~atm})\end{array}$} & \multirow{2}{*}{$\begin{array}{c}\text { Alk } \\
\mathrm{meq} / \mathrm{kg}\end{array}$} & \multirow{2}{*}{$\begin{array}{l}\mathrm{Ca} \\
\mathrm{mM}\end{array}$} & \multirow{2}{*}{$\begin{array}{c}\mathrm{K} \\
\mathrm{mM}\end{array}$} & \multirow{2}{*}{$\begin{array}{l}\mathrm{Mg} \\
\mathrm{mM}\end{array}$} & \multirow{2}{*}{$\begin{array}{c}\mathrm{S} \\
\mathrm{mM}\end{array}$} & \multirow{2}{*}{$\begin{array}{l}\mathrm{Si} \\
\mathrm{M}\end{array}$} & \multirow{2}{*}{$\begin{array}{l}\text { Al } \\
\text { M }\end{array}$} & \multirow{2}{*}{$\begin{array}{l}\mathrm{Fe} \\
\square \mathrm{M}\end{array}$} & \multirow{2}{*}{$\begin{array}{l}\mathrm{Mn} \\
\mathrm{M}\end{array}$} & \multirow{2}{*}{$\begin{array}{l}\mathrm{P} \\
\mathrm{M}\end{array}$} & & $\mathrm{Rb}$ & $\mathrm{Ba}$ & $\mathrm{Sr}$ & Co & $\mathrm{Cr}$ & $\mathrm{Cu}$ & Mo & U & V & & $\delta^{56} \mathrm{Fe}$ & $2 S D$ & $\delta^{57} \mathrm{Fe}$ & $2 S D$ & $\mathrm{Fe} / \mathrm{Mn}$ \\
\hline & & & & & & & & & & & & & & & & $\mathrm{M}$ & $\mathrm{M}$ & $\mathrm{M}$ & $\mathrm{nM}$ & $\mathrm{nM}$ & $\mathrm{nM}$ & $\mathrm{nM}$ & $\mathrm{nM}$ & $\mathrm{nM}$ & $\mathrm{nM}$ & & & & & \\
\hline $\begin{array}{l}\text { Detection Lin } \\
\text { Bottom Sea }\end{array}$ & $\begin{array}{l}\text { mit } \\
\text { awater (b) }\end{array}$ & & & & & & & & & 1.0 & & 0 & 0. & 0 & & 0 . & 0.01 & 0.1 & & 10 & & 10 & 5 & 1 & 2 & & & & & \\
\hline J2-316-N1 & Pele's Pit & t 2007 & 3.4 & .7 & nd & 10.3 & 10.2 & 52.7 & .9 & 116 & bdl & 0.230 & 0.031 & 3.1 & 26.1 & 1.4 & 0.12 & 87.6 & dl & bdl & bdl & 102 & 12.2 & 34 & .5 & -1.24 & 06 & 78 & .09 & n.d. \\
\hline J2-315-N1 & M6 & 2007 & 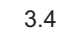 & & nd & 10.9 & 10.0 & 54.0 & & 136 & 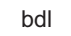 & 0.013 & 0.004 & 0.9 & 25.1 & 1.4 & 0.13 & 90.6 & dl & bdl & 6.9 & 110 & 13.2 & 39 & 0.3 & -0.83 & & & 13 & n.d. \\
\hline $\begin{array}{l}\text { J2-316-N2 } \\
\text { Pit of Death }\end{array}$ & M57 & 007 & 3.4 & 7.7 & nd & 10.0 & 9.9 & 3.0 & 7 & 15 & bdl & 0.070 & 0.063 & 1.0 & 25.1 & 1.3 & 0.10 & 82.7 & bdl & bdl & 30.6 & 106 & 12.1 & 33 & 0.3 & -0.50 & .21 & 0.94 & .42 & d. \\
\hline $\begin{array}{l}\text { J2-365-MS4 } \\
\text { Pele's Pit - }\end{array}$ & $\begin{array}{l}\text { M56 } \\
\text { Lohia }\end{array}$ & rea & 3.4 & 7.77 & nd & 10.6 & .4 & 5 & 28.8 & 430 & bdl & 0.52 & 0.29 & 9 & 2 & 1.5 & 5 & 9 & bdl & bdl & 29.5 & 108 & 12.1 & 20 & 0.3 & & & nd & n.d. & 4 \\
\hline J2-242-MS1 & M5 & 2006 & 21.0 & 21 & 38 & 11.8 & 10.8 & 52.7 & 29.5 & 348 & 0.26 & 52.0 & 3.2 & 2.1 & 28.2 & 1.8 & 0.42 & 93.5 & 14 & bdl & 99.0 & 117 & 13.7 & 27 & 0.9 & -0.46 & 0.09 & -0.65 & .09 & 15.7 \\
\hline$-311-M S 3$ & M5 & 07 & 2 & & 0 & 12.0 & 9.8 & 51.1 & 26.2 & 52 & 0.28 & 60. & 9.6 & 0.3 & 33.2 & 2.1 & 0.31 & 87.3 & 33 & bdl & .3 & 97 & 9.5 & 4 & 2.0 & -0.84 & .06 & 1.28 & .09 & 2 \\
\hline IS4 & M5 & 2007 & 24.5 & 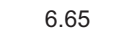 & 64 & 12.8 & 9.9 & 57.4 & 28.9 & 546 & 0.41 & 55 & 8. & 1.0 & 32.5 & 2.0 & 0.37 & 94.6 & 18 & bdl & 222.6 & 109 & 11.2 & 12 & 1.8 & -0.79 & .12 & -1.17 & .22 & .5 \\
\hline Pele's Pit - & Spillwa & Area & & & & & & & & & & & & & & & & & & & & & & & & & & & & \\
\hline J2-241-MS3 & M34 & 2006 & 54.0 & 3 & 0.62 & 22.5 & 13.2 & 56.1 & 30.7 & 3,977 & 0.39 & 68 & 19.9 & 7.3 & 67.3 & 6.7 & 1.11 & 124.8 & 197 & bdl & $1 / 9$ & מ & 3.1 & 19 & 2.3 & 0.25 & .06 & .38 & .09 & 33.8 \\
\hline -MS4 & M34 & 2006 & 52.0 & 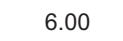 & .56 & 23.3 & 13.3 & 3.3 & 1.7 & 770 & .82 & 648 & 19.2 & 7.9 & 64.5 & 6.7 & 0.73 & 132.8 & 191 & bdl & 20.2 & 66 & 2.6 & 20 & 2.1 & 0.21 & .07 & 33 & 11 & 4.3 \\
\hline -MS3 & M34 & 07 & 47.0 & & .83 & 17.3 & 11.2 & 59.0 & 31.2 & 283 & 0.2 & 34 & 2.5 & 2.7 & 54.4 & 3.7 & 0.66 & 105.7 & 102 & bdl & 192.6 & 84 & 6.4 & 13 & .1 & 0.10 & .06 & 17 & 13 & 7.1 \\
\hline MS4 & M34 & 07 & 47. & & .77 & 16.0 & 11.3 & 52.3 & 6 & 031 & 0.27 & 307 & 1.5 & 2.3 & 43.3 & 3.9 & 0.56 & 102.9 & 91 & bdl & 321.1 & 86 & 7.1 & 14 & .6 & 0.11 & 0.09 & .14 & .17 & 26.9 \\
\hline -MS3 & M38 & 006 & 45.0 & ( & 2.58 & 11.6 & 10.6 & 52.5 & 28.7 & 159 & 0.22 & 5. & 0.24 & 1.7 & 25.8 & 1.6 & 0.38 & 96.9 & 3.6 & bdl & 382.1 & 121 & 15.3 & 23 & 0.5 & d. & n.d. & i.d. & d. & 3.6 \\
\hline & M38 & 07 & 5.0 & & 24 & 15.1 & 10.5 & 57.9 & 29.3 & ,608 & 0.31 & & 8.5 & 2.9 & 43.6 & 3.0 & 0.46 & 101.1 & 64 & bdl & 213.5 & 91 & 7.9 & 21 & 1.2 & 0.10 & .07 & 12 & .20 & 27.3 \\
\hline -MS2 & M38 & 2007 & 55.0 & 21 & 12.30 & 15.9 & 10.9 & 59.2 & 29.4 & 2,004 & 0.15 & 2 & 10.8 & 2.3 & 45.7 & 3.3 & 0.54 & 102.5 & 85 & bdl & 110.2 & 84 & 6.7 & 16 & 1.5 & 0.15 & .09 & .18 & .26 & 26.9 \\
\hline IS3 & M38 & 2007 & 47.0 & & & 17.0 & 12.0 & 55.2 & 28.9 & 2,540 & 0.09 & & 13.9 & 4.1 & 52.8 & 4.1 & 0.63 & 103.2 & 106 & bdl & 418 & 82 & 4.9 & 17 & 1.6 & 0.13 & .03 & .21 & .13 & 27.4 \\
\hline & $\mathrm{HiC}$ & & & & & & & & & & & & & & & & & & & & & & & & & & & & & \\
\hline $\mathrm{J} 2-24$ & M36 & 2006 & 5 & & 2.91 & 18.4 & 14.7 & 48.4 & 25.4 & 445 & 0.2 & & 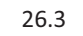 & 4.8 & 65.2 & 8.3 & 1.50 & 109.7 & 57 & 17 & 3 & 56 & 3.6 & 14 & 8.0 & 0.01 & & 1 & 14 & 1.9 \\
\hline S2 & M36 & 6 & 51.0 & & & 2.9 & 11.5 & 54.3 & 3 & 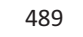 & 0 & 64. & 3. & 2.9 & 30.4 & 2.4 & 0.40 & 101.7 & 6.4 & bdl & 17. & 115 & 14.9 & 31 & .3 & -0.28 & 0.07 & -0.37 & .09 & 1.0 \\
\hline MS2 & M36 & 2006 & 1. & & 2.89 & 8.6 & 14.9 & 9.8 & 25.8 & 840 & 0.75 & $5 \varepsilon$ & 26.8 & .1 & 67.6 & 8.1 & 0.91 & 110.3 & 51 & 15 & 16.0 & 49 & 2.8 & 17 & 7.8 & 0.03 & 0.08 & 0.07 & .12 & 21.7 \\
\hline J2-314-MS3 & M36 & 2007 & 50.0 & & 1.65 & 15.4 & 12.7 & 0.0 & 25.6 & 565 & 0.19 & $3 \varepsilon$ & 18.2 & 4.0 & 56.9 & 5.3 & 0.98 & 95.6 & 42 & bdl & & 62 & 4.1 & 15 & 5.3 & 0.02 & .09 & -0.03 & .26 & 21.0 \\
\hline J2-314-MS4 & M36 & 2007 & 50.0 & 6 & 10.24 & 14.0 & 11.5 & 50.5 & 25.0 & 2,073 & 0.40 & 2 & 14.4 & 3.7 & 49.3 & 4.4 & 0.84 & 90.7 & 33 & bdl & -1.8 & 66 & 5.2 & 15 & 4.4 & 0.03 & 12 & 0.03 & .27 & 20.9 \\
\hline J2-315-MS2 & M36 & 2007 & 51.0 & 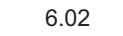 & 11.59 & 14.8 & 13.0 & 49.8 & 24.2 & 2,409 & 0.30 & 35 & 17.0 & 3.9 & 50.2 & 5.2 & 0.89 & 88.6 & 38 & bdl & -7.1 & 56 & 3.7 & 13 & 4.6 & -0.01 & .06 & -0.01 & .09 & 21.0 \\
\hline J2-242-MS3 & M39 & 2006 & 51.0 & 88 & 14.97 & 19.6 & 13.9 & 51.7 & 27.1 & 2,943 & 0.47 & 60 & 25.5 & 5.3 & 62.4 & 7.7 & 1.46 & 113.1 & 65 & 15 & 9.9 & 47 & 3.0 & 13 & 7.0 & 0.07 & .06 & 0.08 & .09 & 23.2 \\
\hline J2-242-MS4 & M39 & 2006 & 51.0 & 94 & .01 & 18.7 & 13.7 & 51.1 & 26.8 & 3,340 & 0.74 & 557 & 24.1 & 2.8 & 64.1 & 7.3 & 0.77 & 113.9 & 58 & bdl & 29.4 & 52 & 2.5 & 13 & 6.6 & 0.04 & 09 & .07 & 12 & 2.9 \\
\hline -MS2 & M39 & 2 & 50.0 & & & 9.2 & 13.8 & & 2 & ,389 & 0.39 & & 25.3 & 5.0 & 58.9 & 7.6 & 0.77 & 11 & 56 & bdl & 8 & 4 & 2 & 15 & 1 & 03 & & 8 & 14 & 3.0 \\
\hline & $\mathrm{M}$ & & 4 & & & 19.7 & 14.2 & & & ,601 & 0.24 & 5 & 26.2 & 5.3 & 59.2 & 7.1 & 1.30 & 10 & 78 & & & 5 & 2.6 & 12 & 1 & & & & 8 & 2.1 \\
\hline 1S2 & M3 & 2 & 45 & & $T$ & 8.3 & 13.5 & 46.3 & 26.3 & 3,345 & 0.19 & 53 & & 4.8 & 58.2 & 6.9 & 1.12 & 104.4 & 72 & & 11.5 & 4 & 2.2 & 13 & 6.2 & 0.07 & 66 & 0.07 & .15 & 2.2 \\
\hline 1-MS1 & M3 & 2 & 47.4 & & & 13.0 & 11.1 & 57. & 27.5 & 1,5 & 0.47 & 2 & & 2.9 & 47 & 3.6 & 0.85 & & 21 & bdl & 2 & 82 & 0 & 19 & 4 & -0.07 & .08 & -0.10 & 0.26 & 21.5 \\
\hline -MS2 & M3s & 2007 & 47. & & & 16 & 13.8 & & & 2,9 & 0.35 & 51 & 23.1 & 4.3 & 59.4 & 5.9 & 1.16 & 97.6 & 41 & bdl & -8.1 & 47 & 1.7 & 13 & 6.0 & -0.02 & .08 & -0.02 & 0.08 & 22.1 \\
\hline J2-315-MS1 & M39 & 2007 & 52.0 & 6.08 & 15.61 & 18.4 & 13.6 & 54.9 & 26.9 & 3,381 & 0.37 & 532 & 24.0 & 5.3 & 69.5 & 6.4 & 1.16 & 103.8 & 67 & 11 & -3.4 & 53 & 1.8 & 11 & 6.3 & 0.04 & 0.07 & 0.05 & 0.10 & 22.1 \\
\hline Pohaku & & & & & & & & & & & & & & & & & & & & & & & & & & & & & & \\
\hline J2-316-MS1 & M57 & 2007 & 26.5 & & 7.8 & 10.8 & 10.3 & 52.1 & 26 & 29 & 5.34 & 48 & & 3.1 & 35.6 & 2.4 & 0.35 & 83.7 & 259 & 203 & 232.6 & 66 & 6.4 & 38 & 9.2 & -0.03 & & .00 & .12 & 42.6 \\
\hline J2-316-MS2 & M57 & 2007 & 26.5 & 7.32 & 7.85 & 12.6 & 11.7 & 58.4 & 29.1 & 2,036 & 10.8 & 818 & 18.9 & 3.0 & 41.8 & 3.3 & 0.50 & 98.0 & 422 & 343 & 544.4 & 60 & 4.7 & 66 & 15.6 & 0.01 & 0.13 & 0.05 & 0.06 & 42.7 \\
\hline
\end{tabular}


Table3: Geochemistry of suspended particles in sampled hydrothermal fluids from Loihi Seamount.

\begin{tabular}{|c|c|c|c|c|c|c|c|c|c|c|c|c|c|c|c|c|c|c|c|c|c|c|}
\hline $\begin{array}{l}\text { Sample } \\
\text { Name }\end{array}$ & Mark & Year & $\begin{array}{c}{ }^{56} \mathrm{Fe}_{\mathrm{PF}} \\
\mathrm{e}\end{array}$ & $2 \mathrm{SD}$ & ${ }^{57} \mathrm{Fe}_{\mathrm{PFe}}$ & $2 \mathrm{SD}$ & $\begin{array}{c}\square^{56} \mathrm{Fe}_{\mathrm{PFe}-} \\
\mathrm{DFe}(\mathrm{a})\end{array}$ & $2 S D$ & $\begin{array}{c}\mathrm{Fe} \\
(w t \%)\end{array}$ & $\begin{array}{c}\mathrm{Al} \\
(\mathrm{mg} / \\
\mathrm{gFe})\end{array}$ & $\begin{array}{c}\mathrm{Ca} \\
(\mathrm{mg} / \\
\mathrm{gFe})\end{array}$ & $\begin{array}{l}\mathrm{Mn} \\
(\mathrm{mg} / \\
\mathrm{gFe})\end{array}$ & $\begin{array}{c}\mathrm{Ti} \\
(\mathrm{mg} / \\
\mathrm{gFe})\end{array}$ & $\begin{array}{c}\mathrm{P} \\
(\mathrm{mg} / \\
\mathrm{gFe})\end{array}$ & $\begin{array}{c}\mathrm{V} \\
(\square \mathrm{g} / \\
\mathrm{gFe})\end{array}$ & $\begin{array}{c}\mathrm{Cr} \\
(\square \mathrm{g} / \\
\mathrm{gFe})\end{array}$ & $\begin{array}{c}\text { Co } \\
(\square g / \\
g F e)\end{array}$ & $\begin{array}{c}\mathrm{Ni} \\
(\square \mathrm{g} / \\
\mathrm{gFe})\end{array}$ & $\begin{array}{c}\mathrm{Cu} \\
(\square \mathrm{g} / \\
\mathrm{gFe})\end{array}$ & $\begin{array}{c}\mathrm{Zn} \\
(\square \mathrm{g} / \\
\mathrm{gFe})\end{array}$ & $\begin{array}{c}\text { Mo } \\
\text { ( } \square \text { g/ } \\
\text { gFe) }\end{array}$ & $\begin{array}{c}\mathrm{U} \\
(\square \mathrm{g} / \\
\mathrm{gFe})\end{array}$ \\
\hline \multicolumn{23}{|l|}{ Lohiau Area } \\
\hline J2-242-MS1 & M5 & \#\#\# & 0.65 & 0.09 & 0.92 & 0.17 & 1.11 & 0.13 & 36.3 & 8.0 & 23 & 0.62 & 1.44 & 12.1 & 390 & \#\#\#\# & 196 & 3430 & 53053 & \#\#\# & 1008 & 11 \\
\hline J2-245-MS1 & M5 & \#\#\# & 0.76 & 0.11 & 1.14 & 0.18 & 1.09 & 0.12 & 42.9 & 10.3 & 27 & 1.13 & 2.16 & 16.3 & 329 & 1767 & 66.0 & 543 & 2912 & 746 & 156 & 16 \\
\hline J2-311-MS3 & M5 & \#\#\# & 1.36 & 0.06 & 1.98 & 0.09 & 2.20 & 0.08 & nd & 3.2 & 26 & 0.18 & 0.70 & 32.0 & 296 & 1743 & 5.2 & 30 & 105 & 202 & 100 & 15 \\
\hline $\begin{array}{l}\text { J2-311-MS4 } \\
\text { Spillway Area }\end{array}$ & M5 & \#\#\# & 1.42 & 0.09 & 2.12 & 0.15 & 2.21 & 0.15 & nd & 5.4 & 32 & \multicolumn{10}{|c|}{ Spillway Area } & 14 \\
\hline J2-241-MS3 & M34 & \#\#\# & 1.65 & 0.08 & 2.44 & 0.11 & 1.40 & 0.10 & 43.8 & 5.4 & 25 & 0.19 & 1.22 & 23.8 & 214 & 344 & 17.7 & 263 & 819 & 512 & 106 & 11 \\
\hline J2-241-MS4 & M34 & \#\#\# & 1.57 & 0.09 & 2.26 & 0.10 & & & 43.2 & 2.5 & 15 & 0.09 & 0.53 & 26.2 & 162 & 83 & 8.0 & 100 & 600 & 709 & 216 & 103 \\
\hline J2-245-MS4 & M34 & \#\#\# & 1.26 & 0.08 & 1.88 & 0.12 & 1.05 & 0.09 & 32.7 & 4.5 & 14 & 0.06 & 0.58 & 17.6 & 179 & 66 & 8.9 & 183 & 4396 & 1961 & 115 & 12 \\
\hline J2-308-MS3 & M34 & \#\#\# & 1.94 & 0.10 & 2.92 & 0.31 & 1.84 & 0.11 & nd & 30.4 & 52 & 0.66 & 5.62 & 29.1 & 323 & 778 & 27.7 & 170 & 507 & 619 & 75 & 10 \\
\hline J2-308-MS4 & M34 & \#\#\# & 1.84 & 0.05 & 2.75 & 0.22 & 1.73 & 0.09 & nd & 15.2 & 32 & 0.33 & 2.79 & 28.4 & 210 & 122 & 16.4 & 73 & 1773 & 961 & 77 & 8 \\
\hline $\begin{array}{l}\text { J2-314-MS2 } \\
\text { Hiolo Area }\end{array}$ & M38 & \#\#\# & 1.31 & 0.06 & 1.95 & 0.15 & 1.16 & 0.19 & nd & 7.0 & 42 & 0.20 & 1.23 & 34.4 & 334 & 1620 & 6.2 & 61 & 196 & 476 & 111 & 17 \\
\hline J2-241-MS2 & M36 & \#\#\# & 1.13 & 0.10 & 1.67 & 0.13 & 1.41 & 0.11 & 26.8 & 34.3 & 43 & 0.50 & 4.44 & 16.7 & 437 & 768 & 295.9 & 2569 & 23047 & 8886 & 157 & 18 \\
\hline J2-242-MS4 & M39 & \#\#\# & 1.16 & 0.13 & 1.73 & 0.20 & 1.12 & 0.15 & 24.4 & 30.03 & 255 & 2.69 & 7.56 & 21.7 & 402 & 937 & 377 & 3131 & 26799 & 9010 & 164 & 20 \\
\hline
\end{tabular}
nd : not determined; (a) fractionation factor between particulate Fe (PFe) and dissolved Fe (DFe). ${ }^{56} \mathrm{Fe}_{\mathrm{DFe}}$ data for each sample are reported in Table 2. 
Table 4: Representative geochemical composition of Fe-richdeposits from Loihi Seamount.

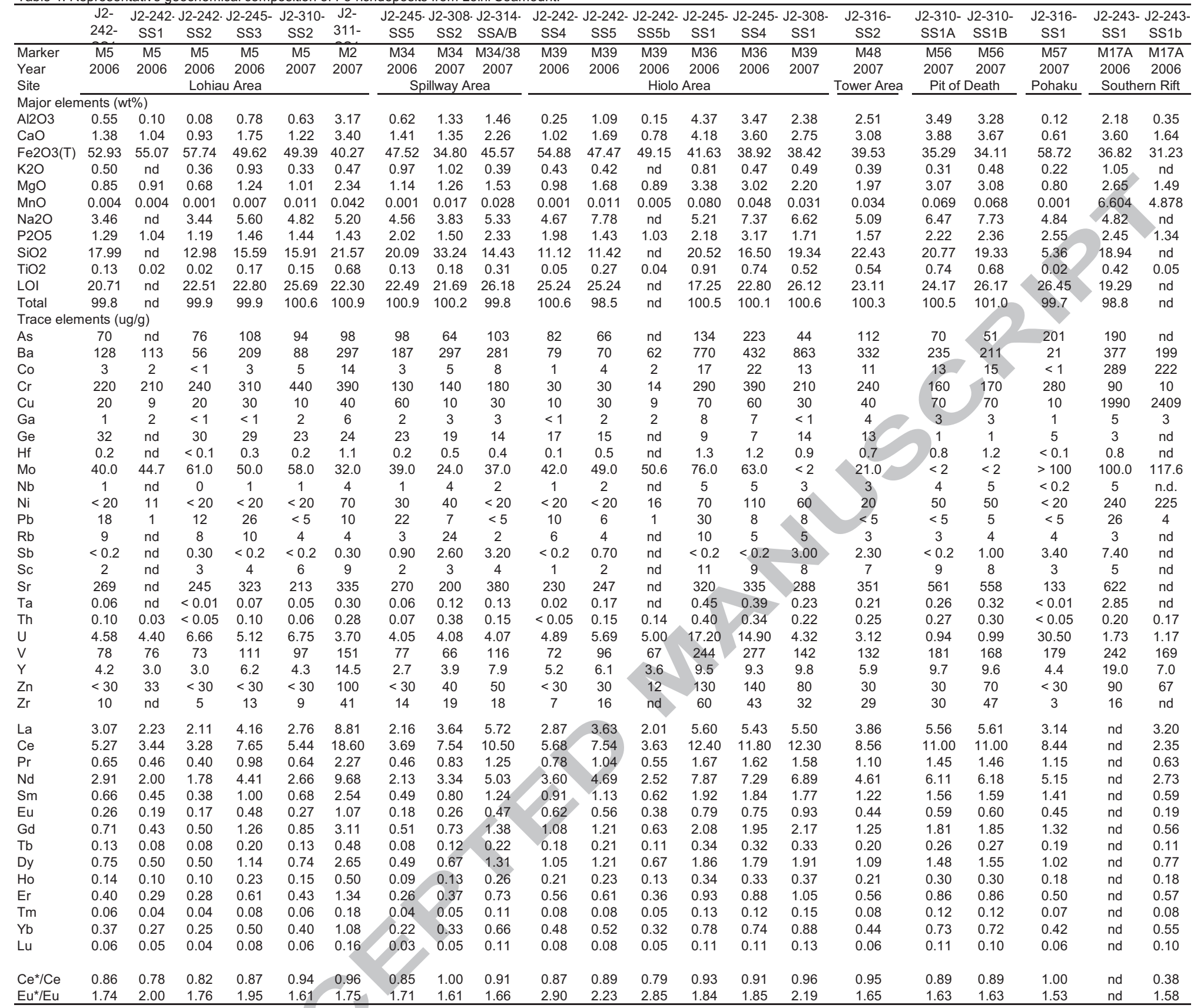

Elements below detection limit include $\mathrm{Be}(<2 \mathrm{ppm}) ; \mathrm{Cs}(<0.1 \mathrm{ppm}) ; \mathrm{Sn}$ (<1 ppm); nd: not determined; $\mathrm{Ce}^{*} / \mathrm{Ce}$ : chondrite $(\mathrm{CH})$ normalized $\mathrm{Ce}$ anomaly determined as $\left(\mathrm{Ce}_{\mathrm{CH}} /\left(0.5\left(\mathrm{Pr}_{\mathrm{CH}}+\mathrm{La}_{\mathrm{CH}}\right) ;\right.\right.$ $\mathrm{Eu}^{*} / \mathrm{Eu}$ : chondrite $(\mathrm{CH})$ normalized Eu anomaly determined as $(\mathrm{EuCH} /(0.5(\mathrm{SmCH}+\mathrm{GdCH})$

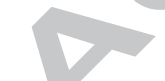


Table 5: Iron isotope composition and Fe-normalized concentrations of selected elements of Fe-rich deposits from Loihi Seamount.

\begin{tabular}{|c|c|c|c|c|c|c|c|c|c|c|c|c|c|c|c|c|c|c|c|c|c|c|c|c|}
\hline Sample Name & Marker & $\begin{array}{l}\mathrm{T}^{\circ} \mathrm{C} \\
\text { (a) }\end{array}$ & Year & $\begin{array}{l}\text { Sample } \\
\text { Type } \\
\text { (b) }\end{array}$ & $\begin{array}{c}\text { Metho } \\
d(c)\end{array}$ & $\begin{array}{c}{ }^{56} \mathrm{~F} \\
\mathrm{e}\end{array}$ & $2 S D$ & $\begin{array}{c}{ }^{57} \mathrm{~F} \\
\mathrm{e}\end{array}$ & $2 \mathrm{SD}$ & $\begin{array}{c}\mathrm{Fe} \\
(w t \%)\end{array}$ & $\begin{array}{c}\mathrm{Al} \\
(\mathrm{mg} / \\
\mathrm{gFe})\end{array}$ & $\begin{array}{c}\mathrm{Ca} \\
(\mathrm{mg} / \\
\mathrm{gFe})\end{array}$ & $\begin{array}{c}\mathrm{Mn} \\
(\mathrm{mg} / \\
\mathrm{gFe})\end{array}$ & $\begin{array}{c}\mathrm{Ti} \\
(\mathrm{mg} / \\
\mathrm{gFe})\end{array}$ & $\begin{array}{c}\mathrm{P} \\
(\mathrm{mg} / \\
\mathrm{gFe})\end{array}$ & $\begin{array}{c}\mathrm{V} \\
(\square \mathrm{g} / \\
\mathrm{gFe})\end{array}$ & $\begin{array}{c}\mathrm{Cr} \\
(\square \mathrm{g} / \\
\mathrm{gFe})\end{array}$ & $\begin{array}{c}\text { Co } \\
(\square \mathrm{g} / \\
\mathrm{gFe})\end{array}$ & $\begin{array}{c}\mathrm{Ni} \\
(\square \mathrm{g} / \\
\mathrm{gFe})\end{array}$ & $\begin{array}{c}\mathrm{Cu} \\
(\square \mathrm{g} / \\
\mathrm{gFe})\end{array}$ & $\begin{array}{c}\mathrm{Zn} \\
(\square \mathrm{g} / \\
\mathrm{gFe}) \\
\end{array}$ & $\begin{array}{c}\mathrm{Mo} \\
\text { ( } \mathrm{g} / \\
\mathrm{gFe})\end{array}$ & $\begin{array}{c}\mathrm{U} \\
(\square \mathrm{g} / \\
\mathrm{gFe})\end{array}$ & $\begin{array}{c}\mathrm{Ba} \\
(\square \mathrm{g} / \\
\mathrm{gFe})\end{array}$ \\
\hline \multicolumn{25}{|l|}{ Lohiau Area } \\
\hline J2-311-SS1 & M2 & 6 & 2007 & SS & E2 & 0.89 & 0.09 & 1.26 & 0.13 & nd & 9.0 & 34 & 0.26 & 1.45 & 22.7 & 296 & 732 & 10.0 & 61 & 27 & 143 & 121 & 14 & 186 \\
\hline J2-481-SC2 & M2 & 4 & 2009 & $\mathrm{SC}$ & AES & 0.55 & 0.06 & 0.82 & 0.10 & 32.4 & 13.4 & 54 & 0.60 & 3.11 & 26.5 & 604 & 331 & 2.5 & 17 & nd & 112 & nd & nd & 424 \\
\hline J2-242-SS1 & M5 & 22 & 2006 & SS & $E 2$ & 0.81 & 0.11 & 1.19 & 0.21 & 38.5 & 1.3 & 19 & 0.09 & 0.24 & 11.78 & 198 & 545 & 3.9 & 29 & 23 & 85 & 116 & 11 & 294 \\
\hline J2-242-SS2 & M5 & 22 & 2006 & SS & E2 & 0.47 & 0.06 & 0.71 & 0.11 & 45.7 & 0.3 & 14 & 0.10 & 0.08 & 9.0 & 175 & 604 & 0.9 & 15 & 12 & 32 & 165 & 15 & 108 \\
\hline J2-245-SS3 & M5 & nd & 2006 & SS & E2 & 0.87 & 0.10 & 1.29 & 0.16 & 37.1 & 4.2 & 23 & 0.20 & 0.78 & 15.7 & 313 & 1047 & 5.6 & 39 & 35 & 44 & 154 & 14 & 533 \\
\hline J2-310-SS2 & M5 & 22 & 2007 & SS & E2 & 0.77 & 0.06 & 1.12 & 0.08 & nd & 1.4 & 17 & 0.08 & 0.42 & 19.0 & 264 & 1211 & 9.4 & 39 & 11 & 12 & 181 & 26 & 121 \\
\hline J2-310-SS2 (d) & M5 & 22 & 2007 & SS & EXR & 0.83 & 0.06 & 1.28 & 0.11 & 12.5 & 1.0 & 17 & 0.04 & 0.32 & 15.7 & 239 & 1008 & 9.5 & 43 & 12 & 14 & 146 & 21 & 122 \\
\hline \multicolumn{25}{|l|}{ Spillway Area } \\
\hline J2-245-SS5 & M34 & 52 & 2006 & SS & $E 2$ & 1.37 & 0.04 & 2.03 & 0.03 & 34.2 & 1.6 & 25 & 0.11 & 0.29 & 19.9 & 199 & 29 & 4.5 & 150 & 86 & 205 & 110 & 11 & 370 \\
\hline J2-308-SS2 & M34 & 50 & 2007 & SS & $E 2$ & 1.57 & 0.07 & 2.35 & 0.10 & nd & 13.9 & 38 & 0.28 & 3.18 & 27.3 & 215 & 62 & 14.7 & 109 & 98 & $<10$ & 89 & 18 & 975 \\
\hline J2-308-SS2 (d) & M34 & 50 & 2007 & SS & $E X R$ & 1.57 & 0.06 & 2.40 & 0.11 & 7.0 & 4.1 & 27 & 0.1 & 0.51 & 25.6 & 204 & 35 & 9 & 69 & 26 & 116 & 67 & 19 & 367 \\
\hline J2-314-SSA/B (d) & M34/38 & nd & 2007 & SS & $E X R$ & 0.99 & 0.05 & 1.48 & 0.08 & 11.5 & 5.0 & 30 & 0.2 & 0.67 & 27.4 & 252 & 30 & 11 & 66 & 30 & 73 & 99 & 11 & 489 \\
\hline J2-314-SSA/B & $\mathrm{M} 34 / 38$ & nd & 2007 & SS & $E 2$ & 0.97 & 0.07 & 1.42 & 0.13 & nd & 7.9 & 33 & 0.28 & 1.27 & 31.1 & 271 & 47 & 6.9 & 24 & 26 & 54 & 120 & 13 & 407 \\
\hline J2-479-SC1 (d) & M34/38 & 3.9 & 2009 & SC & EXR & 0.90 & 0.05 & 1.36 & 0.08 & 12.2 & 0.7 & 22 & 0.1 & 0.08 & 20.4 & 202 & 11 & 2 & 21 & 8 & 14 & 71 & 12 & 218 \\
\hline $\mathrm{J} 2-479-\mathrm{SC} 1$ & M34/38 & 3.9 & 2009 & SC & $A E S$ & 0.87 & 0.06 & 1.27 & 0.10 & 34.3 & 7.0 & 33 & 0.24 & 2.27 & 24.3 & 265 & 45 & nd & 37 & nd & 23 & nd & nd & 351 \\
\hline J2-479-SC4 (d) & M34/38 & nd & 2009 & SC & EXR & 0.83 & 0.05 & 1.24 & 0.08 & 13.3 & 0.7 & 22 & 0.1 & 0.10 & 21.4 & 215 & 10 & 1 & 18 & 7 & 7 & 69 & 9 & 256 \\
\hline J2-479-SC4 & M34/38 & nd & 2009 & SC & AES & 0.82 & 0.06 & 1.25 & 0.10 & 37.3 & 5.4 & 29 & 0.18 & 1.16 & 26.2 & 259 & 21 & nd & 33 & nd & 12 & nd & nd & 362 \\
\hline J2-371-SC1 (d) & M38 & nd & 2008 & SC & EXR & 0.91 & 0.05 & 1.29 & 0.08 & 10.6 & 1.3 & 29 & 0.1 & 0.16 & 21.6 & 215 & 15 & 5 & 36 & 16 & 51 & 80 & 9 & 276 \\
\hline J2-371-SC1 & M38 & nd & 2008 & SC & AES & 0.94 & 0.07 & 1.38 & 0.13 & 36.1 & 6.8 & 16 & 0.11 & 1.71 & 39.7 & 625 & 2251 & 3.9 & 10 & nd & 34 & nd & nd & 168 \\
\hline J2-371-SC5 (d) & M38 & nd & 2008 & SC & EXR & 0.93 & 0.05 & 1.34 & 0.08 & 10.2 & 0.4 & 33 & 0.0 & 0.06 & 15.0 & 171 & 369 & 3 & 44 & 8 & 21 & 54 & 10 & 214 \\
\hline J2-371-SC5 & M38 & nd & 2008 & SC & AES & 1.00 & 0.06 & 1.41 & 0.10 & 38.0 & 6.2 & 31 & 0.13 & 1.46 & 19.9 & 217 & 406 & 14.1 & 38 & nd & 41 & nd & nd & 344 \\
\hline J2-483-SC3 & M38 & 18.2 & 2009 & SC & $A E S$ & 1.03 & 0.06 & 1.50 & 0.10 & 33.7 & 16.1 & 38 & 0.35 & 3.74 & 29.8 & 300 & 132 & 4.0 & 56 & nd & 35 & nd & nd & 1126 \\
\hline \multicolumn{25}{|l|}{ Hiolo Area } \\
\hline J2-245-SS1 & M36 & 51 & 2006 & SS & E2 & 0.29 & 0.08 & 0.46 & 0.12 & 20.4 & 4.3 & 18 & 0.45 & 0.88 & 24.4 & 454 & 43 & 9.7 & 68 & 83 & 89 & 314 & 58 & 610 \\
\hline J2-245-SS4 & M36 & 51 & 2006 & SS & $E 2$ & 0.39 & 0.08 & 0.59 & 0.12 & 30.0 & 15.2 & 31 & 0.74 & 3.27 & 38.0 & 728 & 159 & 53.8 & 409 & 221 & 389 & 243 & 51 & 1596 \\
\hline J2-242-SS4 & M39 & 52 & 2006 & SS & E2 & 1.30 & 0.04 & 1.92 & 0.07 & 41.5 & 1.2 & 15 & 0.07 & 0.22 & 16.2 & 176 & 21 & 2.1 & 22 & 18 & 18 & 117 & 12 & 303 \\
\hline J2-242-SS5 & M39 & 52 & 2006 & SS & $E 2$ & 0.87 & 0.12 & 1.31 & 0.18 & 34.4 & 2.2 & 16 & 0.11 & 0.72 & 13.1 & 196 & 40 & 6.7 & 47 & 26 & 34 & 147 & 15 & 180 \\
\hline J2-308-SS1 (d) & M39 & & & & EXR & 1.19 & 0.06 & 1.80 & 0.11 & 8.8 & 6.0 & 27 & 0.1 & 0.92 & 27.8 & 291 & 42 & 21 & 132 & 60 & 868 & 103 & 15 & 436 \\
\hline J2-308-SS1 & M39 & 53 & 2007 & SS & E2 & 1.13 & 0.08 & 1.70 & 0.18 & 25.0 & 32.8 & 56 & 0.59 & 7.64 & 31.4 & 385 & 114 & 42.8 & 258 & 337 & $<10$ & 109 & 19 & 1516 \\
\hline \multicolumn{25}{|l|}{ Tower Area } \\
\hline J2-483-SC1 & Little dike & 3.4 & 2009 & SC & AES & 0.64 & 0.06 & 0.92 & 0.10 & 23.2 & 65.1 & 103 & 1.35 & 16.42 & 18.7 & 489 & 391 & 54.4 & 201 & 54 & 196 & nd & nd & 1432 \\
\hline J2-483-SSrg & Little dike & 46.6 & 2009 & SS & $A E S$ & 0.45 & 0.06 & 0.61 & 0.10 & 33.4 & 2.7 & 28 & 0.18 & 0.56 & 30.4 & 379 & 15 & 5.2 & 38 & nd & 16 & nd & nd & 254 \\
\hline J2-316-SS2/or-gr & M48 & nd & 2007 & SS & Actlabs & 0.93 & 0.20 & 1.38 & 0.24 & 27.7 & 47.2 & 80 & 0.95 & 11.49 & 24.8 & 477 & 867 & 39.8 & 72 & 145 & 108 & 76 & 11 & 1200 \\
\hline J2-316-SS2/or-gr (d & M48 & nd & 2007 & SS & EXR & 1.01 & 0.05 & 1.48 & 0.08 & 9.6 & 6.5 & 33 & 0.1 & 0.88 & 21.1 & 233 & 77 & 15 & 99 & 32 & 78 & 71 & 8 & 464 \\
\hline J2-368-chimlet & M48 & nd & 2008 & $\mathrm{SC}$ & $A E S$ & 0.95 & 0.06 & 1.41 & 0.10 & 18.8 & 72.4 & 110 & 1.32 & 17.71 & 30.1 & 556 & 449 & 46.9 & 217 & 44 & 298 & nd & nd & 1582 \\
\hline PV-546-R3 & M48 & nd & 2002 & PV & E2 & 1.02 & 0.13 & 1.40 & 0.20 & n.d. & 47.5 & 82 & 1.00 & 10.03 & 26.0 & 522 & 358 & 51.2 & 280 & 172 & 855 & 138 & 17 & 200 \\
\hline PV-546-R3 & M48 & nd & 2002 & PV & $E 2$ & 1.08 & 0.12 & 1.50 & 0.21 & n.d. & 26.3 & 69 & 0.54 & 5.28 & 27.5 & 389 & 287 & 28.9 & 207 & 123 & 682 & 142 & 17 & 360 \\
\hline \multicolumn{25}{|l|}{ Pit of Death } \\
\hline J2-310-SS1A & M56 & 6 & 2007 & SS & Actlabs & -0.14 & 0.14 & -0.19 & 0.19 & 24.7 & 73.5 & 112 & 2.2 & 17.46 & 39.2 & 733 & 648 & 52.6 & 202 & 283 & 121 & nd & 4 & 951 \\
\hline \multicolumn{25}{|c|}{ 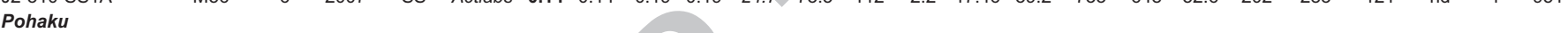 } \\
\hline $\mathrm{J} 2-316-\mathrm{SS} 1 / \mathrm{rb}$ & M57 & nd & 2007 & SS & Actlabs & 0.82 & 0.12 & 1.25 & 0.15 & 41.1 & 1.5 & 11 & 0.02 & 0.26 & 27.1 & 435 & 681 & nd & nd & 24 & $<10$ & nd & 74 & 51 \\
\hline J2-368-SS-Black & M57 & nd & 2008 & SS & AES & 0.93 & 0.06 & 1.37 & 0.10 & 41.3 & 19.6 & 48 & 0.45 & 5.77 & 26.8 & 347 & 134 & 10.8 & 75 & nd & 6605 & nd & nd & 533 \\
\hline J2-368-SS-Black (d & M57 & & & & EXR & 1.41 & 0.05 & 2.02 & 0.08 & 13.9 & 2.0 & 12 & 0.0 & 0.46 & 36.4 & 592 & 1873 & 1 & 11 & 10 & 10 & 311 & 41 & 114 \\
\hline Naha & & & & & & & & & & & & & & & & & & & & & & & & \\
\hline J2-478-SS gr-bl (d) & M3 & & & & EXR & 0.84 & 0.05 & 1.25 & 0.08 & 9.7 & 0.8 & 30 & 0.6 & 0.11 & 36.9 & 234 & 44 & 16 & 23 & 75 & 32 & 3 & 6 & 210 \\
\hline J2-478-SS gr-bl & M3 & 4.5 & 2009 & SS & $A E S$ & 0.83 & 0.06 & 1.25 & 0.10 & 28.4 & 3.8 & 31 & 0.77 & 0.81 & 41.5 & 230 & 47 & nd & 30 & n.d. & 16 & nd & nd & 221 \\
\hline J2-478-SC7 & M6 & nd & 2009 & SC & $A E S$ & -0.14 & 0.06 & -0.23 & 0.10 & 28.4 & 50.9 & 71 & 3.8 & 14.04 & 24.4 & 559 & 186 & 81.5 & 135 & 12 & 192 & nd & nd & 967 \\
\hline J2-478-SS bl-re (d) & M6 & & & & EXR & -0.19 & 0.05 & -0.27 & 0.08 & 10.0 & 1.9 & 34 & 3.0 & 0.25 & 23.9 & 256 & 14 & 41 & 47 & 43 & 32 & 11 & 6 & 252 \\
\hline J2-478-SS bl-re & M6 & nd & 2009 & SS & AES & -0.20 & 0.06 & -0.23 & 0.10 & 34.7 & 15.9 & 42 & 7.4 & 3.88 & 26.5 & 344 & 58 & 63.0 & 75 & nd & 46 & nd & nd & 280 \\
\hline J2-478-SS bl-re (\$) & & & & & & -0.24 & 0.07 & -0.36 & 0.13 & nd & nd & nd & nd & nd & nd & nd & nd & nd & nd & nd & nd & nd & nd & nd \\
\hline Southern Rift & & & & & & & & & & & & & & & & & & & & & & & & \\
\hline PV-547-12-R3 & M17 & nd & 2002 & & E2 & -1.20 & 0.07 & -1.77 & 0.13 & nd & 12.4 & 627 & 6.4 & 2.32 & 16.4 & 561 & 4774 & 38.5 & 2467 & 911 & nd & 522 & 8 & 600 \\
\hline PV-547-13-R2 & M17 & nd & 2002 & PV & E2 & -0.91 & 0.04 & -1.32 & 0.05 & nd & 12.6 & 110 & 5.5 & 2.34 & 32.3 & 393 & 377 & 25.1 & 181 & 785 & 72 & 54 & 3 & 427 \\
\hline PV-547-16-53 & M17 & nd & 2002 & PV & $E 2$ & -0.70 & 0.04 & -0.98 & 0.10 & nd & 9.1 & 123 & 11.1 & 1.55 & 36.7 & 442 & 519 & 43.2 & 187 & 747 & 159 & 80 & 4 & 454 \\
\hline PV-547-16-53 & M17 & nd & 2002 & PV & E2 & -0.65 & 0.06 & -0.98 & 0.07 & nd & 9.7 & 136 & 12.0 & 1.67 & 38.2 & 449 & 458 & 51.0 & 243 & 719 & 49 & 74 & 4 & 499 \\
\hline PV-547-17-R1 & M17 & nd & 2002 & PV & E2 & -0.65 & 0.06 & -0.98 & 0.05 & nd & 38.5 & 465 & 3.1 & 7.65 & 33.2 & 682 & 2975 & 35.3 & 1429 & 771 & 386 & 317 & 10 & 935 \\
\hline J2-243-SS1 & M17A & $<2$ & 2006 & SS & E2 & -1.50 & 0.07 & -2.21 & 0.11 & 21.9 & 8.4 & 54 & 172.9 & 1.45 & 26.7 & 774 & 45 & 1015 & 1029 & 11020 & 306 & 538 & 5 & 908 \\
\hline J2-369-SS-red & M17A & : & 2008 & SS & $A E S$ & -1.67 & 0.06 & -2.47 & 0.10 & 25.6 & 28.2 & 80 & 216.4 & 6.54 & 35.8 & 934 & 185 & 1215 & 1154 & 14426 & 344 & nd & nd & 738 \\
\hline basalt averag & & & & & & & & & & & 798 & 932 & 15 & 167 & 12 & 3616 & 3165 & 756.5 & 3945 & 1007 & 1308 & & 3.314 & 2.97 \\
\hline basalt $1 S D$ & & & & & & & & & & & 31 & 48 & 0 & 19 & 2 & 889 & 1092 & \#\#\# & 4450 & 581 & 173 & & \#\#\# & 1.44 \\
\hline
\end{tabular}




\section{ACCEPTED MANUSCRIPT}

Table 6: summary of $\mathrm{Fe}$ isotope compositions and fractionation factors between dissolved $\mathrm{Fe}$ ( $\mathrm{C}$ suspended particulate $\mathrm{Fe}$ (PFe) and Fe-rich deposits (FeOx)

\begin{tabular}{lcccccccccc}
\hline & $\delta^{56} \mathrm{Fe}_{\mathrm{DFe}}$ & $1 \mathrm{SD}$ & $\mathrm{N}$ & $\begin{array}{c}\delta^{56} \mathrm{Fe}_{\mathrm{FeO}} \\
\times\end{array}$ & $1 \mathrm{SD}$ & $\mathrm{N}$ & $\begin{array}{c}\square^{56} \mathrm{Fe}_{\mathrm{FeO}-} \\
\mathrm{DFe}\end{array}$ & & & \\
\hline M5 & -0.60 & 0.25 & 4 & 0.73 & 0.18 & 4 & 1.33 & 0.31 & 1.65 & 0.64 \\
M34 & 0.17 & 0.07 & 4 & 1.47 & 0.02 & 2 & 1.30 & 0.08 & 1.51 & 0.36 \\
M38 & 0.13 & 0.03 & 3 & 1.16 & 0.26 & 3 & 1.03 & 0.26 & 1.16 & 0.19 \\
M36 & -0.03 & 0.12 & 6 & 0.34 & 0.07 & 2 & 0.37 & 0.14 & 1.41 & 0.11 \\
M39 & 0.03 & 0.06 & 8 & 1.10 & 0.22 & 3 & 1.06 & 0.22 & 1.12 & 0.15 \\
M57 & -0.01 & 0.03 & 2 & 0.88 & 0.08 & 2 & 0.89 & 0.08 & nd & nd \\
\hline
\end{tabular}

nd: not determined 


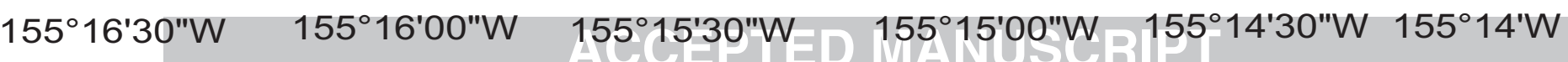

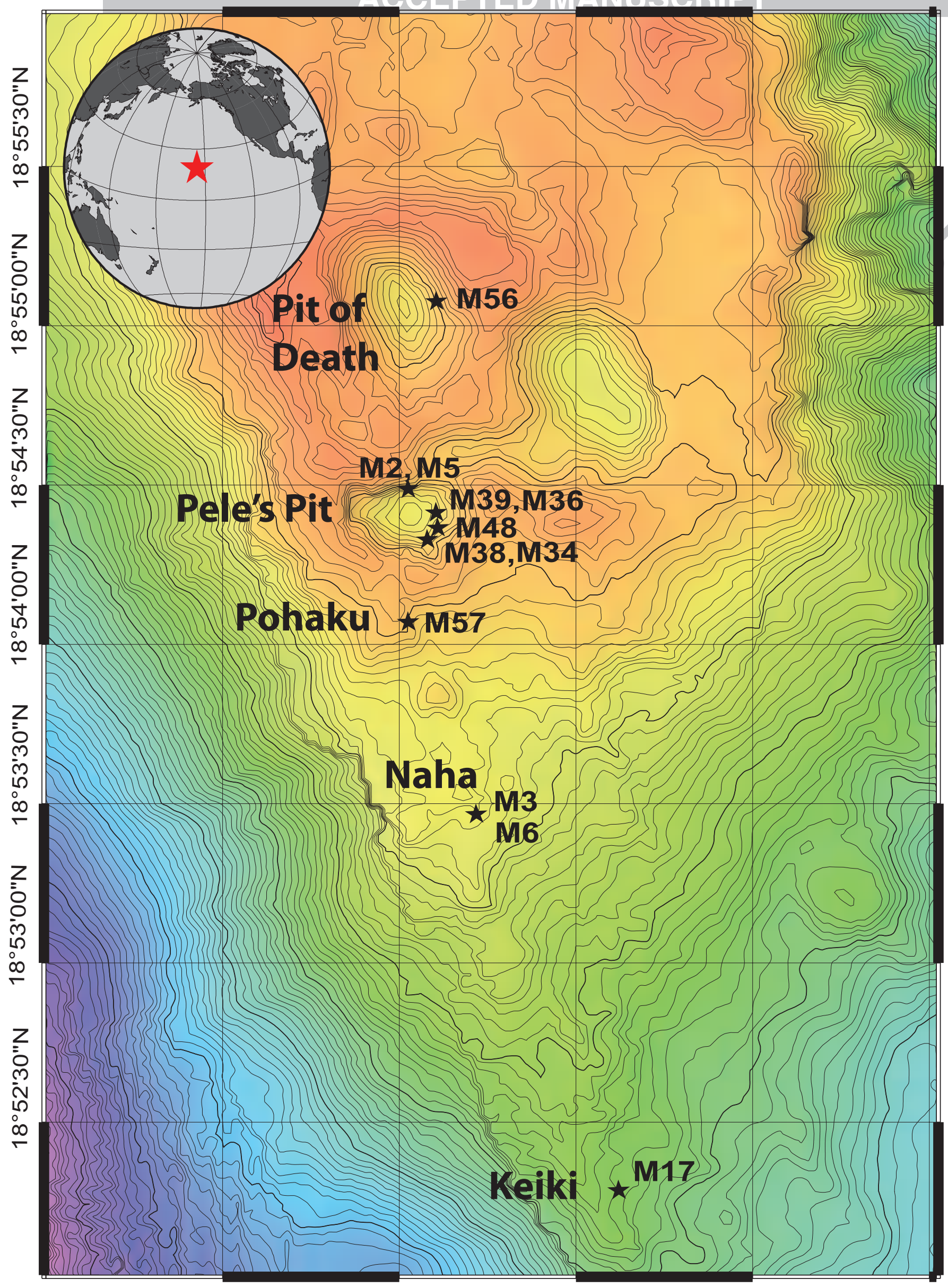




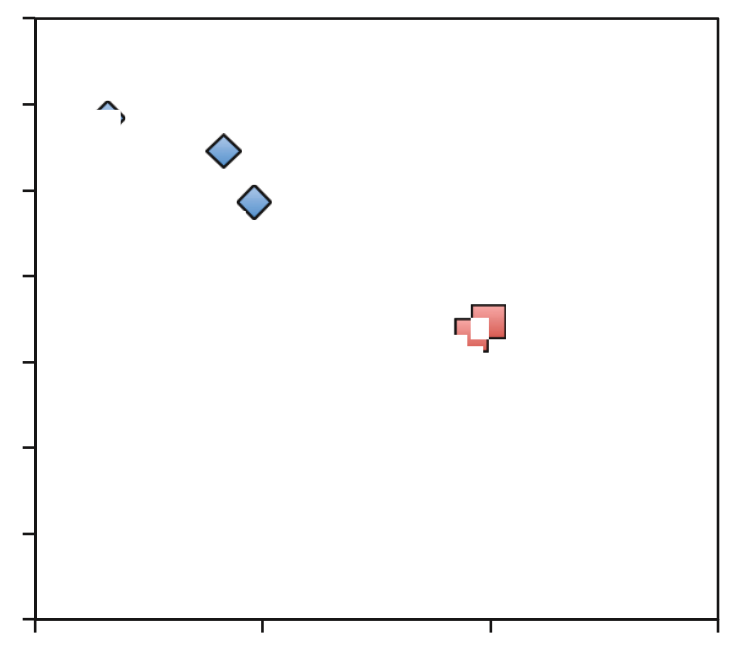




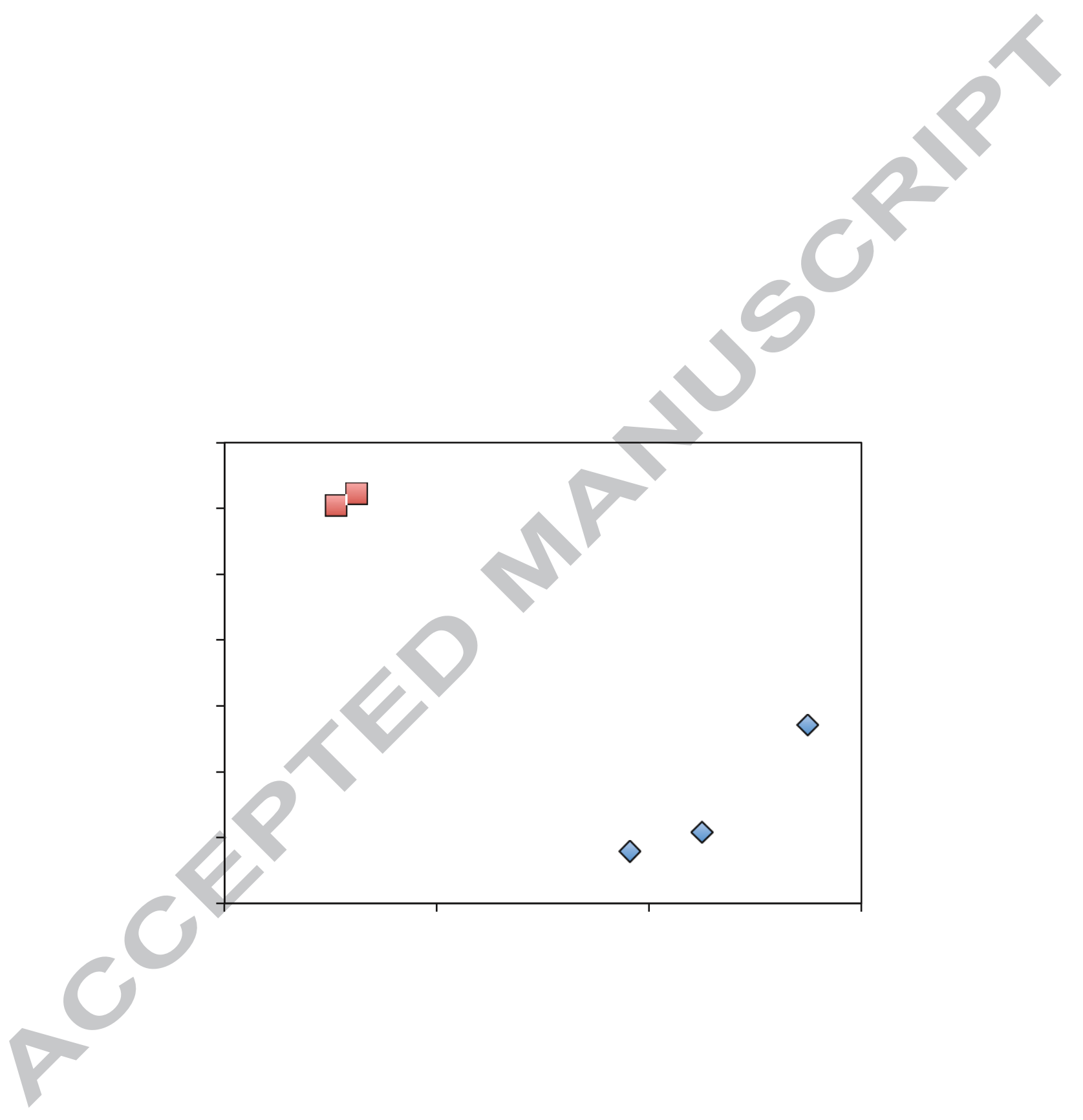




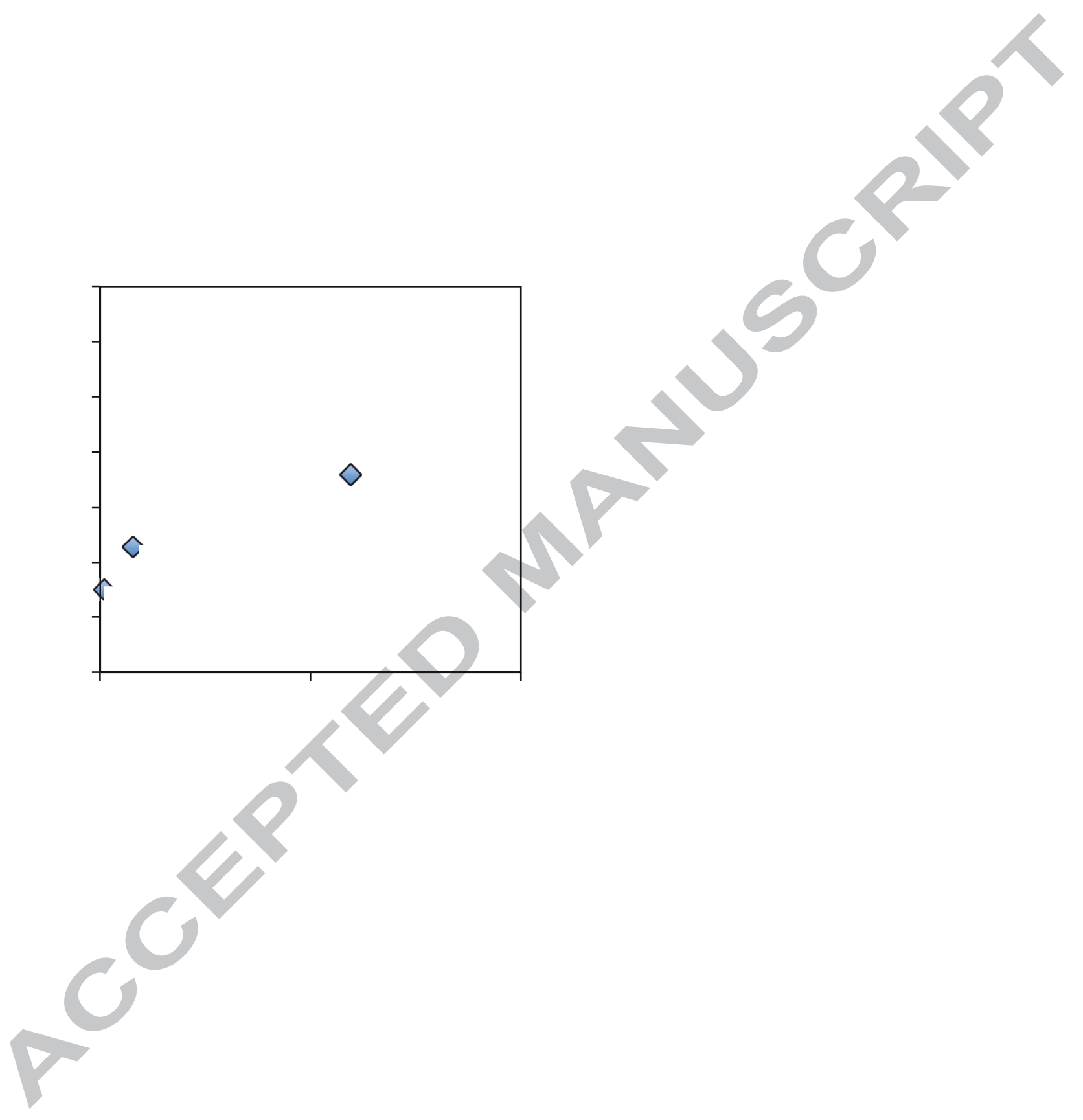




\section{ACCEPTED MANUSCRIPT}
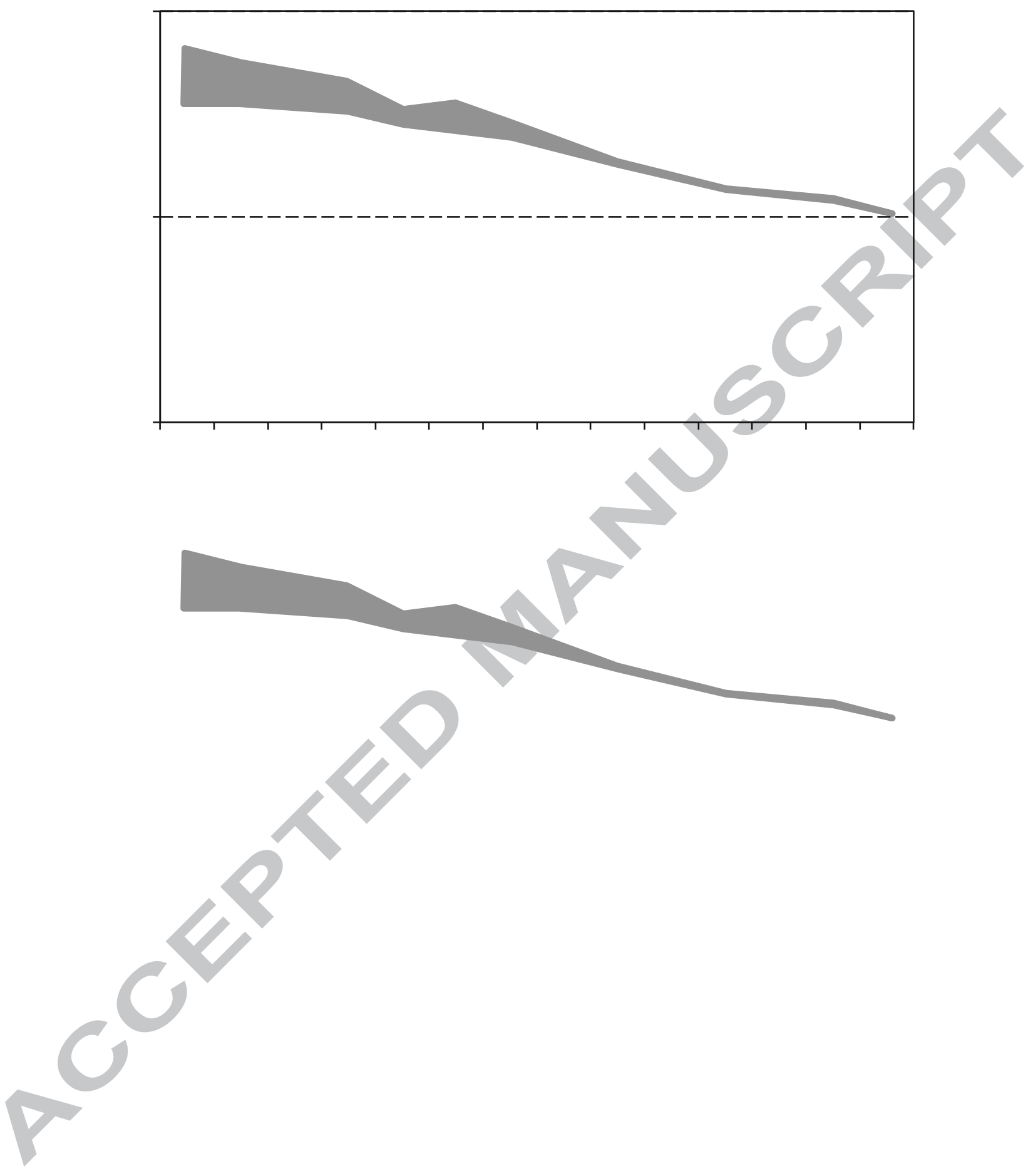


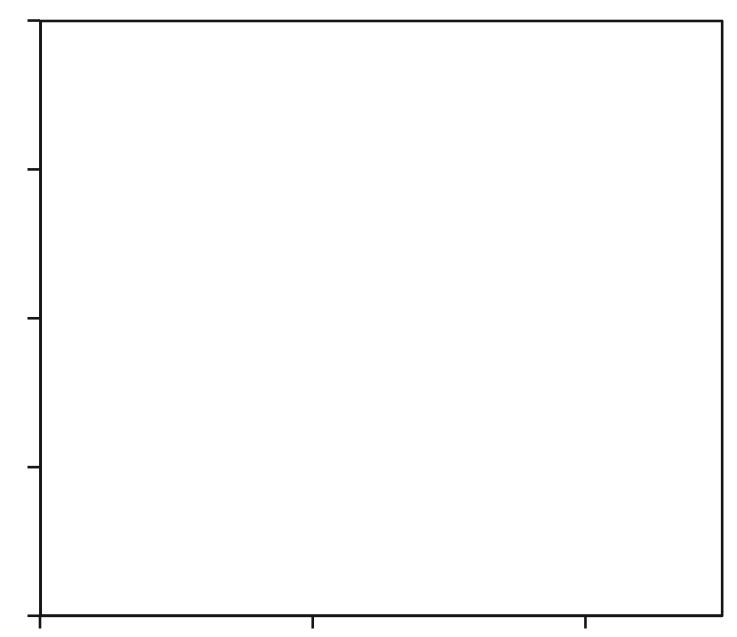



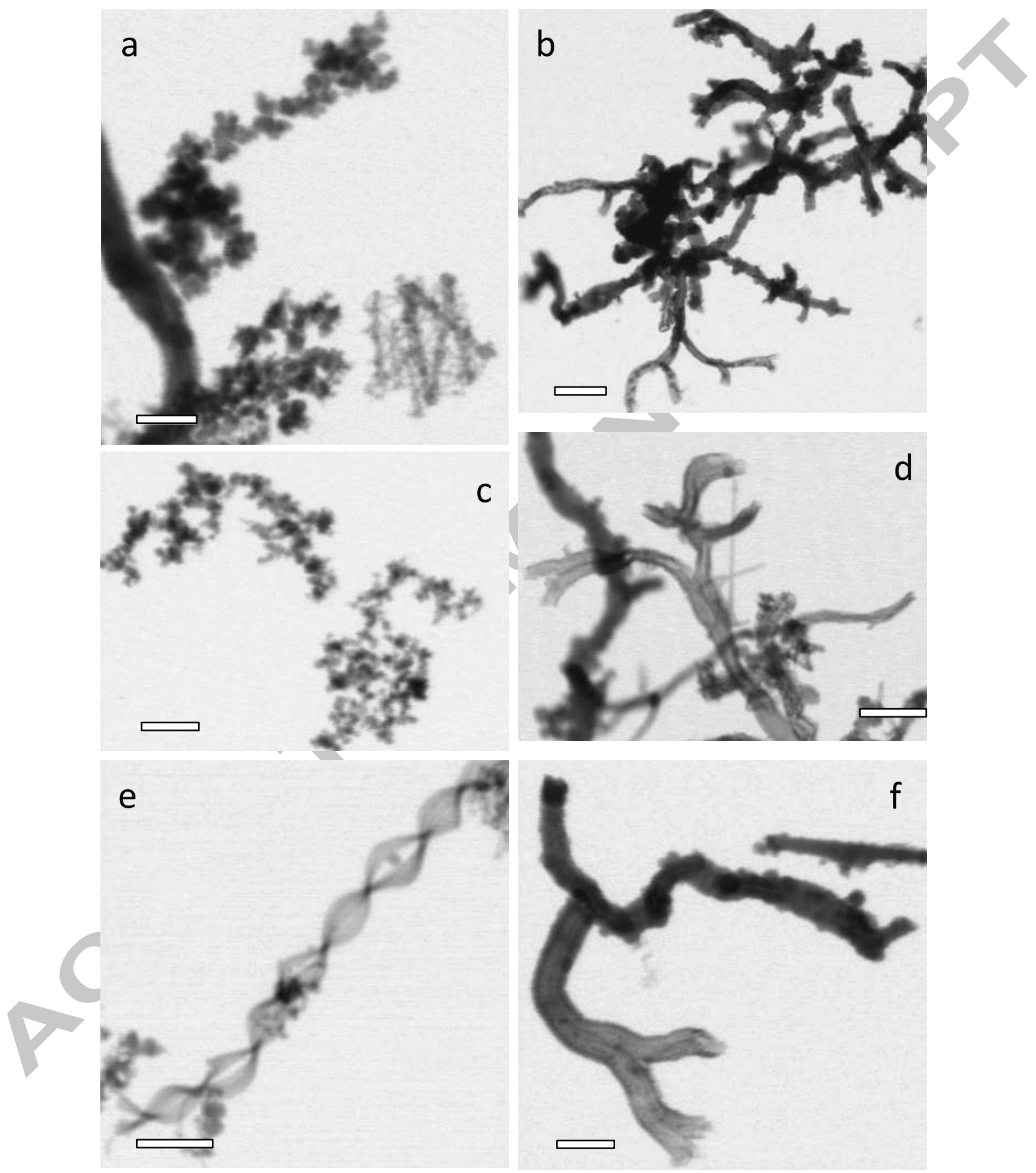

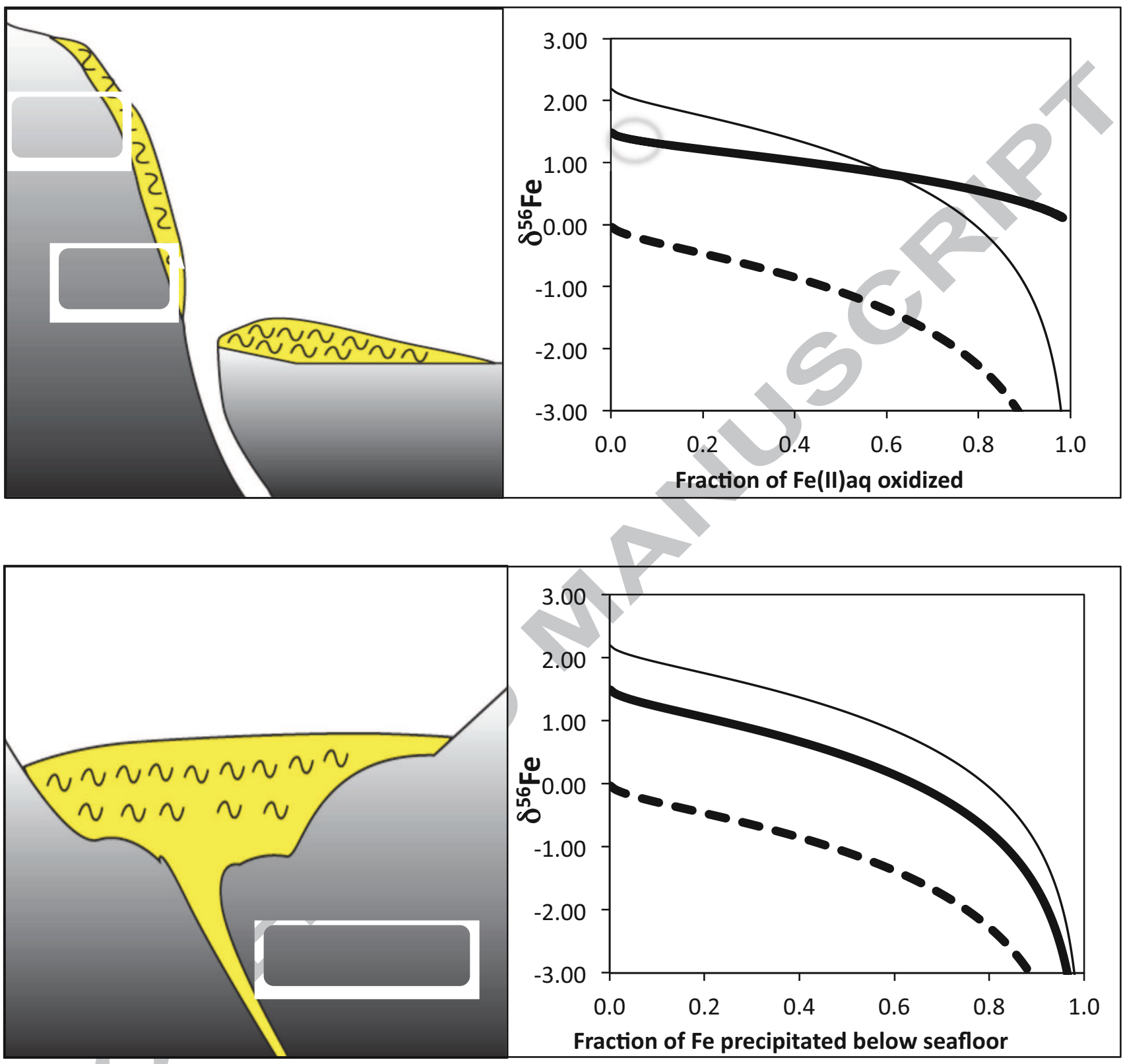


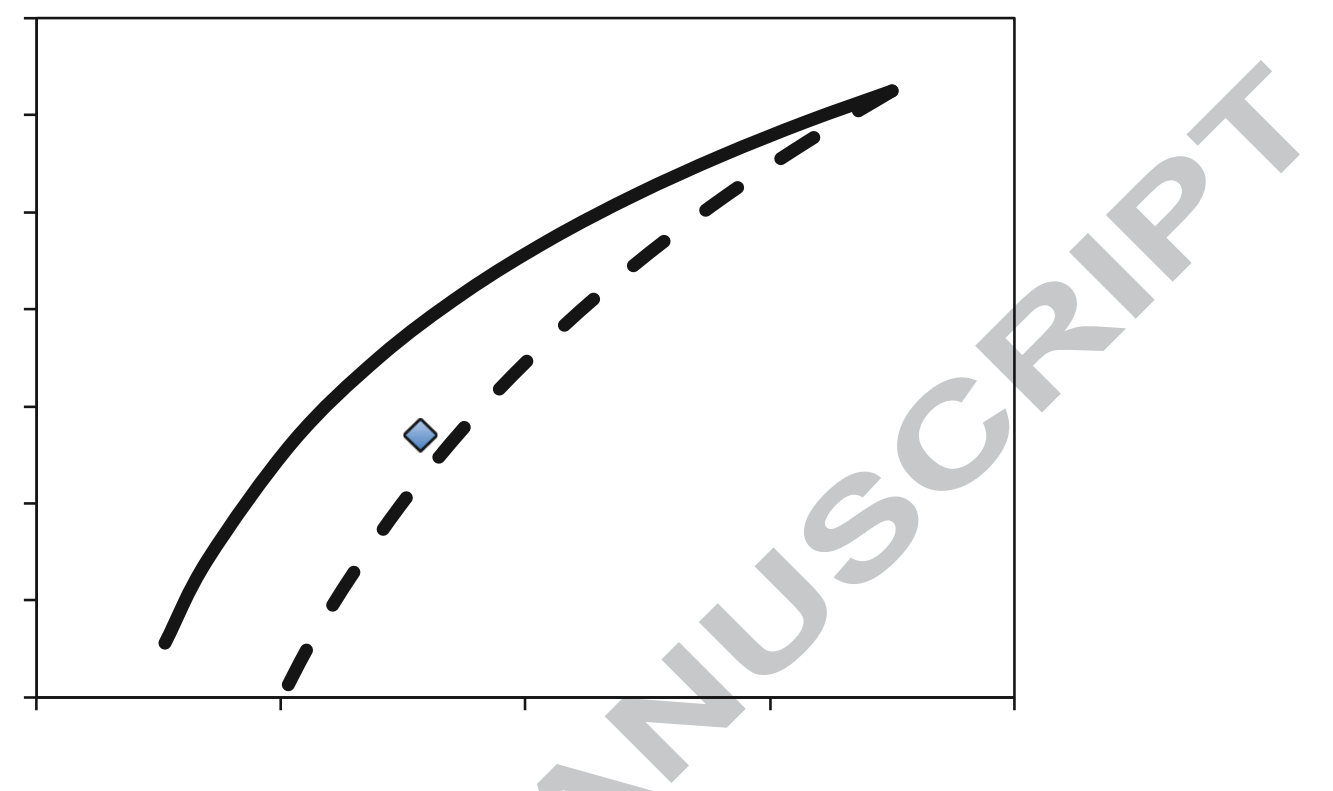




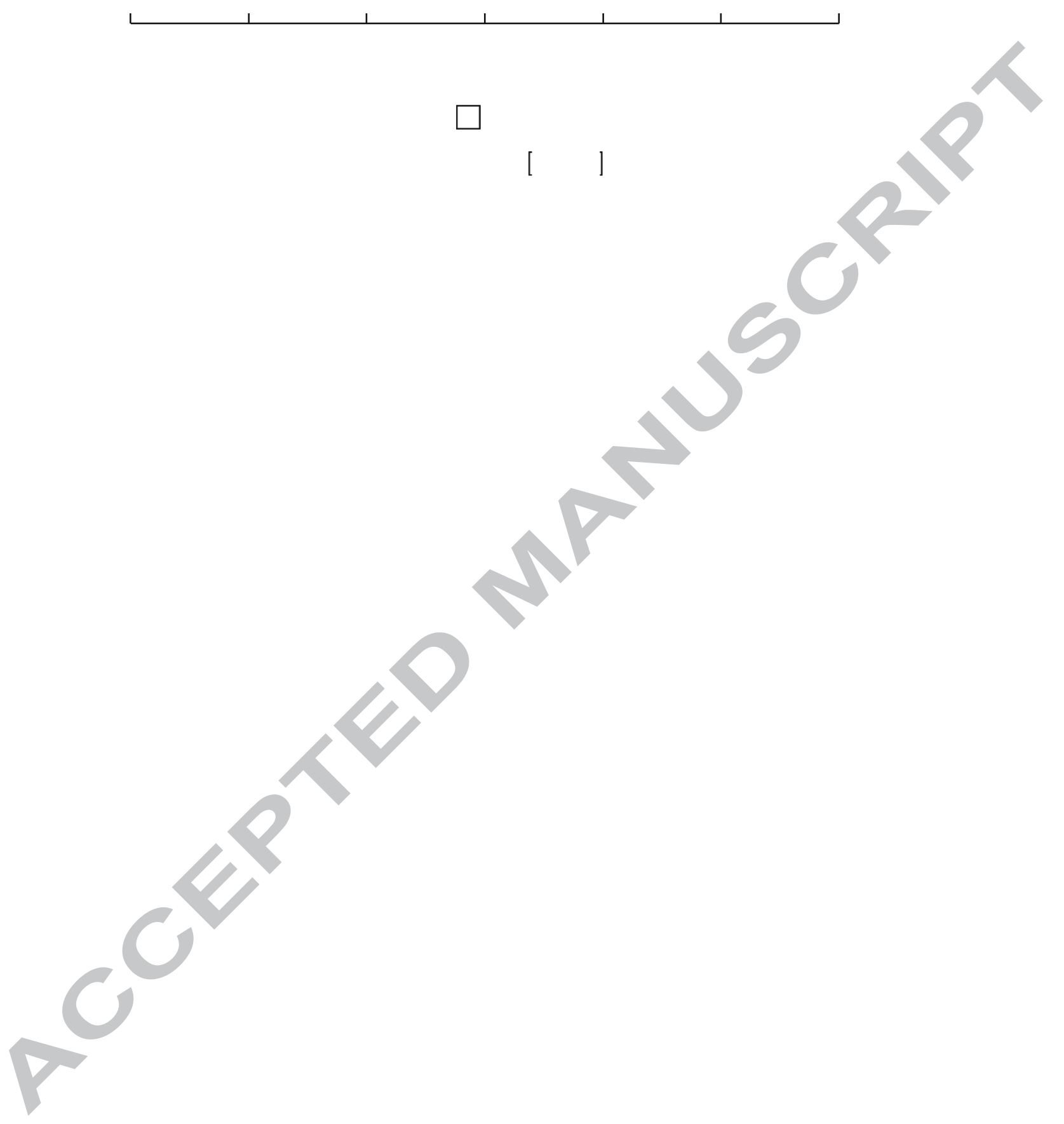

